\title{
NET-ZERO ENERGY TECHNICAL SHELTER
}

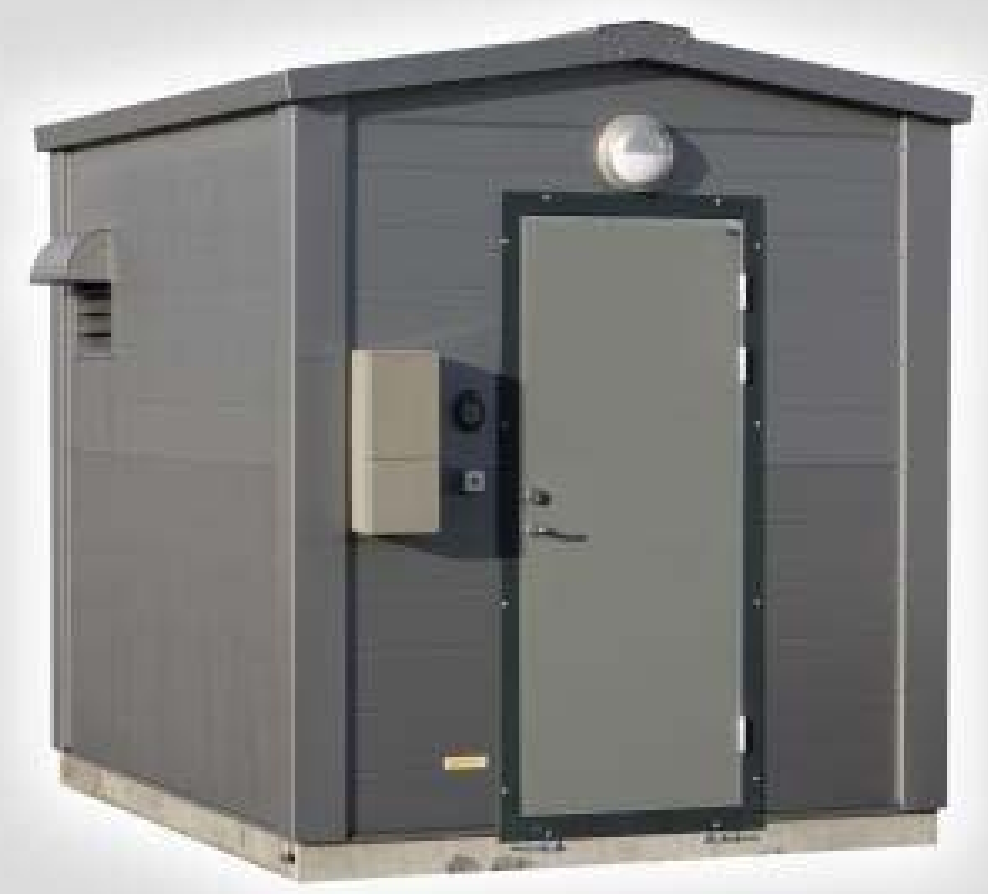

Chen Zhang

Master's Degree Programme in

Renewable Energy

Department of Physics

University of Jyväskylä 16/06/2011 


\section{NET-ZERO ENERGY TECHNICAL SHELTER}

by

Chen Zhang

Supervisors

Prof. Per Heiselberg

Jussi Maunuksela

Aalborg, 16/06/2011 


\section{PREFACE}

This report is the master thesis Net-Zero Energy Technical Shelter which was done in the Indoor Environmental Engineering Program at Department of Civil Engineering, Aalborg University from January 2011 to June 2011.

I would like to address great thanks to my supervisors Professor Per Heiselberg. Thank you for inspiring supervision, giving useful suggestions and helping to deal with the problems. I also would like to express my appreciation to As. Prof. Rasmus Lund Jensen for helping in experiments and preparing laboratory equipments. And deepest thanks go to Secretary Bente Jul Kjærgaard for her great patience and perfect attitude in answering questions.

In addition, I am great indebted to Intego A/S for the technical support and cooperation. Finally, I wish to thank my supervisor Jussi Maunuksela form University of Jyväskylä for the useful suggestions.

Chen Zhang 


\begin{abstract}
Technical shelter for storing electronic and technical equipments has high indoor heat dissipation rate, and cooling load exists almost all year around. Energy consumption of cooling system takes majority of entire energy use. Our project aims in reducing the energy consumption by proper design of building envelop and optimal control of cooling system. Both experimental measurements and computer simulation are carried out to analyze the indoor climate and energy performance of technical shelter in different conditions.

The experiments are made on a stand technical shelter. Vertical temperature gradient and air flow rate are measured by thermocouples and tracer gas technology. Energy balance is calculated by simplified analysis method based on measurement results. Simulation program BSim is applied in the study. The simulation results are compared with measurement results.
\end{abstract}

Finally, PV system is planned to build on the roof to power technical shelter. Both off-grid and ongrid PV systems are designed based on PVSYST software.

Master Thesis

Master's Degree Programme in Renewable Energy

Department of Physics

University of Jyväskylä

Jyväskylä 


\section{Contents}

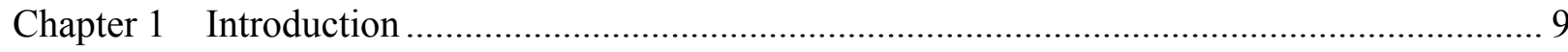

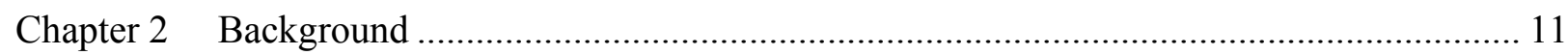

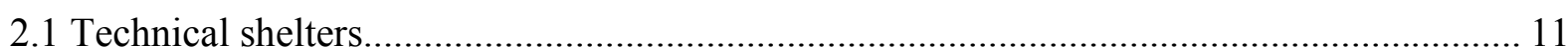

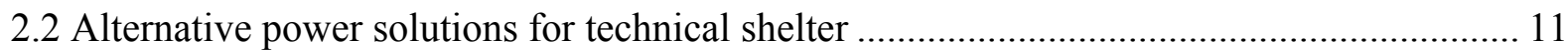

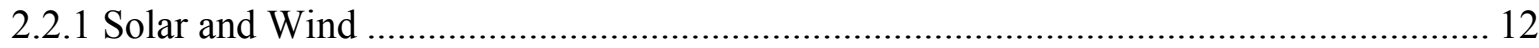

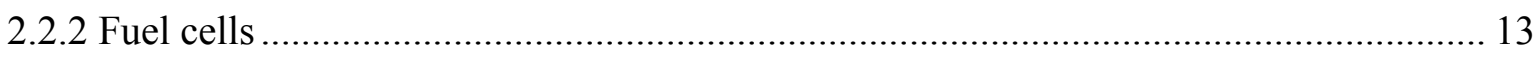

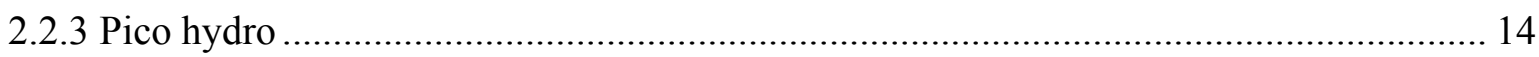

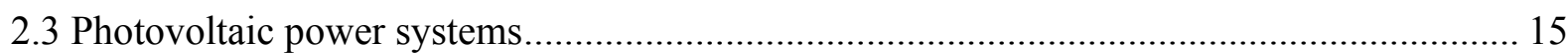

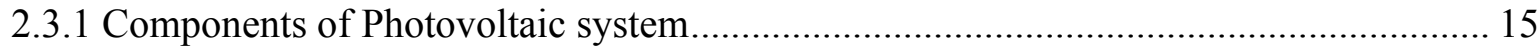

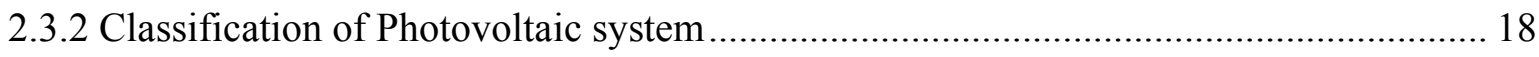

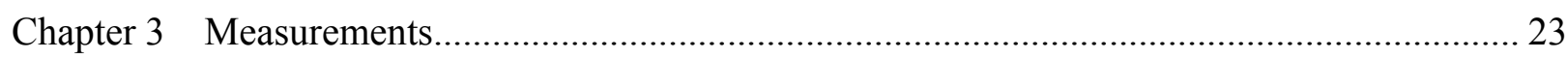

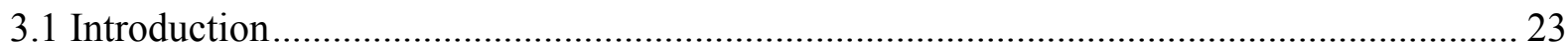

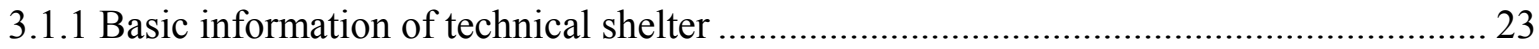

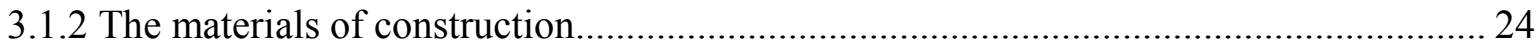

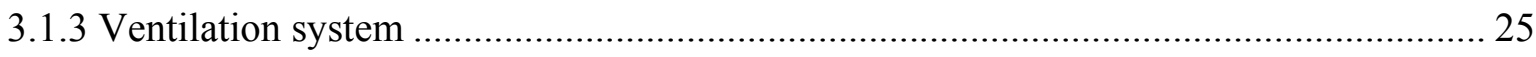

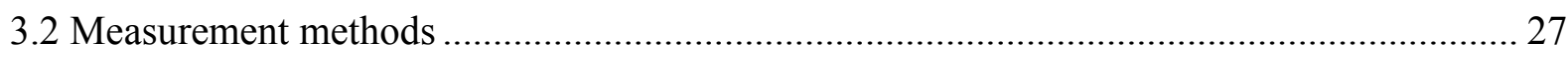

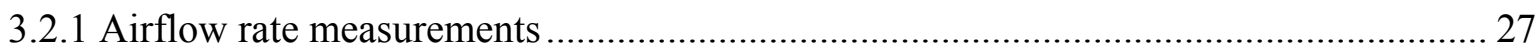

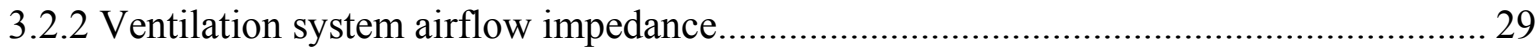

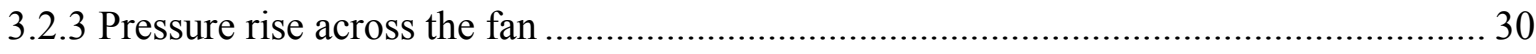

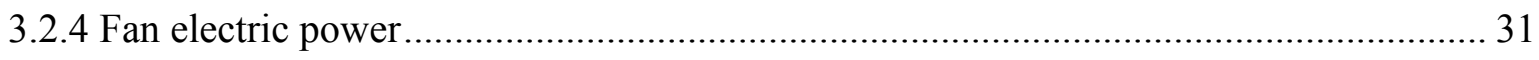

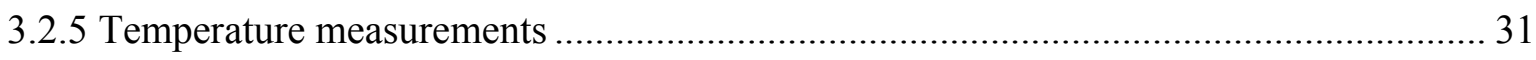

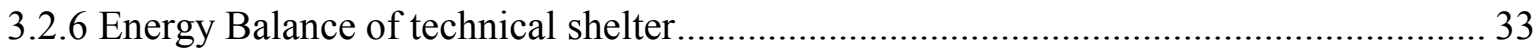

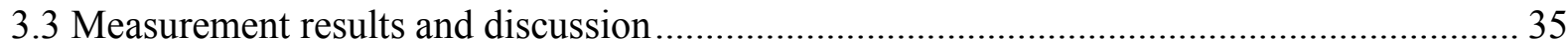

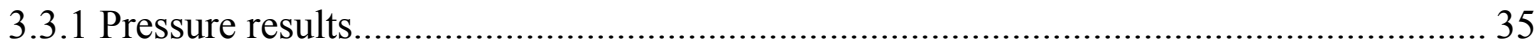

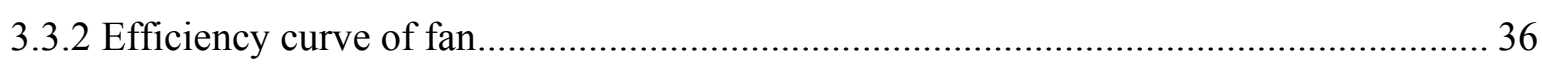

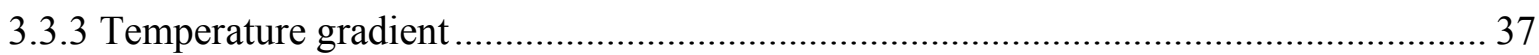

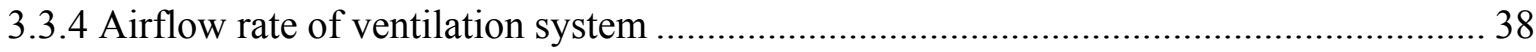

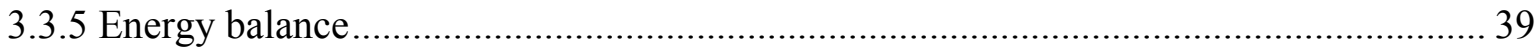

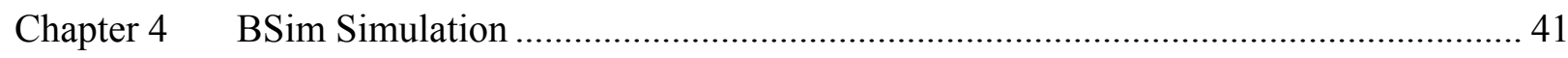

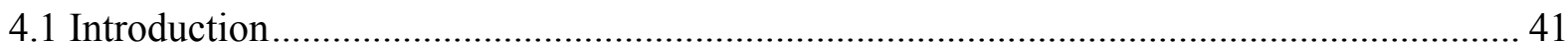

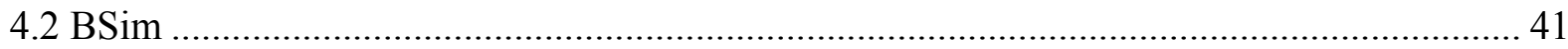

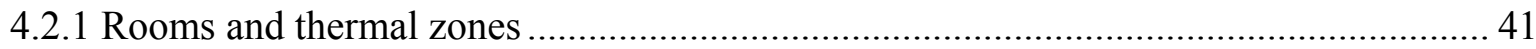




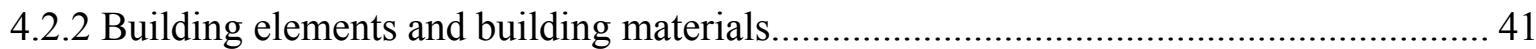

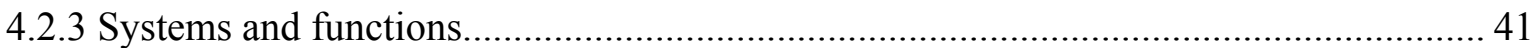

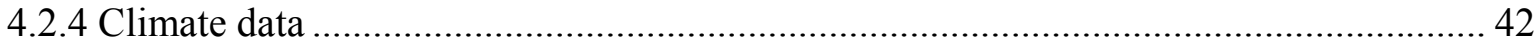

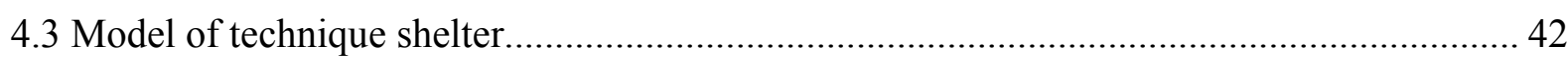

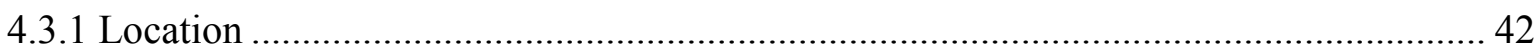

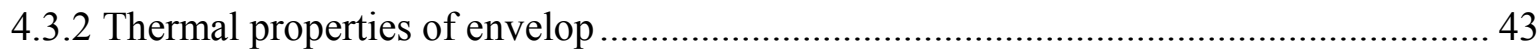

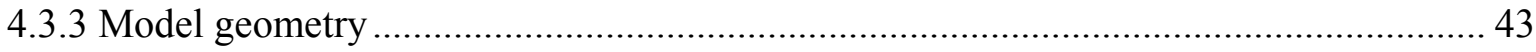

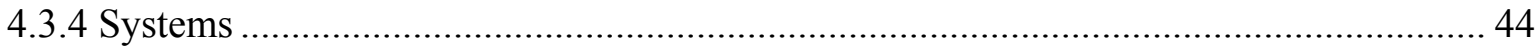

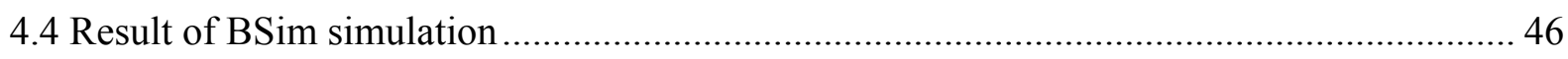

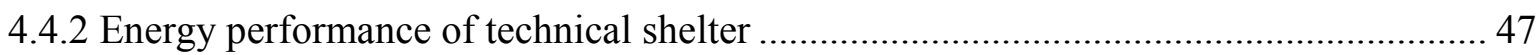

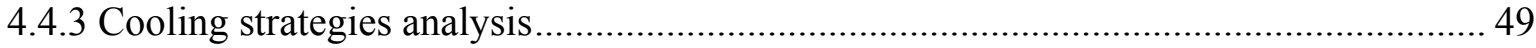

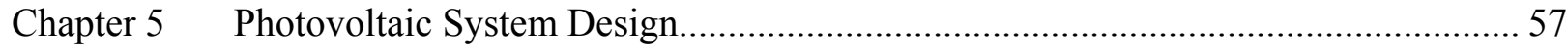

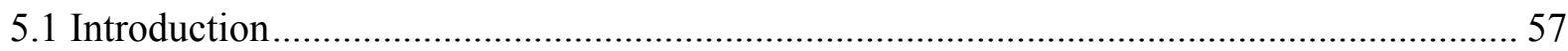

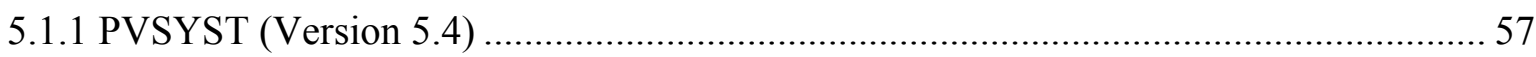

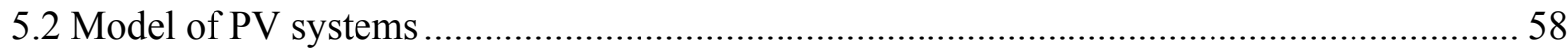

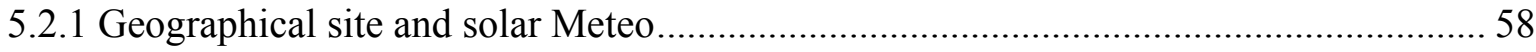

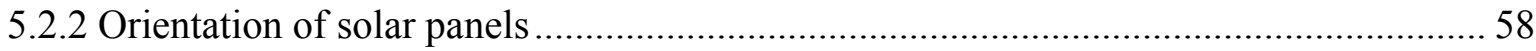

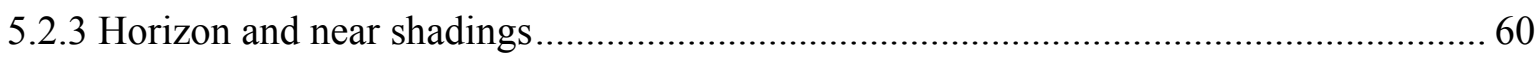

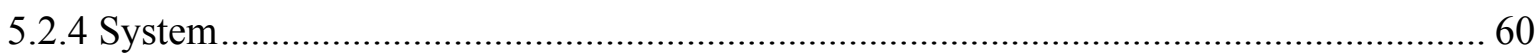

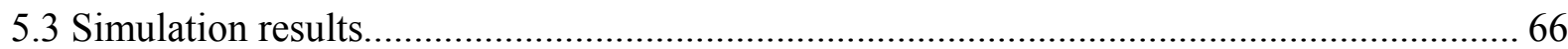

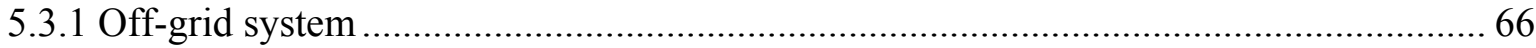

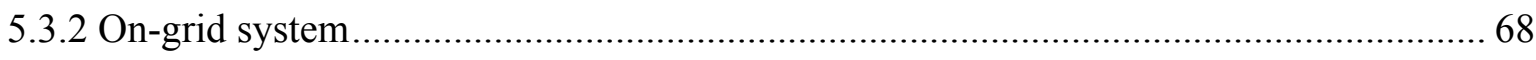

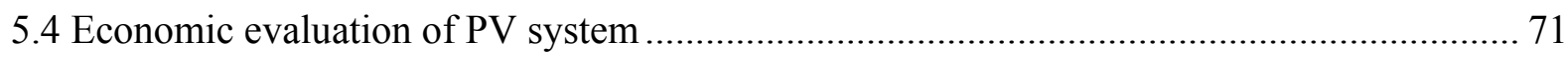

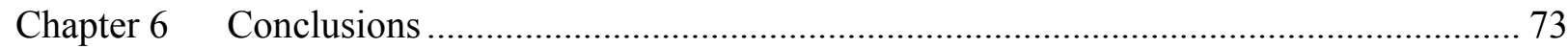

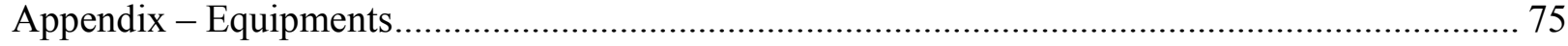

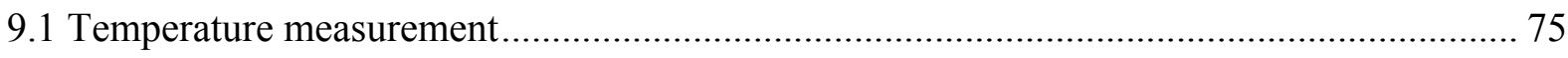

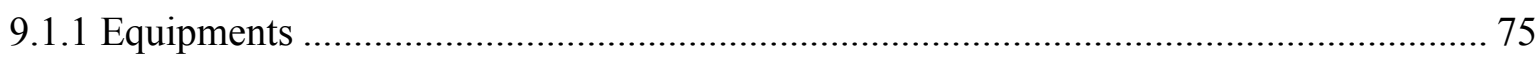

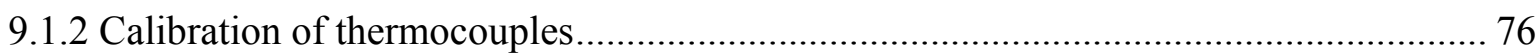

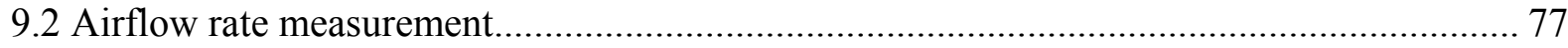

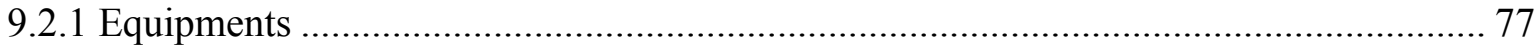

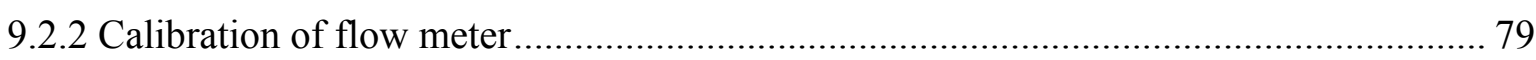

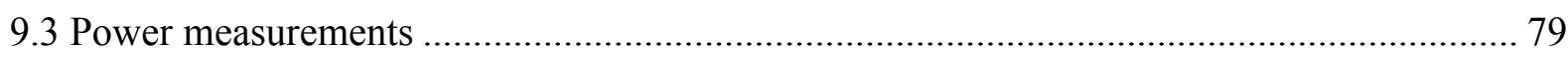

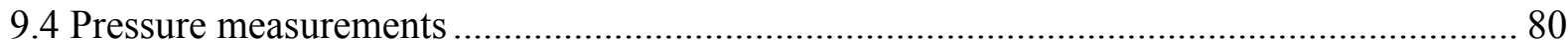




\section{Chapter 1 Introduction}

Technical shelters are the basic structures for storing electronic and technical equipments, which are common used for telecommunication base station, windmill, gas station, etc. Compared with the normal public buildings, for instance office buildings, technical shelters consume more energy due to their high inner heat density and special operating schedule. In order to maintain indoor temperature within a safe range, cooling demand is needed almost all year around, which makes cooling systems use majority electricity of the entire technical shelter. There are two main methods for saving energy will discuss in our project, one is to reduce the cooling load by proper design of envelop components, and the other is to optimize the cooling strategy.

The envelope is the physical separator between the interior and the exterior environments of a building which strongly affect the energy performance of building. Envelop with good heat dissipation ability is good for reduction of cooling load, when the outdoor temperature is lower than the indoor temperature, but it also increases the possibility of heating need. In our project, technical shelter with different insulation thickness envelop are analyzed using simulation software BSim, to find out the optimal envelop options.

To make full use of the natural outdoor cooling resources, ventilation cooling technology was proposed. By applying ventilation cooling technology, the outdoor cold air is imported by fans to dissipate the internal heat of electric equipments directly. However, when the heat load of equipments reaches a very high level, it needs more airflow to dissipate the internal heat which will significantly increase the energy consumption of fan. Thus, we want to explore the optimal solution for the cooling strategy which combines mechanical cooling with ventilation cooling to achieve energy savings.

Because the technical shelters are usually located in remote area where grids are either not available or their extensions is extremely expensive, obtaining reliable and cost effective power solutions for the technical shelters is a very challenging problem. An alternative power solution is to use renewable energy sources. Solar resource is used in our project to provide energy for technical shelter. Both off-grid and on-grid PV systems are designed based on PVSYST software.

Our project aims in analyzing the indoor climate and energy performance of technical shelter in different conditions. Both experimental measurements and computer simulations are carried out in the study. Finally, PV systems will be designed to achieve net-zero energy target. 


\section{Chapter 2 Background}

\subsection{Technical shelters}

Shelter is a basic structure or building that provides cover [1]. Technical shelters are the basic structures for storing electronic and technical equipments, which are common used for telecommunication base station, windmill, gas station, etc. They are produced according to different functions and the local feature of area where the shelters are delivered. Because the technical shelters are usually located in suburban or country and lack of occupancy by person, so they require great reliability. Very often the technical shelters should be designed taking into consideration various request such as:

- Fire resistance

- High level of air tightness

- High level of water tightness

- Insulation for extreme low or high temperatures

- Protection against corrosion for extreme weather conditions

- Sound insulation

Compared with the normal public buildings, for instance office buildings, technical shelters consume more energy due to the high inner heat density and special operating schedule. Thus, it's very important to optimize the control of the indoor temperature for obtaining high performance and operation reliability of electric equipments inside the technical shelter. Our project aims to optimize the energy performance of technical shelter and design renewable energy power solution to achieve net-zero energy goals.

\subsection{Alternative power solutions for technical shelter}

Obtaining reliable and cost effective power solutions for the technical shelters into rural and remote areas presents a very challenging problem. Grids are either not available or their extensions can be extremely costly in remote area. Although initial costs are low, powering these sites with generators require significant maintenance, high fuel consumption and delivery costs due to hike in fuel prices. In addition, legislative pressures and the potential for Carbon trading revenues are causing the public to become mindful of the impact on carbon emissions. "Green" considerations are more and more important in power solution design [2].

A sustainable alternative to power remote technical shelter is to use renewable energy sources. Recent research and development of renewable energy sources have shown excellent potential as a form of contribution to conventional power generation systems. In order to meet sustained load demands of technical shelter during varying natural conditions, different renewable energy sources should be taken into account. 


\subsubsection{Solar and Wind}

Solar and wind energy are the most rapidly expanding sources of energy in the world today. Due to the costs steadily falling of solar and wind technology, Solar and wind power have significantly progressed in recent years where they can be considered as supplementary or even the primary power source in some locations where the grid is difficult to connect. As the cost of renewable energy technology continues to fall, and the cost and lack of fossil fuels increase, solar and wind energy will become increasingly cost effective compared with more conventional power sources.

Solar power is a method of generating electrical power by converting solar radiation directly into electricity using the photovoltaic properties of semi-conductors. Manufacturing costs for solar cells have been declining by 3-5\% per year in recent years, leading to growth capped only by silicon supply issues. For wind power, it's the technology involves converting wind energy into electricity by using wind turbines. Over the past 10 years, the worldwide installed capacity of wind energy has grown at an average rate of over 28\% per year [3]. According to the European Wind Energy Association (EWEA) report of February 2011, there are over 12,000 wind turbines in Europe with a total capacity of $84 \mathrm{GW}$. It accounts for $20 \%$ of electricity use in Denmark, $9 \%$ in Spain, and 7\% in Germany [4]. The global adoption of wind and solar as commercially viable technologies, together with the falling costs and growing reliability of the technologies, make them cost effective technologies for the alternative power solutions.

Wind and solar are intermittent resources, so some short-term storage is required to deliver reliable 24-hour "utility-grade" power. Back-up generators are necessary for larger sites. Combining two generating technologies, like wind and diesel, creates a "hybrid system." Wind and solar are often combined in a hybrid system because they reinforce each other on a daily and seasonal basis. The wind often blows when the sun is not shining (night, storms, winter, etc.). The sun often shines during periods with low wind (summer, wind lulls due to high pressure systems, etc.).

For very small loads, up to $\sim 50$ watts continuous, an all-solar system will usually be the best choice. For continuous loads from 50 - 300 watts, a hybrid system with wind, solar, and a 3 - 10 day battery bank can power a site without need for a back-up generator. Using both wind and solar will reduce the battery bank size and the total cost compared to solar-only or wind-only systems. For larger loads, a hybrid system with a back-up generator will generally be more cost-effective. As the load size increases the relative size of the solar array shrinks due to the higher cost of solar, compared to wind [5]. 


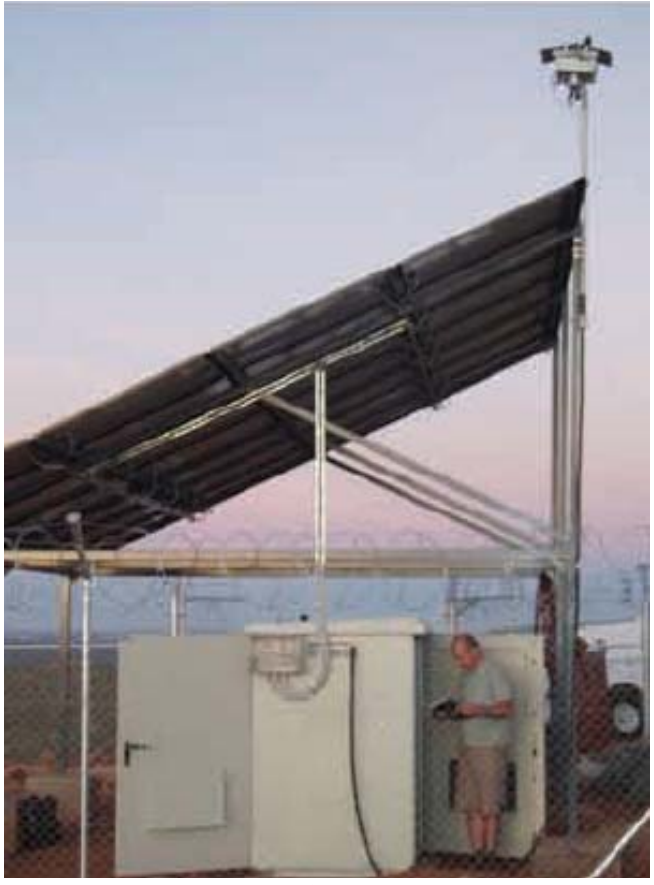

(a)

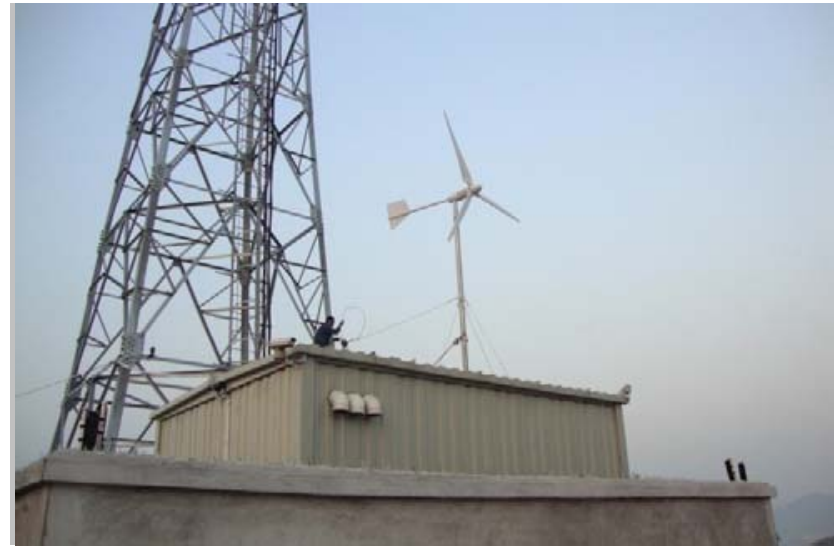

(b)

Figure 2.1 (a) Solar power for technical shelter (b) Wind power for remote telecom base station [2]

\subsubsection{Fuel cells}

Fuel cells are regarded as a strong alternative power source candidate. The technology has matured in recent years and has many benefits compared to generators, such as fuel efficiency, climate resistance, reliable start-up, and being very compact. Their silent operation means there will be no indication that a power source is operating on the cell site, reducing the likelihood of theft. Having reached volume manufacturing and with prices falling, they will challenge conventional engine driven generators in terms of cost and reliability [2].

Fuel cells are electrochemical cells that convert chemical energy from a fuel into electric energy. Electricity is generated from the reaction between a fuel supply and an oxidizing agent. The reactants flow into the cell, and the reaction products flow out of it, while the electrolyte remains within it. Fuel cells can operate continuously as long as the necessary reactant and oxidant flows are maintained.

Fuel cells are different from conventional electrochemical cell batteries in that they consume reactant from an external source, which must be replenished- a thermodynamically open system. By contrast, batteries store electric energy chemically and hence represent a thermodynamically closed system [6].

Many combinations of fuels and oxidants are possible. A hydrogen fuel cell uses hydrogen as its fuel and oxygen (usually from air) as its oxidant. Other fuels include hydrocarbons and alcohols. Other oxidants include chlorine and chlorine dioxide. The most promising for technical shelter is the Proton Exchange Membrane Fuel Cell (PEMFC). The PEMFC operates at low temperatures, and runs at $40-60 \%$ efficiency. 


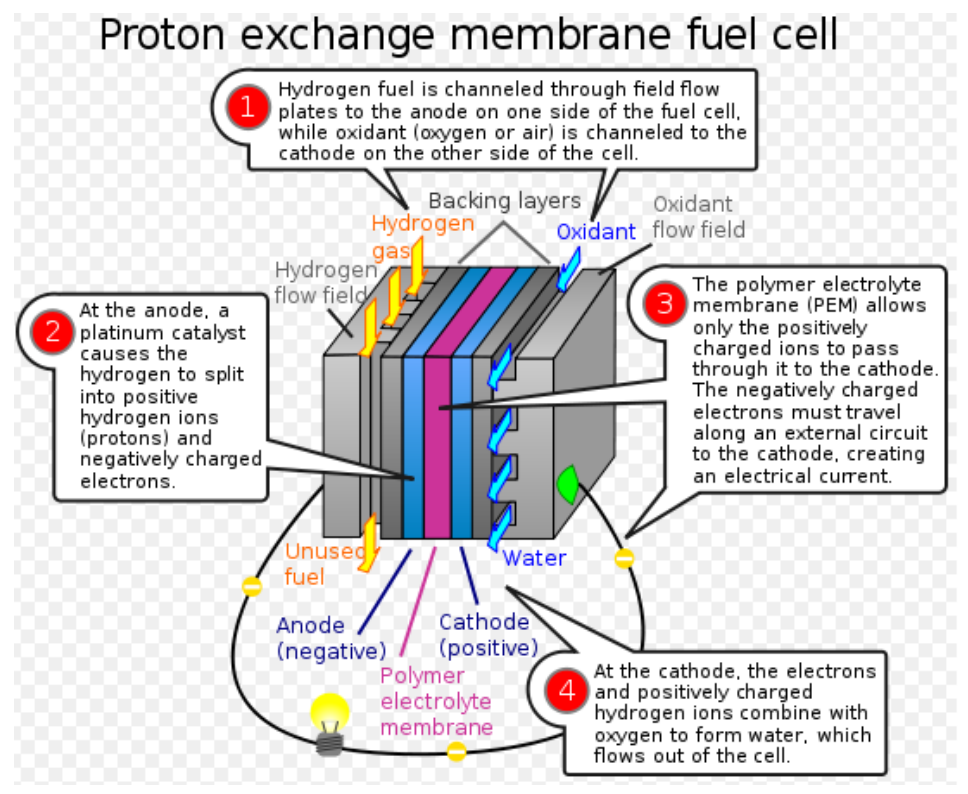

Figure 2.2 Proton exchange membrane fuel cell [6]

\subsubsection{Pico hydro}

Pico hydro is a term used for hydroelectric power generation of under $5 \mathrm{~kW}$. It is useful in small, remote communities that require a small amount of electricity. There is a large potential market for pico hydro due to the fact that:

- Small water flows are required

- Small communities in the developing world are often not linked to a power grid

- Locally manufactured pico hydro systems have lower long term costs per kilowatt than solar, wind, or diesel systems

- Hydro systems provide constant energy during times of normal rainfall

Pico hydro setups typically are run-of-stream, where dams are not used, but rather pipes divert some of the flow, drop this down a gradient, and through the turbine before being exhausted back to the stream [7]. So the areas with high rainfall, steep flowing streams and rivers provide an ideal source of generating power by pico hydro. Today, the primary use of pico hydro is for lighting and basic electrical needs in remote areas.

Figure 2.3 is an example of a basic pico hydro system set up to power a telecom base station. The potential energy stored in the elevated water supply flows through a pipe called a penstock, to drive a turbine which drives a generator which converts the mechanical energy to electrical power. Typical energy efficiency in such is a system is $40-50 \%$. Alternative hydro solutions include submersible and tidal systems [2]. 


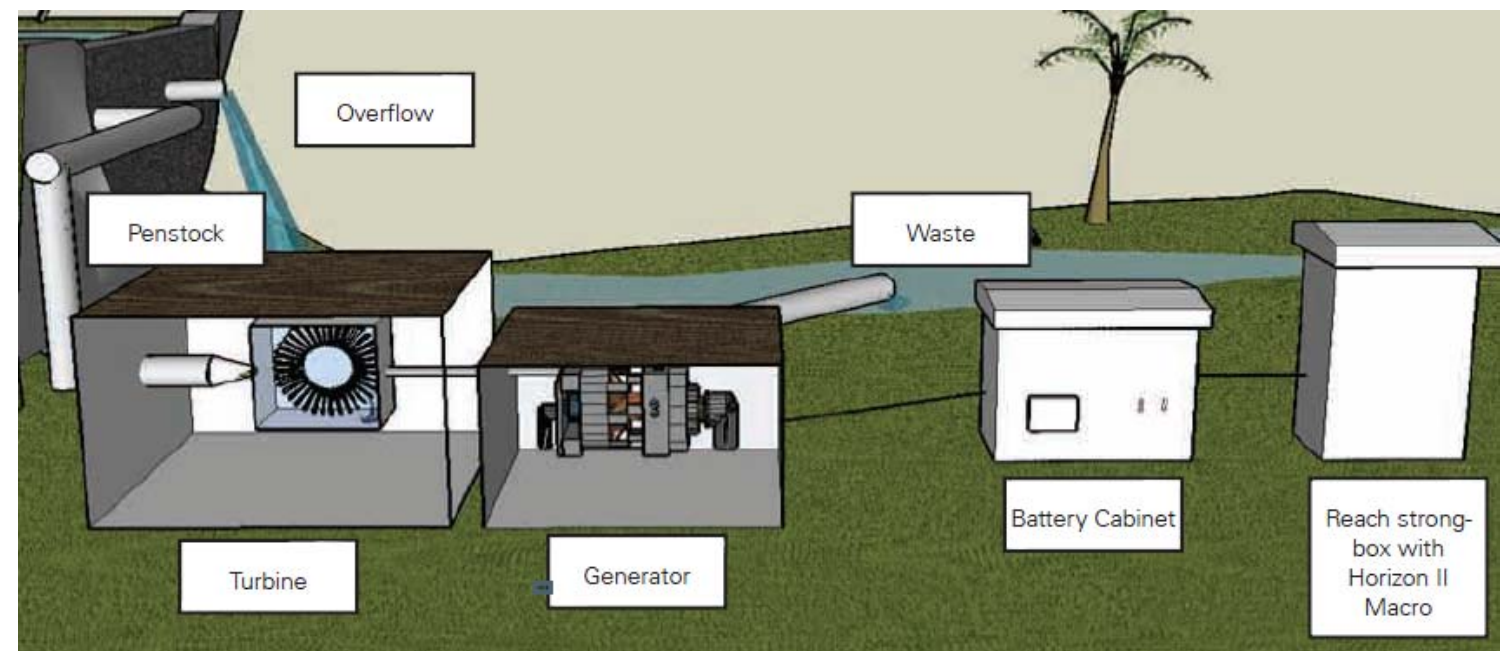

Figure 2.3 Pico Hydro Power Generation Schematic [2]

\subsection{Photovoltaic power systems}

As mentioned above, solar power system is good for small load condition, which is suitable for the power solution of technical shelter. Solar power system converts sunlight directly into electricity by photovoltaic panels. A residential PV power system enables a homeowner to generate some or all of their daily electrical energy demand on their own roof, exchanging daytime excess power for future energy needs (i.e. night time usage).

\subsubsection{Components of Photovoltaic system}

As shown in Figure 2.4, photovoltaic system usually includes four parts:

a) PV modules: converts sunlight directly into electricity by the photoelectric effect

b) Controllers: manage the energy storage to the battery and deliver power to the load

c) Batteries: store electricity to provide energy on demand at night or on overcast days

d) Inverters : required to convert the DC power produced by the PV module into AC power 


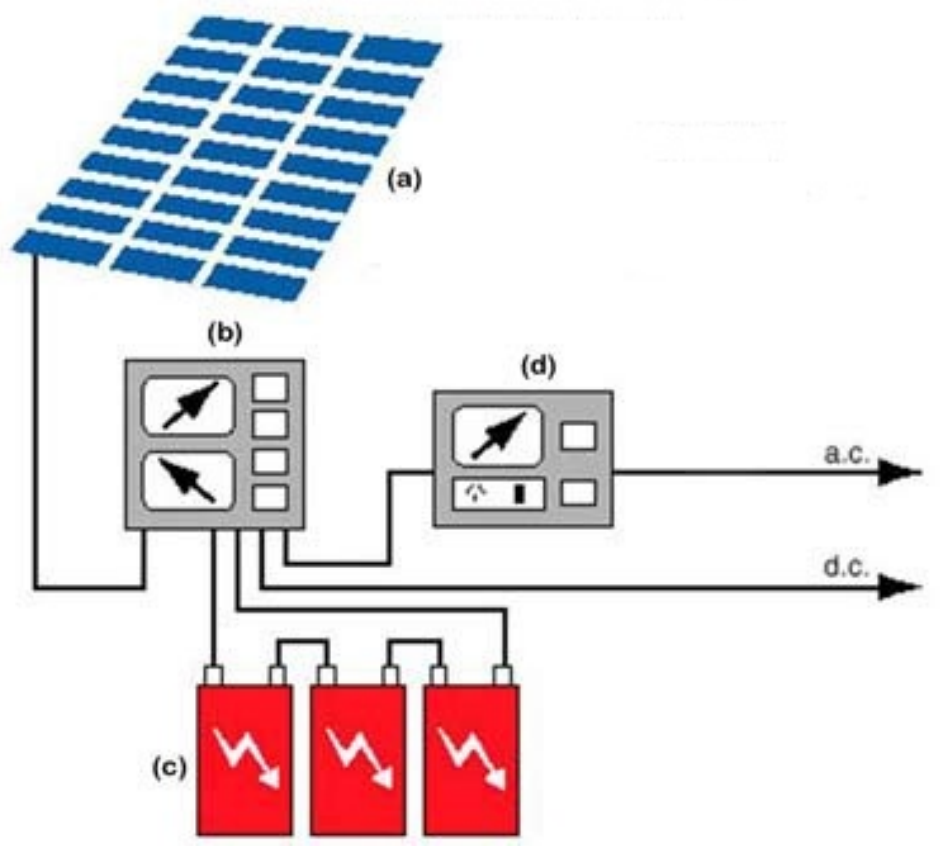

Figure 2.4 A simple Photovoltaic system [9]

However, not all PV systems will require all these components. For example in on-grid systems, the utility grid serves as the storage medium and batteries will not be required. Or in some other systems where AC load is not present the inverter is not necessary. Some systems also require other components which are not strictly related to photovoltaics.

\subsubsection{PV modules}

The PV modules are the most obvious and most visible component of your PV system. A photovoltaic module is made up of rows of solar cells that are connected in series to produce 12 DC volts. When several modules are connected in parallel to create rows and/or columns, they make arrays that can accumulate and convert significant amounts of solar radiation into direct current.

Solar cells are the basic building blocks of PV modules, which is a type of semiconductor which is sensitive to light. When sunlight strikes them, the electrons within these semiconductors absorb the sunlight's energy, become excited and move around. There are different types of solar cells. The basic types of solar cells sold on the market are as follows:

- Monocrystalline - These are made using cells cut from a single cylindrical crystal of silicon. While monocrystalline cells offer the highest efficiency (approximately 18\% conversion of incident sunlight), their complex manufacturing process makes them slightly more expensive. 
- Polycrystalline - These are made by cutting micro-fine wafers from ingots of molten and recrystallized silicon. Polycrystalline cells are cheaper to produce, but there is a slight compromise on efficiency (approximately 14\% conversion of incident sunlight).

- Thin film - Thin film PV is made by depositing an ultra thin layer of photovoltaic material onto a substrate. The most common type of thin-film PV is made from the material a-Si (amorphous silicon), but numerous other materials such as CIGS (copper indium/gallium diselenide) CIS (copper indium selenide), CdTe (Cadmium Teluride), dye-sensitized cells and organic solar cells are also possible. Thin film technology has the distinct advantage of being easier to mass produce than crystal cell technology. It costs less, though its durability is questionable. Thin film is also less efficient than crystal silicon, according to most sources [9].

\subsubsection{Controllers}

A charge controller is used in combination with a battery, which is used for controlling the charge battery receiving. The charge controller is placed between PV module and the battery. When the battery has received enough charge, the charge controller will withhold further charging. This is also called "voltage regulating" within the solar industry. Without a charge controller, the battery will over-charge. This can damage battery and it may be dangerous in other ways-it can even cause fires.

\subsubsection{Batteries}

If an off-grid PV system must provide electricity on demand rather than only when the sunshine is available, a battery is requires as an energy storage device. The most common battery types are lead-calcium and lead-antimony. Nickel-cadmium batteries can also be used, in particular when the battery is subject to a wide range of temperatures.

Because of variable nature of solar radiation, batteries must be able to go through many cycles of charge and discharge without damage. The amount of battery capacity that can be discharged without damaging the battery depends on the battery type. Lead-calcium batteries are suitable only where less than $20 \%$ discharge occurs each cycle. Nickel-cadmium batteries and some leadantimony batteries can be used where the depth of discharge can exceed $80 \%$.

Depending on size conditions, and on the presence of a backup generator, the batteries are sized to provide of system autonomy ranging from a few days to a couple of weeks. It's very important to optimize battery size in obtaining good battery life, suitable system performance, and optimal system life-cycle costs.

\subsubsection{Inverters}

An inverter is an important component of any power system, which is the interface between the PV modules, the load and which converts the direct current (DC) output of the array or the battery into alternating current (AC). AC is required by many appliances and motors; it is also the type of power used by utility grids and therefore on-grid systems always require the use of an inverter. There are two main types of inverters that differentiate by the system that they are used in. A battery-based inverter is used in a system that is not connected to an outside utility, such as the 
national grid, and has a stand-alone energy storage system. The battery-based inverter inputs the DC electricity coming in from the energy storage system and converts it into AC electricity. Interactive inverters are used in systems that are connected to the national grid, which runs on AC, and provides the standard configuration for most household appliances. An interactive inverter monitors the grid to see whether it is stable, converts the DC electricity to AC electricity, and ensures that the frequency and voltage are in phase with the configurations of the grid [10].

\subsubsection{Classification of Photovoltaic system}

Photovoltaic system can be classified based on the end-use application of the technology: on-grid system, off-grid system.

\subsubsection{On-grid system}

On-grid system is also called grid-connected system, which is connected to a large independent grid (typically the public electricity grid) and feeds power into the grid. Batteries are not necessary in this kind of system. Grid connected systems vary in size from residential $(2-10 \mathrm{kWp})$ to solar power stations (up to $10 \mathrm{~s}$ of $\mathrm{GWp}$ ). This is a form of decentralized electricity generation. In the case of residential or building mounted grid connected PV systems, the electricity demand of the building is mainly met by the PV system. Only the excess is fed into the grid when there is an excess. The feeding of electricity into the grid requires the transformation of DC into AC by a special, grid-controlled inverter [11].

The benefits of grid-connected PV system are generally evaluated based on its potential to reduce cost for energy production and generator capacity, as well as its environmental benefits. For some grid-connected PV systems, such as building integrated PV, the electric generators (PV) are located at or near the site of electrical consumption, which helps reduce both energy losses in the utility distribution network. In addition, the utility can avoid or delay upgrades to the transmission and distribution network where the average daily output of the PV system corresponds with the utility's peak demand period. PV manufacturers are also developing photovoltaic materials used to replace conventional building materials in parts of the building envelope such as the roof, skylights, or facades. The advantage of integrated photovoltaics over more common non-integrated systems is that the initial cost can be offset by reducing the amount spent on building materials and labor that would normally be used to construct the part of the building that the BIPV modules replace. These advantages make BIPV one of the fastest growing segments of the photovoltaic industry. 


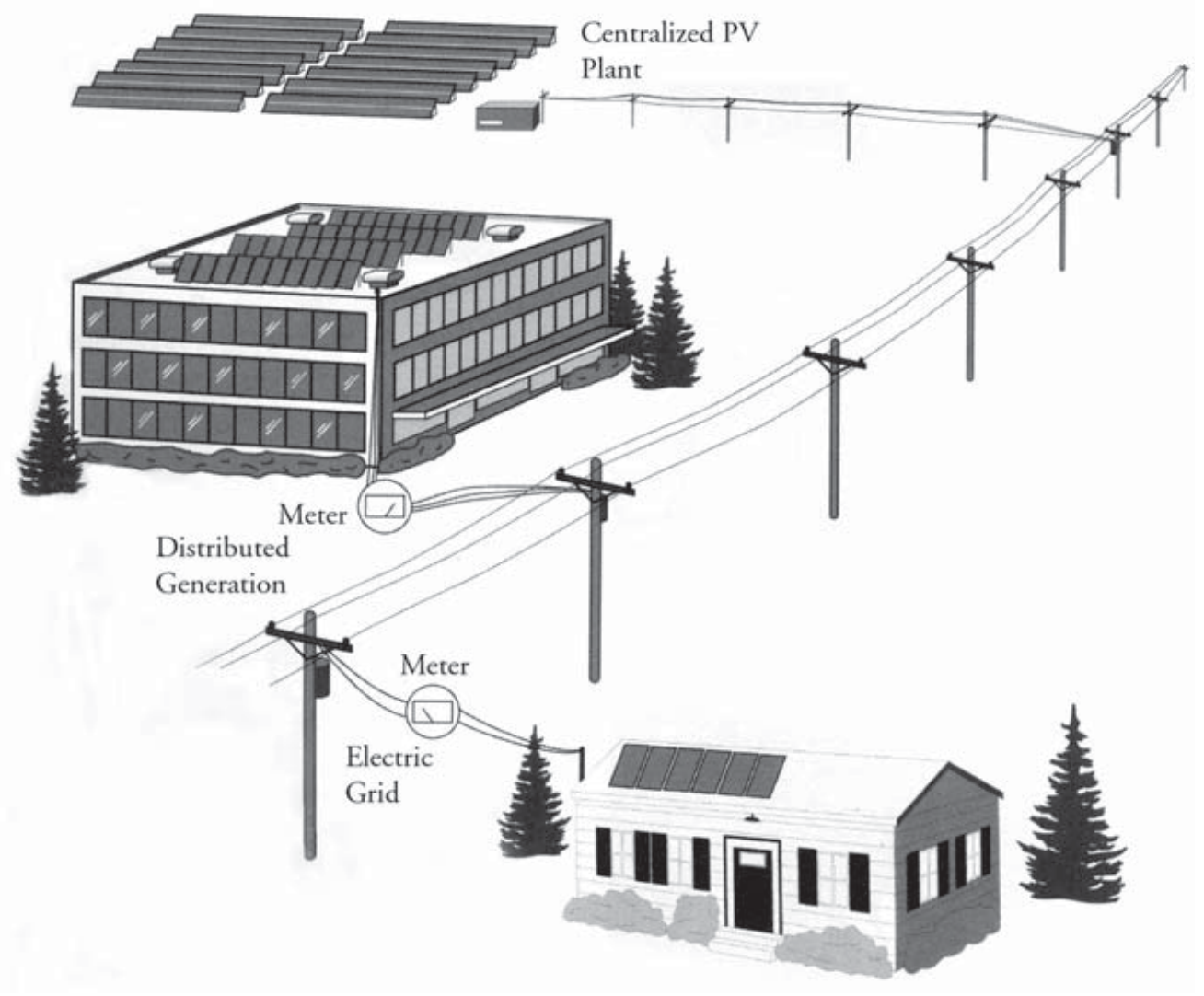

Figure 2.5 On-grid PV system schematic [12]

\subsubsection{Off-grid system}

An off grid PV system, sometimes called a stand-alone system, is designed to provide electricity to home or commercial use without drawing on supplemental power from the electrical utility. Currently, off-grid PV system is most competitive in remote sites, away from the electrical utility and requiring relatively small amount of power, typically less than $10 \mathrm{~kW}$.

In the off-grid PV systems, PV is frequently used in the charging of batteries, thus storing the electrical energy produced by the modules and providing the user with electrical energy on demand. The key competitive arena for off-grid PV system in remote sites is against electric grid extension or diesel, gasoline and thermoelectric generators. A 2000 World Bank/UNDP study on rural electrification programmes placed the average cost of grid extension per $\mathrm{km}$ at between $\$ 8000-10,000$, rising to around $\$ 22,000$ in difficult terrains [13]. The cost of grid extension is significantly higher the built of off-grid PV system. And compared to fossil fuel generators, the key advantage of PV is the reduction in operation, maintenance and replacement costs, which results in lower lift-cycle costs for PV systems [12].

Off-grid PV system can be classified in two types: stand-alone PV system and hybrid PV system. In the hybrid PV system, it usually includes a fossil fuel generator to meet some load requirements and provide a higher reliability. 


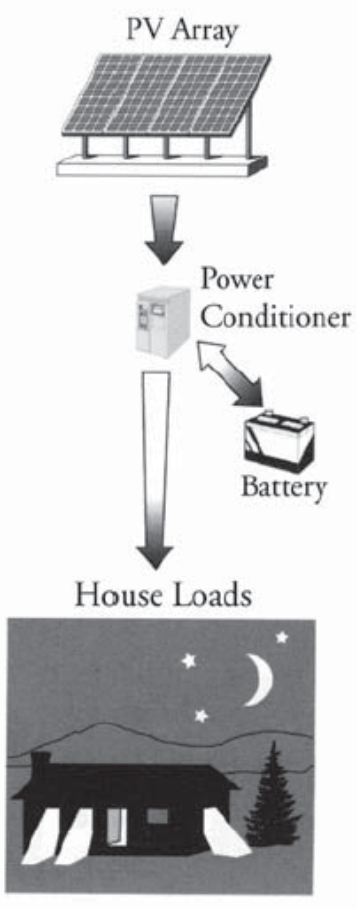

(a)

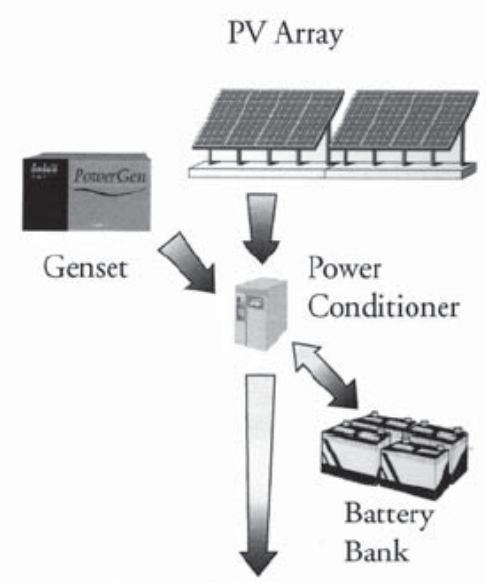

TV-Radio Transmitter

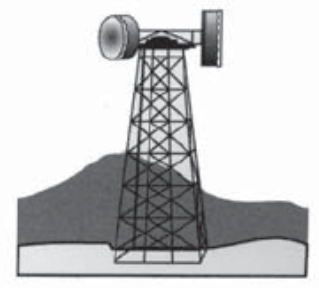

(b)

Figure 2.6 Off-grid PV system schematic

(a) Stand-alone off-grid PV system (b) Hybrid off-grid PV system [12] 


\section{References}

[1] "Shelter". [Online]. Available: http://en.wikipedia.org/wiki/Shelter. [Accessed: May.3, 2011]

[2] "White paper: Alternatives for Powering Telecommunications Base Stations", Motorola, Inc, 2007

[3] Frank Kreith and D. Yogi Goswami, "Handbook of energy efficiency and renewable energy", CPC Press Taylor \& Francis Group, 2007

[4] "Wind power in the European Union". [Online]. Available: http://en.wikipedia.org/wiki/Wind power in the European Union. [Accessed: Jun.10, 2011]

[5] "Wind Power for Remote Telecom", Bergey Windpower, 2011. [Online]. Available: $\mathrm{http} / / \mathrm{www} \cdot$ bergey.com/pages/wind power_for_remote telecom. [Accessed: Jun.10, 2011]

[6] "Fuel cell", [Online]. Available: http://en.wikipedia.org/wiki/Fuel cell. [Accessed: May.10, 2011]

[7] "Pico hydro", [Online]. Available: http://en.wikipedia.org/wiki/Pico_hydro. [Accessed: May.10, 2011]

[8] “A Photovoltaic System”, [Online]. Available: http://www.top-alternative-energysources.com/ photovoltaic -system.html. [Accessed: May.10, 2011]

[9] "The solar guide- PV system components", [Online]. Available: http://www.thesolarguide.com/solarenergy-systems/pv-system-components.aspx. [Accessed: May 10, 2011]

[10] Dmitry Liapitch, "Optimizing Solar Energy Collection in Photovoltaic Systems", Wells College, 2010, pp.15-16

[11] "Photovoltaic system", [Online]. Available: http://en.wikipedia.org/wiki/Photovoltaic system. [Accessed: May 10, 2011]

[12] Clean energy decision support center, "Photovoltaic project analysis", in Clean Energy Project Analysis: Engineering \& Cases textbook, Minister of Natural Resources Canada, 2004

[13] Guido Glania, Simon Rolland, "Aneri Patel Best practices of the Alliance for Rural Electrification", 2nd edition, Alliance for Rural Electrification, Feb. 2011 


\section{Chapter 3 Measurements}

\subsection{Introduction}

\subsubsection{Basic information of technical shelter}

Compared with the normal public buildings, for instance office buildings, technical shelters consume more energy due to the high inner heat density and special operating schedule. Our experiments aim to analysis the energy performance of technical shelter. As shown in Figure 3.1, the experiments are made on the scale of one to one standard technical shelter, where the dimensions can be seen from Figure 3.2.

Two internal heat load conditions are carried out in our experiments: $1.5 \mathrm{~kW}(1.52 \mathrm{~kW})$ and $3 \mathrm{~kW}$ $(3.11 \mathrm{~kW})$, respectively, which are maintained at a constant level during the whole experiments. The densities of the internal heat source are about $173 \mathrm{~W} / \mathrm{m}^{2}$ and $346 \mathrm{~W} / \mathrm{m}^{2}$, which are much larger than that for normal public buildings. In addition, because the tested technical shelter is located in the workshop, no climate factors (solar or wind factors) are taken into account.

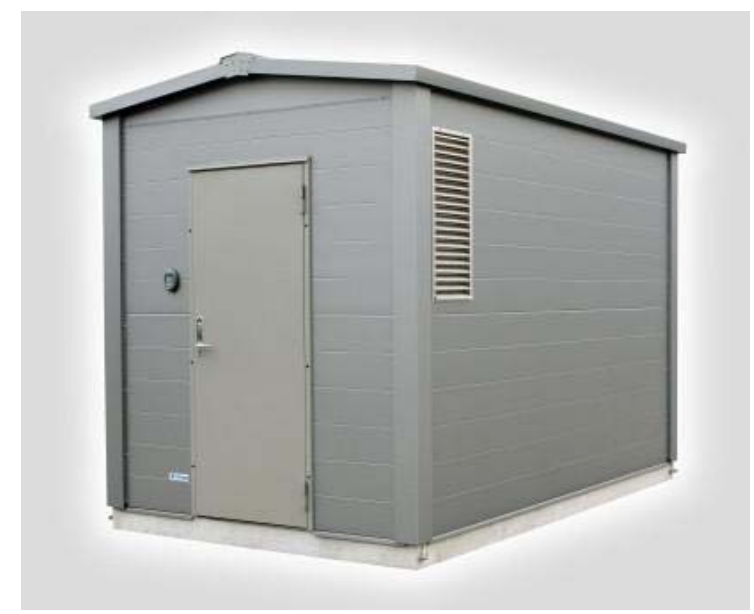

Figure 3.1 Standard technical shelter schematic 

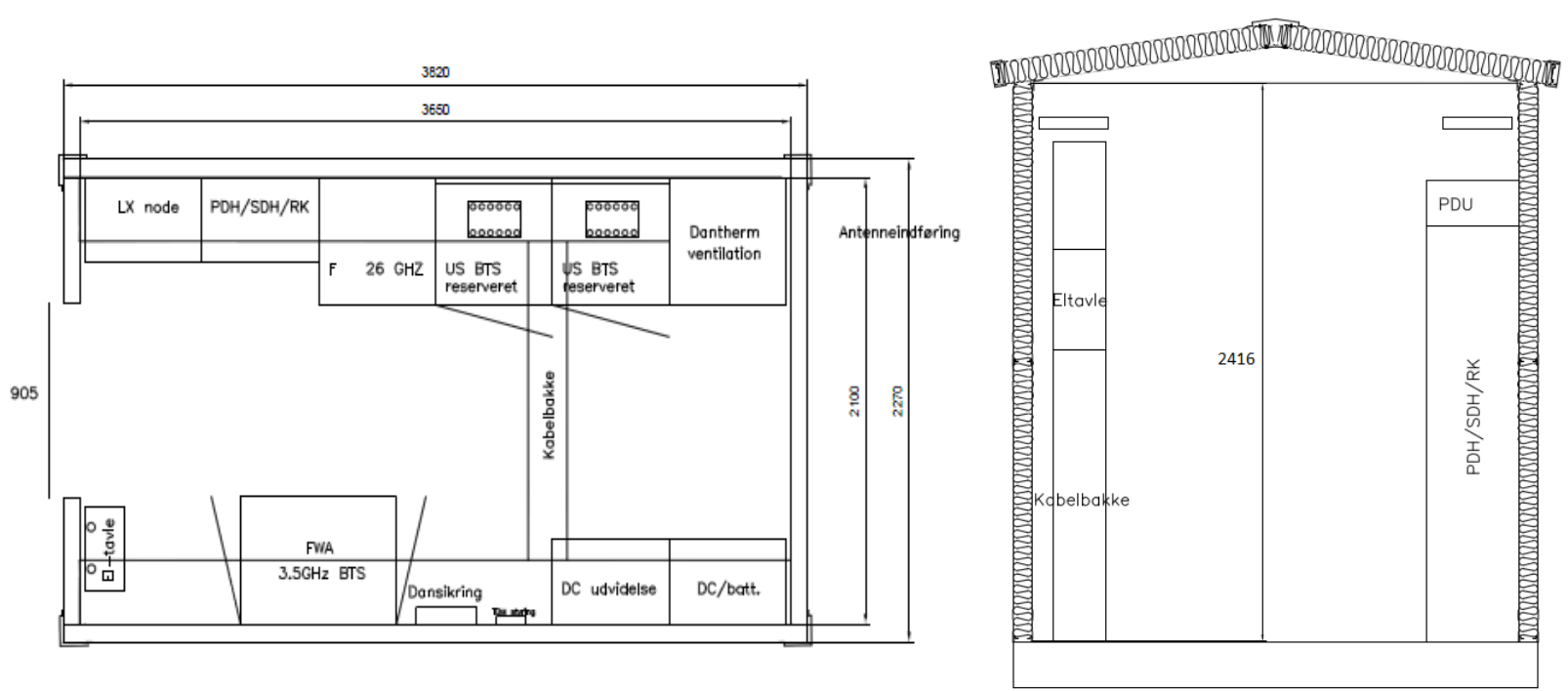

Figure 3.2 Dimensions of the standard technical shelter

\subsubsection{The materials of construction}

The building envelope is the physical separator between the interior and the exterior environments of a building which strongly affect the energy performance of building. The technical shelter envelop includes three parts: wall \& ceiling, foundation and door.

I. Wall \& Ceiling

Wall \& Ceiling panels are sandwich constructions, as shown in Figure 3.3, which are free of thermal bridges and provided with a factory installed gasket.

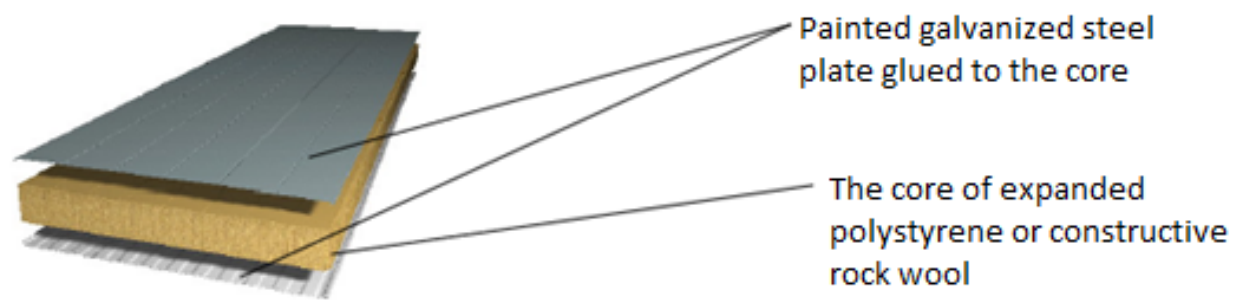

Figure 3.3 Construction of sandwich panel for wall \& ceiling [1]

Thickness:

Weight:

Maximum recommended length:

U value:

Sound reduction $\mathrm{Rw}+\mathrm{C}_{50} \mathrm{~dB}$ :
$86 \mathrm{~mm}$

$11.5 \mathrm{~kg} / \mathrm{m}^{2}$

$12200 \mathrm{~mm}$

$0.42 \mathrm{~W} / \mathrm{m}^{2} . \mathrm{K}$

24 
Corrosion:

For the manufacture of the panels used galvanized painted steel plate. Imposed $275 \mathrm{~g} / \mathrm{m}^{2}$, which corresponds to approx. $20 \mu \mathrm{m}$ zinc per side.

II. Foundation

Foundation uses reinforced concrete, which is fitted with 4 lifting points.

Dimensions: $\quad 3820 * 2270 * 150 \mathrm{~mm}^{3}$

U value:

$3.29 \mathrm{~W} / \mathrm{m}^{2} . \mathrm{K}$

III. Door

D-rated steel door

Thickness:

$60 \mathrm{~mm}$

Door Blade:

$1.0 \mathrm{~mm}$ stainless steel

Insulation:

Rockwool

Glade leaf:

$825 * 2045 \mathrm{~mm}^{2}$

\subsubsection{Ventilation system}

As shown in Figure 3.4 (a), Delta Master 6L 48EC ventilation system is installed in the tested technical shelter. Delta Master 6L is a compact free air cooler with flexible air intake, specifically designed to control the internal environment of communications enclosures. It is designed to remove excess heat from temperature sensitive electronic equipments where the temperature is required to be maintained within defined limits to achieve optimum performance and to maximize component life. Figure 3.4 (b) shows the components and principle of Delta Master 6L 48EC ventilation system.

1. Delta Master 6L

2. Connection box

3. X04 control unit

4. Electric fan heater

5. Outdoor air temperature sensor

6. Air intake cowl

7. Exhaust air back draught shutter

8. Exhaust air cowl

9. Filter socks

10. Power supply

Delta Master 6L ventilation system is mainly control by regulator X04 unit, which controls the alarm relay, fan speed and start signal for heater and Air-conditioner (heater and Air-conditioner are not available in our case). As shown in Figure 3.5, X04 unit can be connected to PC where the user is able to define set point temperature and $\mathrm{max} / \mathrm{min}$ output value. The fan speed in of is controlled by the difference between indoor and outdoor temperature. As the indoor temperature 
increased so does the fan speed. As the temperature decreases so does the fan speed, until it reaches a minimum value (adjustable).

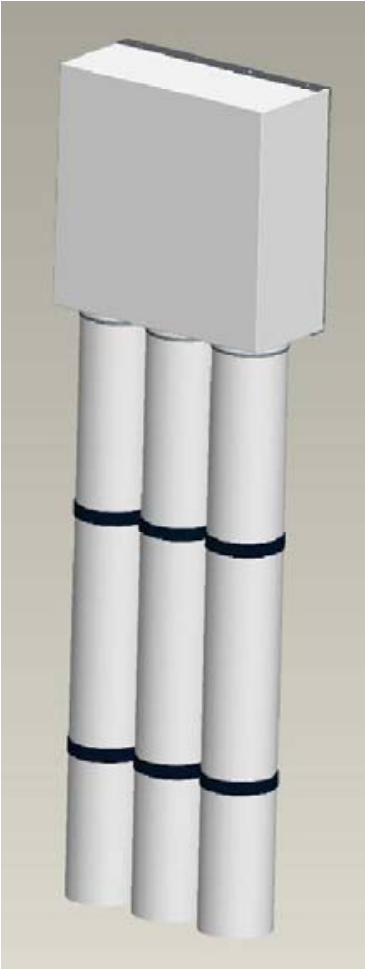

(a)

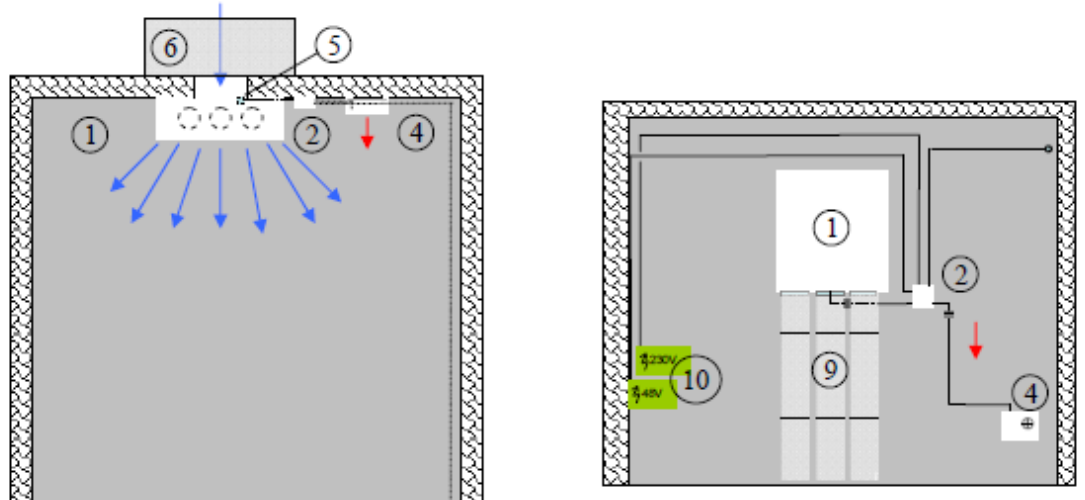

(b)

Figure 3.4 (a) Schematic of Delta Master 6L 48EC ventilation system

(b) Principle of Delta Master 6L 48EC ventilation system [2]
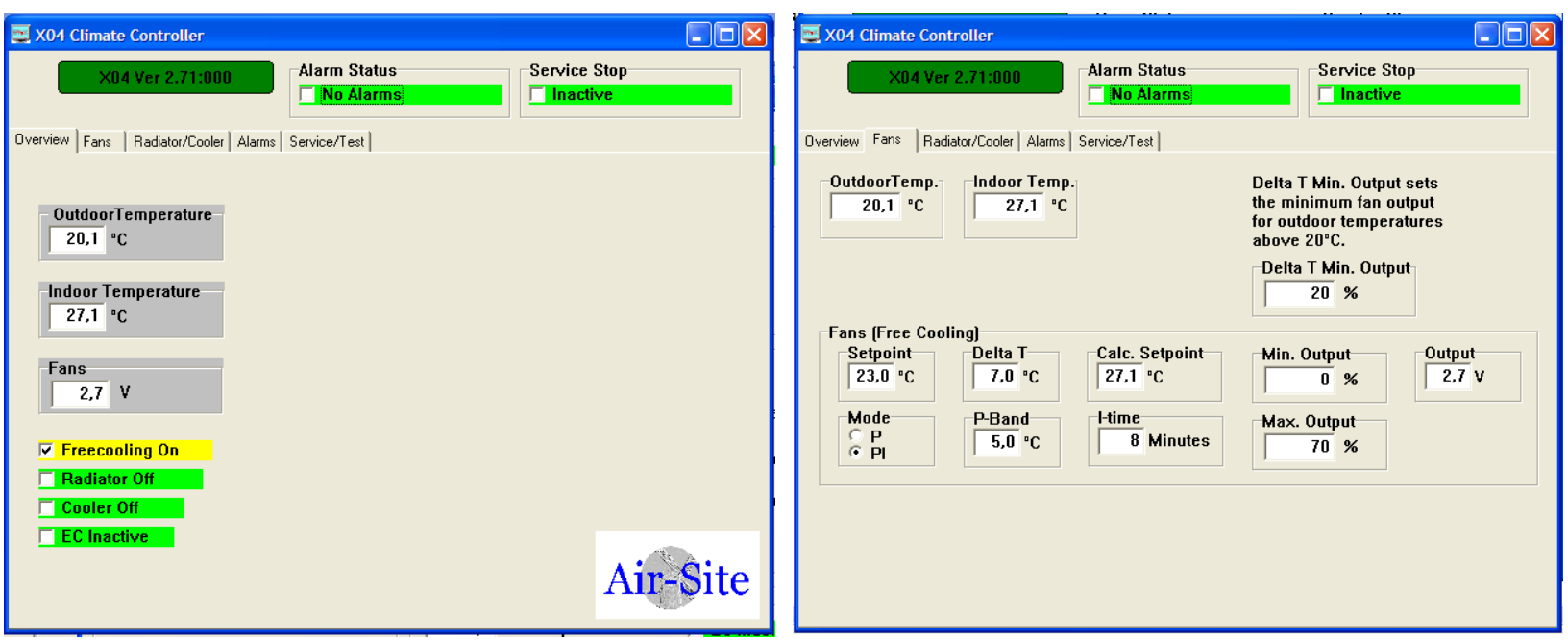

Figure 3.5 X04 Climate Controller 


\subsection{Measurement methods}

\subsubsection{Airflow rate measurements}

Tracer gases have been used to measure air infiltration and ventilation characteristics of building for about 30 years. There are three principal tracer gas techniques for measuring airflow rate within a structure: the tracer dilution method, the constant injection method, and the constant concentration method. The tracer dilution method is a direct way of measuring the airflow rate extant within a building under ambient flow conditions. The constant injection method is an indirect method, i.e., it measures the equilibrium tracer concentration within a ventilated area. This concentration can be related to the airflow rate if the tracer release rate is known. The constant concentration method is also an indirect method. It measures the amount of tracer as a function of time required to maintain a constant concentration within a ventilated zone. The quantity of tracer injected can be related to the airflow rate. These tracer techniques can also be used to measure induced airflow rates in buildings such as those created by a mechanical air-handling system [3].

In our measurements, the second method 'the constant injection method' is used. This is referred to as the constant injection technique in which $\dot{m}$ is constant. Nitrous oxide $\left(\mathrm{N}_{2} \mathrm{O}\right)$ serves as the tracer gas during all measurements. The $\mathrm{N}_{2} \mathrm{O}$ injection rate can be read from the flow meter which connected with manometer. The airflow rate of $\mathrm{N}_{2} \mathrm{O}$ injected into the shelter is $0.025 \mathrm{l} / \mathrm{s}$ which is constant value during all experiments. So the airflow rate can be expressed by the equation below:

$$
q=\frac{\dot{m}}{\left(C_{\text {exhaust }}-C_{\text {supply }}\right)}
$$

Where:

$q \quad$ is airflow rate, $1 / \mathrm{s}$.

$\dot{m} \quad$ is tracer gas injection rate, $\mathrm{g} / \mathrm{s}$, where $\dot{m}=q_{N_{2} O} \cdot \rho_{N_{2} O}$

$C_{\text {exhaust }}$ is exhaust air concentration, ppm

$C_{\text {supply }}$ is supply air concentration, ppm

$$
1 \mathrm{ppm}=\frac{V_{m}}{M} \frac{1 \mu g \text { gas }}{1 l \text { air }}
$$

Where:

$V_{m} \quad$ is standard molar volume of ideal gas, where $V_{m}=24.4651 / \mathrm{mol}$ at $25^{\circ} \mathrm{C}, 1$ atmosphere pressure

$M \quad$ is molecular weight of gas, where $M_{N_{2} O}=44.01 \mathrm{~g} / \mathrm{mol}$

In the following chapters, sometimes we will use the definition of Air change rate. Air change rate is a measure of how many times the air within a defined space (normally a room or house) is replaced, which can be expressed by eq (3.3) 


$$
N=\frac{q}{V}
$$

Where:

$N \quad$ is the air change rate in the shelter, $/ \mathrm{h}$

$V \quad$ is the volume of shelter, $\mathrm{m} 3, V=19.96 \mathrm{~m}^{3}$ in our case

It's important to notice that the results obtained by tracer gas technique are exact only when the system is in equilibrium. Otherwise, the results will be subject to errors, with the magnitude of these errors depending on the extent of the departure from equilibrium. The use of this technique is illustrated schematically in Figure 3.6.

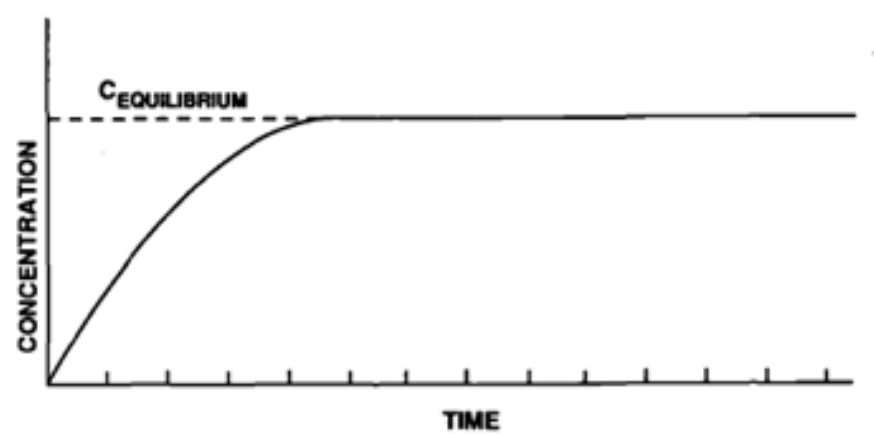

Figure 3.6 Schematic of constant flow injection test [3]

All tubes used to measure tracer gas concentration are connected to the Multipoint Sample and Dozer type 1303 (Bruel \& Kjær, Denmark). The concentration data are analyzed by Tracer Gas Monitoring system and then stored in the PC. In order to let tracer gas completely mixed with supply fresh air, tracer gas is directly supply into the ventilation system (before the filters). And two mixing fans are used inside the shelter to mix supply air with space air, in order to reduce concentration gradient. Tracer gas concentrations are measured at six positions, as shown in Figure 3.7 . 


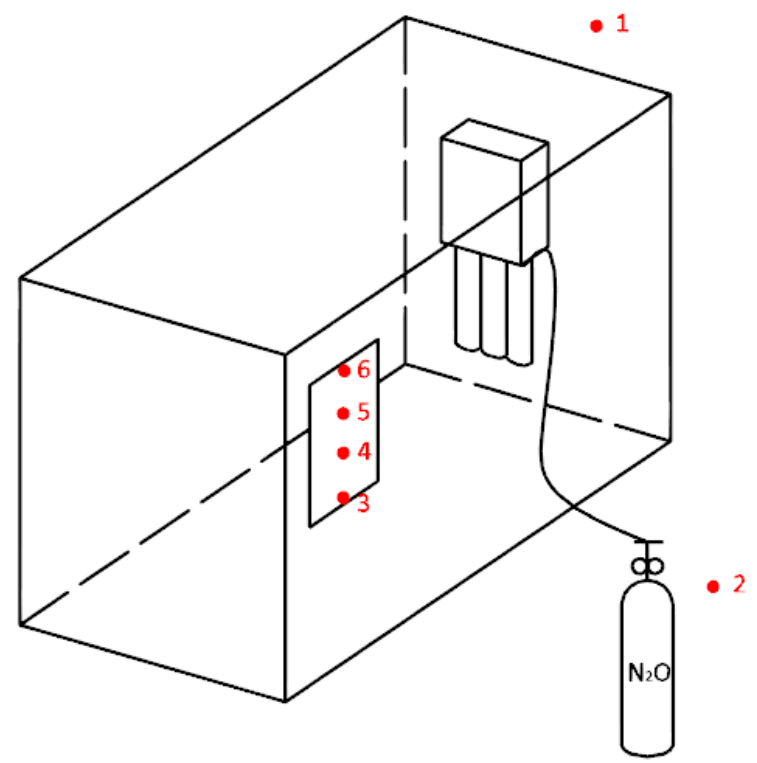

Figure 3.7 Positions of tracer gas sensors

1. Supply air concentration (outside the shelter)

2. Outside air concentration (near the tracer gas bottle, for safety reason)

3. Exhaust air concentration 1 (inside the shelter, near exhaust opening, $1.3 \mathrm{~m}$ height above floor)

4. Exhaust air concentration 2 (inside the shelter, near exhaust opening, $1.6 \mathrm{~m}$ height above floor)

5. Exhaust air concentration 3 (inside the shelter, near exhaust opening, $1.9 \mathrm{~m}$ height above floor)

6. Exhaust air concentration 4 (inside the shelter, near exhaust opening, $2.2 \mathrm{~m}$ height above floor)

\subsubsection{Ventilation system airflow impedance}

Impedance is an obstruction to movement, in our case an obstruction to the flow of air. As the flow slows down due to 'impedances', a pressure gradient is formed upstream of the obstacle. This pressure drop represents the impedance of the system and works in opposition to the flow. The summation of individual impedances contributes to the system's overall pressure drop, which is represented by an impedance curve. The impedance curve represents the amount of pressure head a flow must overcome to achieve the desired flow rate. An impedance curve is generated empirically by measuring the pressure drop within the system using a wind tunnel (Figure 3.8).

As shown in Figure 3.8, the airflow rate can be measurement by orifice plate. With an orifice plate, the fluid flow is measured through the difference in pressure from the upstream side to the downstream side of a partially obstructed pipe. The plate obstructing the flow offers a precisely measured obstruction that narrows the pipe and forces the flowing fluid to constrict. We also need to know the pressure drop through the tested ventilation system. In our case, the tested ventilation 
system includes a fan unit and three filter socks. The pressure drop can be determined by subtracting the atmospheric pressure from the measured pressure in front of ventilation system. The pressure drop through orifice plate is using micromanometer which type is Debro Meerbush Germany. And the pressure drop through tested ventilation system is using manometer which type is Furness Controls Limited FCO510 micromanometer.

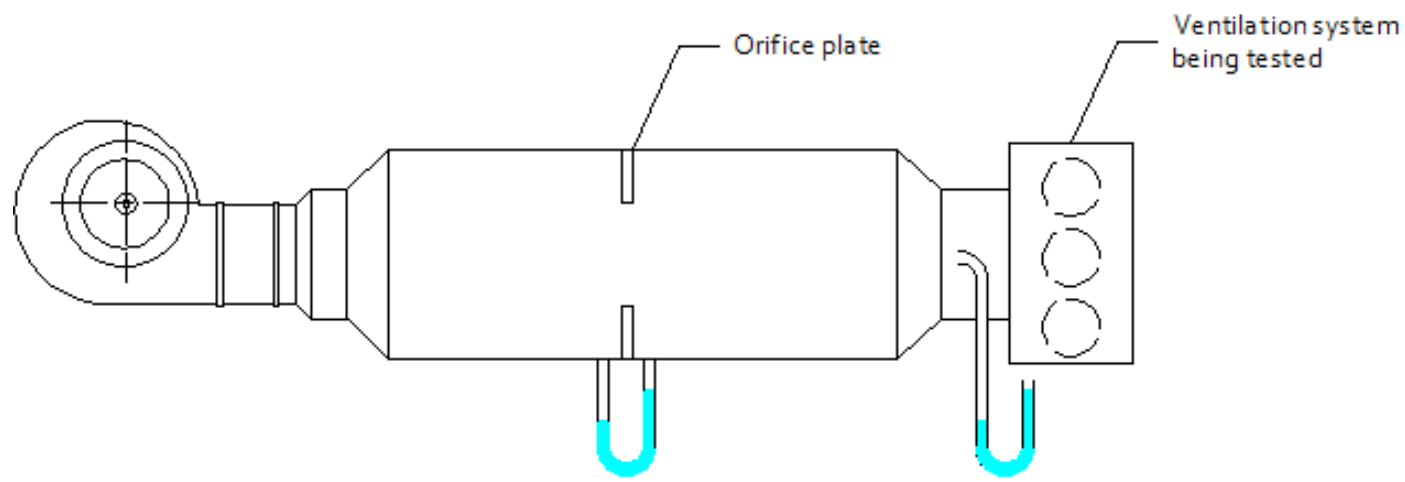

Figure 3.8 Schematic of Airflow Test Chamber and the airflow from left to right

\subsubsection{Pressure rise across the fan}

The pressure rise across the fan must be sufficient to overcome the total pressure drop of the overall system. Any type of obstruction, restriction or roughness in the system will cause resistance to air flow and cause pressure drop. In the distribution system, the highest pressure drops usually are found at the points of use, including in undersized or leaking hoses, tubes, disconnects, filters, regulators and lubricators. On the supply side of the system, air/lubricant separators, after coolers, moisture separators, dryers and filters are the main items causing significant pressure drop [4].

The pressure rise of the fan can be expressed by eq (3.4), which is the summation of pressure drop of ventilation system and the pressure difference between inside and outside. The pressure difference between inside and outside shelter is measured by Digital manometer FC016 Furness Controls Limited.

$$
\Delta P_{\text {fan }}=\left(P_{\text {in }}-P_{\text {out }}\right)+\Delta P_{\text {vent }}
$$

Where:

$\Delta P_{f a n} \quad$ is pressure rise cross the fan

$P_{\text {in }} \quad$ is pressure inside the shelter

$P_{\text {out }} \quad$ is pressure outside the shelter

$\Delta P_{\text {vent }} \quad$ is pressure drop through ventilation system 


\subsubsection{Fan electric power}

Fan electric power depends on airflow through the fan and pressure rise across the fan, fan efficiency. None of these parameters is constant for systems with variable flows or pressures and all are interrelated. In our project, the power of fan is measured by AC Power Analyzer D5255 S which produced by NORMA. Through this power analyzer, we can read current, voltage and power directly.

The fan efficiency is the ratio between power transferred to the airflow and the power used by the fan. The fan efficiency is in general independent of the air density and can be expressed as:

$$
\eta=\frac{\Delta P_{f a n} \cdot q}{E}
$$

Where:

$\eta \quad$ is fan efficiency,

$\Delta P_{\text {fan }} \quad$ is pressure rise across the fan, $\mathrm{Pa}$

$q \quad$ is airflow rate, $\mathrm{m}^{3} / \mathrm{s}$

$E \quad$ is electric power, W

\subsubsection{Temperature measurements}

In our experiments, $\mathrm{K}$ type thermocouples are used for temperature measurements, which have a wide variety of probes from $-200{ }^{\circ} \mathrm{C}$ to $+1350{ }^{\circ} \mathrm{C}$ range. Thermocouples are connected to data acquisition device '2040 series Squirrel Data Logger'. Data logger transfers all the data to PC, where SquirrelView Assistant analyses results and exports them to excel files.

Both supply and exhaust air temperatures and vertical temperature profiles inside the technical shelter are measured during experiments. When measuring the vertical temperature profiles, thermocouples are located in the middle of shelter. The exhaust opening is a shutter which is $0.9 \mathrm{~m}$ height and $0.4 \mathrm{~m}$ width. Because of the temperature gradient inside the shelter, we measured the exhaust air temperature at three positions: at the top, middle and bottom of exhaust opening. Then, average value is taken from these three temperatures to get exact exhaust air temperature. Figure 3.9 indicates the positions of all thermocouples. 


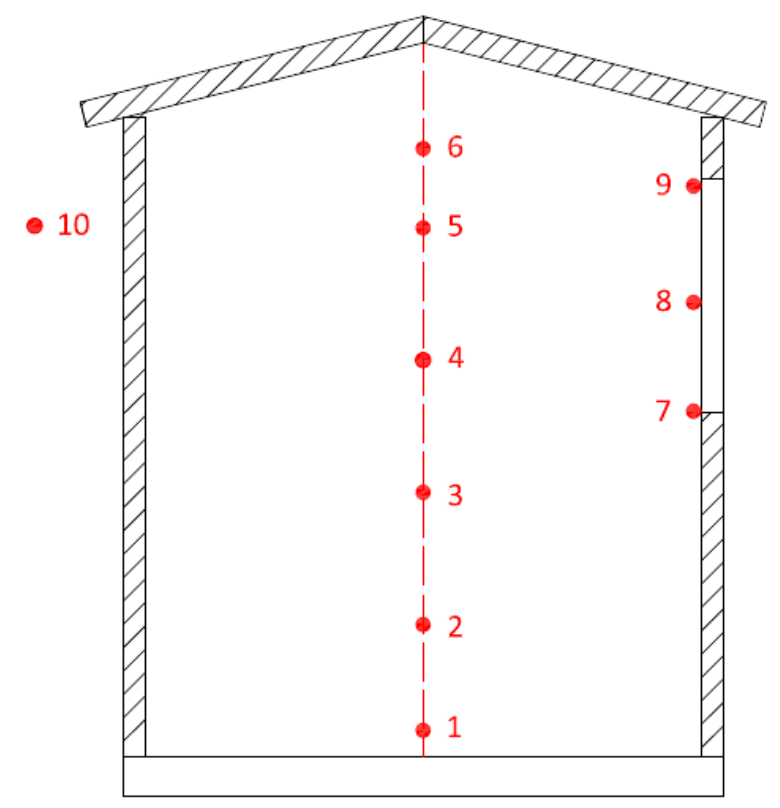

Figure 3.9 Positions of thermocouples

1. Temperature at $0.1 \mathrm{~m}$ height

2. Temperature at $0.5 \mathrm{~m}$ height

3. Temperature at $1.0 \mathrm{~m}$ height

4. Temperature at $1.5 \mathrm{~m}$ height

5. Temperature at $2.0 \mathrm{~m}$ height

6. Temperature at $2.3 \mathrm{~m}$ height

7. Exhaust air temperature at the bottom of exhaust opening ( $1.3 \mathrm{~m}$ height above floor)

8. Exhaust air temperature in the middle of exhaust opening (1.75 $\mathrm{m}$ height above floor)

9. Exhaust air temperature at the top of exhaust opening ( $2.2 \mathrm{~m}$ height above floor)

10. Supply air temperature (outside the shelter) 


\subsubsection{Energy Balance of technical shelter}

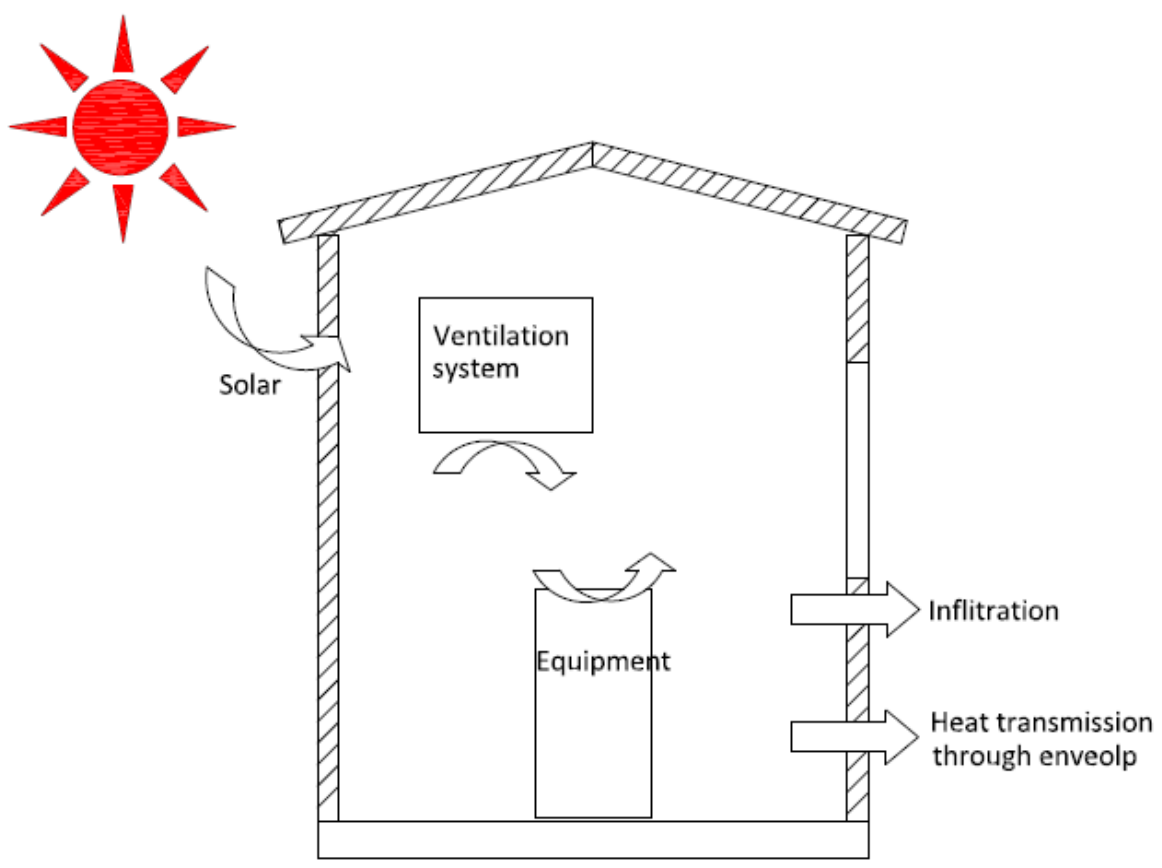

Figure 3.10 Heat sources in a technical shelter

As shown in Figure, there are several heat sources in a technical shelter: Heat dissipation by equipments $\left(Q_{e q}\right)$, heat transmission through envelops $\left(Q_{\text {trans }}\right)$, heat by infiltration $\left(Q_{\text {inf }}\right)$, heat removed by ventilation system $\left(Q_{\text {ventil }}\right)$ and solar radiation $\left(Q_{\text {sun }}\right)$. However, in our experiment the shelter was located in a workshop where no solar radiation is available and the temperature in the workshop keeps constant during measurement. In addition, due to infiltration rate can't be measure directly, we combine infiltration and ventilation together which expressed by $Q_{v e n t}$. Thus, the energy balance in the shelter can be expressed by the eq (3.6), where $Q_{\text {cooling }}$ is the extra cooling load.

$$
Q_{\text {cooling }}=Q_{e q}-Q_{\text {trans }}-Q_{\text {vent }}
$$

In our measurement, two radiators serve as equipments to dissipate heat into the shelter. The powers of these two radiators are $1.52 \mathrm{~kW}$ and $1.59 \mathrm{~kW}$, respectively. Because the ventilation system is located inside the shelter, $Q_{e q}$ will include two parts: both heat dissipation by radiators and by ventilation system.

Heat transmission through the building envelop can be expressed by the equation below:

$$
Q_{\text {trans }}=U \cdot A \cdot\left(T_{\text {inter }}-T_{\text {exter }}\right)
$$


Where:

$U \quad$ is U-value (or U-factor), more correctly called the overall heat transfer coefficient, which describes how well a building element conducts heat, $\mathrm{W} /\left(\mathrm{m}^{2} . \mathrm{K}\right)$

$A$ is the area of building envelop, $\mathrm{m}^{2}$

$T_{\text {inter }} \quad$ is interior surface temperature of building envelop, ${ }^{\circ} \mathrm{C}$

$T_{\text {exter }}$ is exterior surface temperature of building envelop, ${ }^{\circ} \mathrm{C}$

Heat removed by ventilation system (include infiltration) has the definition below:

$$
Q_{\text {vent }}=C_{p} \cdot \rho \cdot q \cdot\left(T_{\text {ex }}-T_{\text {sup }}\right)
$$

Where:

$C_{p} \quad$ is specific heat capacity of air, $\mathrm{C}_{\mathrm{p}}=1.005 \mathrm{~kJ} / \mathrm{kg} . \mathrm{K}$

$\rho \quad$ is density of air, $\rho=1.205 \mathrm{~kg} / \mathrm{m}^{3}$

$q \quad$ is airflow rate, $\mathrm{m}^{3} / \mathrm{s}$

$T_{e x} \quad$ is average exhaust air temperature, ${ }^{\circ} \mathrm{C}$

$T_{\text {sup }} \quad$ is supply air temperature, ${ }^{\circ} \mathrm{C}$ 


\subsection{Measurement results and discussion}

\subsubsection{Pressure results}

Depending on system configuration, the pressure drop of system is a function of the duct static pressure set point, duct leakage, and the pressure drops across duct and duct-like elements (e.g., dampers, fittings), coils, and filters that are connected to the fan. It is generally recognized that duct and duct-like pressure drops increase approximately as the square of the flow through them (ASHRAE 2009). However, pressure drops across coils and filters behave differently: the pressure drop versus flow relationship is less parabolic and more linear like in some cases such as with wet coils or high-efficiency filters.

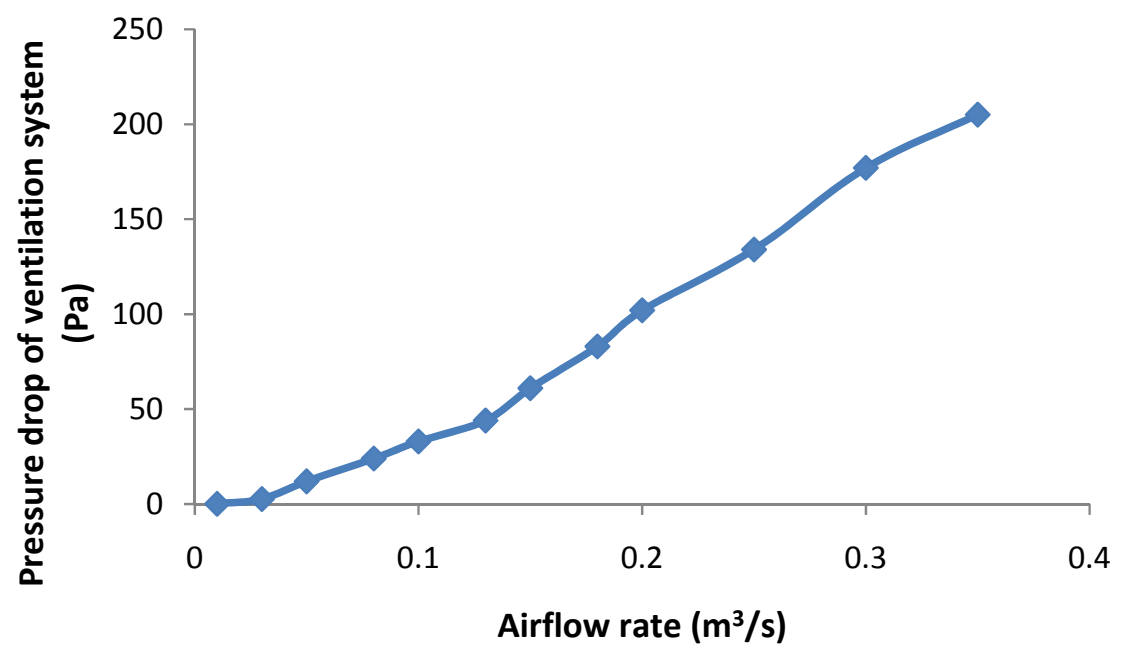

Figure 3.11 Impedance curve of ventilation system

As shown in Figure 3.11, the pressure drop of ventilation system is more linear like rather than as the square of the airflow through them. This is because pressure drop of ventilation system is mainly caused by filter socks connected with the fan. Generally, the pressure drop is a direct function of the filtration efficiency; in other words, high-efficiency filtration results in a high pressure drop.

Table 3.1 Pressure drop of overall system versus airflow rate

\begin{tabular}{|l|r|r|r|r|r|r|r|r|}
\hline $\mathrm{q}\left(\mathrm{m}^{3} / \mathrm{s}\right)$ & 0 & 0.092 & 0.149 & 0.22 & 0.301 & 0.329 & 0.391 & 0.431 \\
\hline$\Delta \mathrm{P}_{\text {vent }}(\mathrm{Pa})$ & 0 & 34.94 & 70.93 & 115.77 & 166.91 & 184.59 & 223.74 & 248.9 \\
\hline$\Delta \mathrm{P}_{\text {in-out }}(\mathrm{Pa})$ & 0 & 5.02 & 9.28 & 11.64 & 10.06 & 15.43 & 16.93 & 18.60 \\
\hline$\Delta \mathrm{P}_{\text {total }}(\mathrm{Pa})$ & 0 & 39.96 & 80.21 & 127.41 & 176.97 & 200.02 & 240.67 & 267.50 \\
\hline
\end{tabular}

Figure 3.12 demonstrates the total pressure rise across the tested fan, which must be sufficient to overcome the total pressure drop of the overall system. As shown in Table 3.1, the total pressure drop of overall system includes two parts: pressured drop of ventilation system and pressure drop 
between inside and outside of technical shelter. Pressured drop of ventilation system takes a large part of total pressure drop, especially at higher airflow rate.

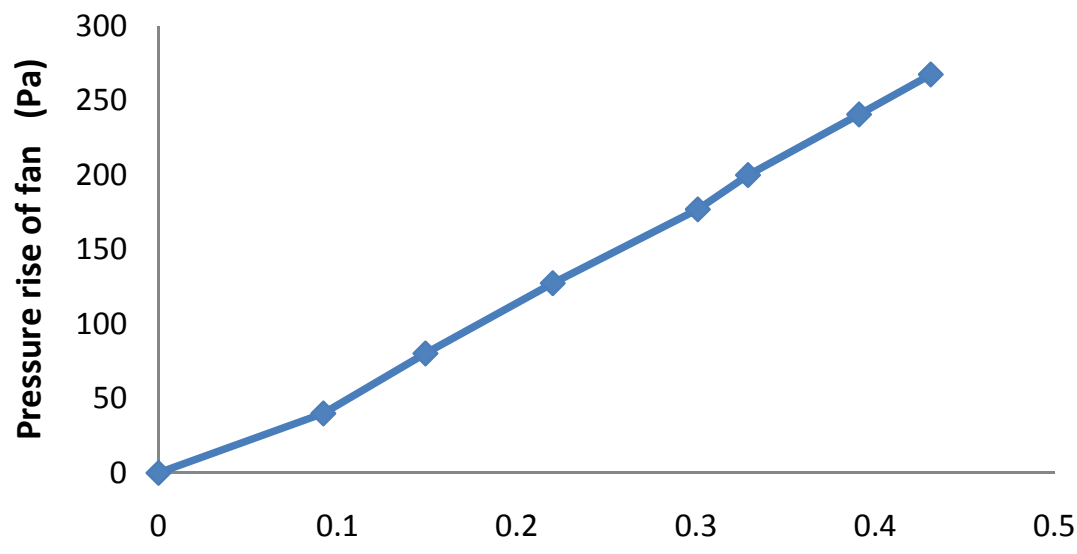

Airflow rate $\left(\mathrm{m}^{3} / \mathrm{s}\right)$

Figure 3.12 Total pressure rise of fan versus airflow rate

\subsubsection{Efficiency curve of fan}

In our experiments, because the supply air temperature is almost constant, the airflow rate must vary to meet the rising or falling heat gains or losses within the technical shelter, which is also called as Variable air volume (VAV) system. The VAV strategy is achieved by controlling fan's speed. Control of the system's fan speed is critical in VAV systems. Without proper and rapid flow rate control, the system's ductwork, or its sealing, can easily be damaged by overpressurization [5]. The fan speed control, especially with modern electronic variable speed drives, reduces the energy consumed by fans which can be a substantial part of the total cooling energy requirements of a building. In order to explore the relationship between energy consumption of fan and air flow rate, the efficiency curve of tested fan is made in our experiment.

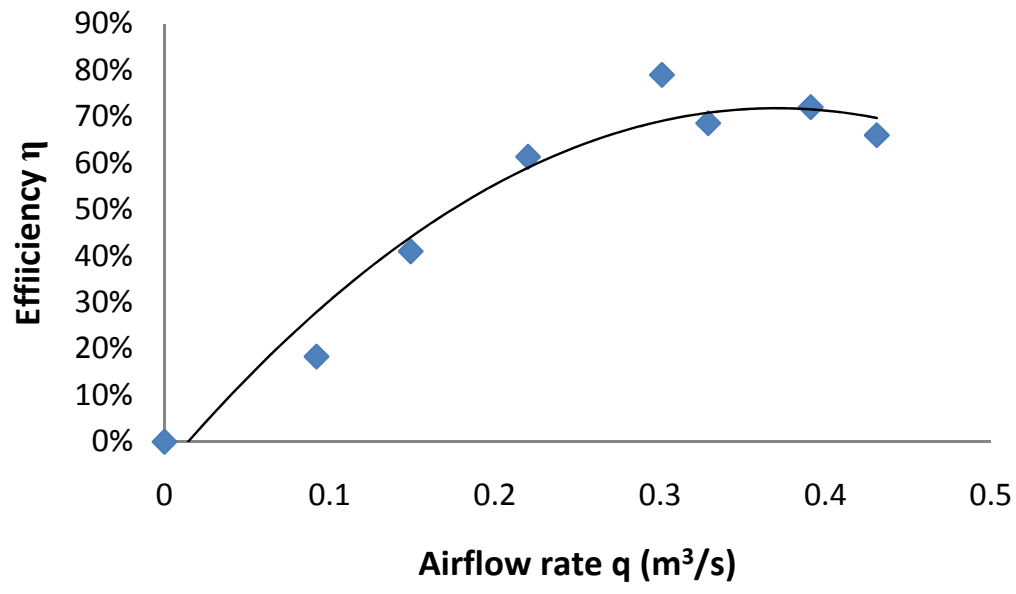

Figure 3.13 Efficiency curve of fan 
Figure 3.13 shows the efficiency curve of tested fan. The fan's efficiency is a function of airflow rate, total pressure increase and power used by the fan. As indicated in Figure 3.13, the fan efficiency significantly increases while increases the airflow rate and reaches a peak efficiency of $78.95 \%$ when the airflow rate is around $0.3 \mathrm{~m}^{3} / \mathrm{s}$. After that, fan efficiency gradually decreases while increases airflow rate until reaches maximum value. It needs to notice that even when the airflow rate is zero, electric power of tested fan is almost $13 \mathrm{~W}$, which is quite inefficiency to operate the fan in this condition.

\subsubsection{Temperature gradient}

Controlling the indoor temperature in an acceptable level is very important for obtaining high performance and operation reliability of electric equipments. In order to explore the temperature performance inside technical shelter, vertical temperature profiles are measured in both $1.5 \mathrm{~kW}$ and $3 \mathrm{~kW}$ heat load conditions.

In our experiments, in order to keep the average indoor around $30{ }^{\circ} \mathrm{C}$, the ventilation system are running at $0.092 \mathrm{~m}^{3} / \mathrm{s}$ and $0.22 \mathrm{~m} / \mathrm{s}$ airflow rate for $1.5 \mathrm{~kW}$ and $3 \mathrm{~kW}$ cases, respectively. It can be seen from Table 3.2 that the vertical temperature gradients are quite high in both cases. The air temperature is lower at floor level than at ceiling level and the temperature difference can reach more than $10{ }^{\circ} \mathrm{C}$. This fact will be good for reducing the cooling need if the electric equipments are located at the lower level. Even though the temperatures at the higher part have exceeded the set point temperature, the temperatures at lower part are still in an acceptable level. In addition, it will be more energy efficiency if the exhaust opening is positioned at the higher part of the technical shelter. This means that the warmest air can be extracted to outside directly.

Table 3.2 Vertical temperature gradient inside the shelter

\begin{tabular}{|r|r|r|}
\hline \multirow{2}{*}{ Height } & \multicolumn{2}{|c|}{ Temperature } \\
\cline { 2 - 3 } & $1.5 \mathrm{~kW}$ & $3 \mathrm{~kW}$ \\
\hline \multicolumn{1}{|c|}{$\mathrm{m}$} & \multicolumn{2}{|c}{$\mathrm{C}$} \\
\hline 0.1 & 21.31 & 23.63 \\
\hline 0.5 & 21.85 & 25.73 \\
\hline 1 & 23.24 & 28.5 \\
\hline 1.5 & 29.2 & 31.81 \\
\hline 2 & 32.89 & 32.99 \\
\hline 2.3 & 35.24 & 34.05 \\
\hline
\end{tabular}




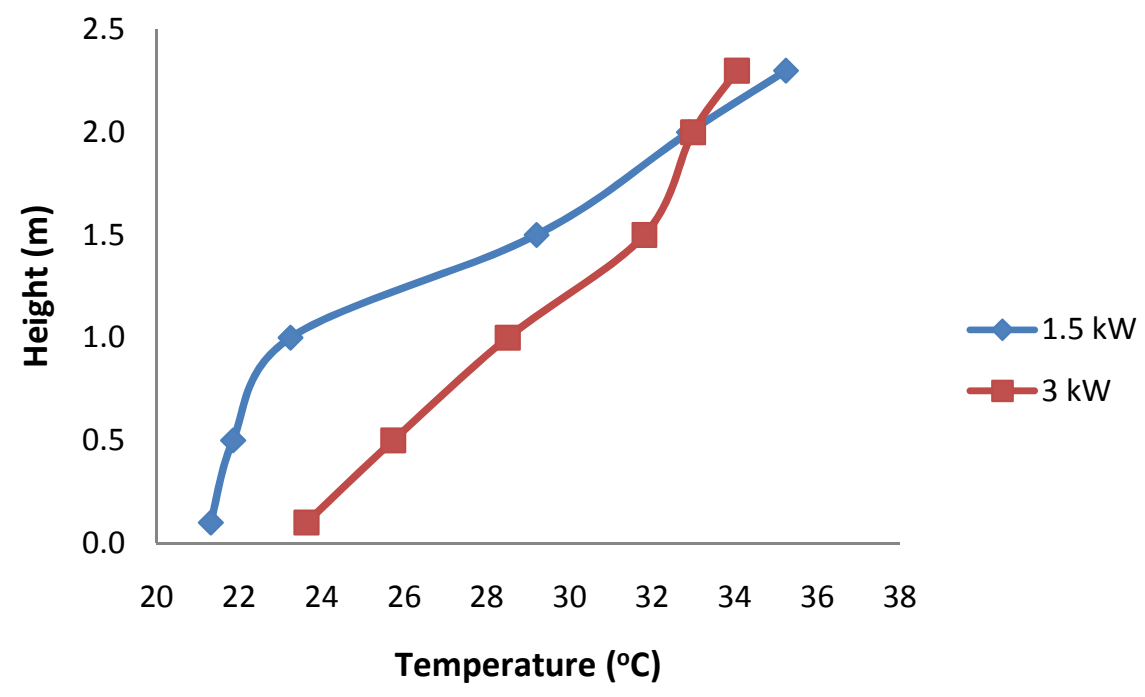

Figure 3.14 Vertical temperature profiles for both cases

Figure 3.14 demonstrates the vertical temperature profiles for both $1.5 \mathrm{~kW}$ and $3 \mathrm{~kW}$ cases. In 1.5 $\mathrm{kW}$ case, it's easy to find out the temperature is almost constant from $0.1 \mathrm{~m}$ to $1 \mathrm{~m}$ height, after that the temperature increases significantly with the height. This is because in $1.5 \mathrm{~kW}$ case, the heat source is too weak to generate great convection flow which causes completely mixing between cold supply air and warm space air. So that high density cold air is trapped at the lower level. In addition, the airflow rate is higher in $3 \mathrm{~kW}$ case, thus the supply air velocity is higher which will cause higher turbulence level to improve mixing process.

\subsubsection{Airflow rate of ventilation system}

The tracer gas technique is used to measure induced airflow rate in the technical shelter by ventilation system. Due to two mixing fans work inside the shelter, space air is completely mixed with space air. As shown in Figure 3.15, the vertical concentration gradient near the exhaust opening is almost constant. The ventilation rate can be calculated by eq (3.1), and the exhaust air concentration takes the average value of the temperatures at four different heights near the exhaust opening. Accordingly, the airflow rate and air change rate caused by ventilation is as given in Table 3.3 .

Table 3.3 Ventilation flow rate and air change rate in both $1.5 \mathrm{~kW}$ and $3 \mathrm{~kW}$ cases

\begin{tabular}{|c|c|c|}
\hline Cases & $\begin{array}{l}\text { Airflow rate } \mathrm{q} \\
\left(\mathrm{m}^{3} / \mathrm{s}\right)\end{array}$ & $\begin{array}{l}\text { Air change rate } \\
N(1 / \mathrm{h})\end{array}$ \\
\hline $1.5 \mathrm{~kW}$ & 0.092 & 16.59 \\
\hline $3 \mathrm{~kW}$ & 0.22 & 39.68 \\
\hline
\end{tabular}




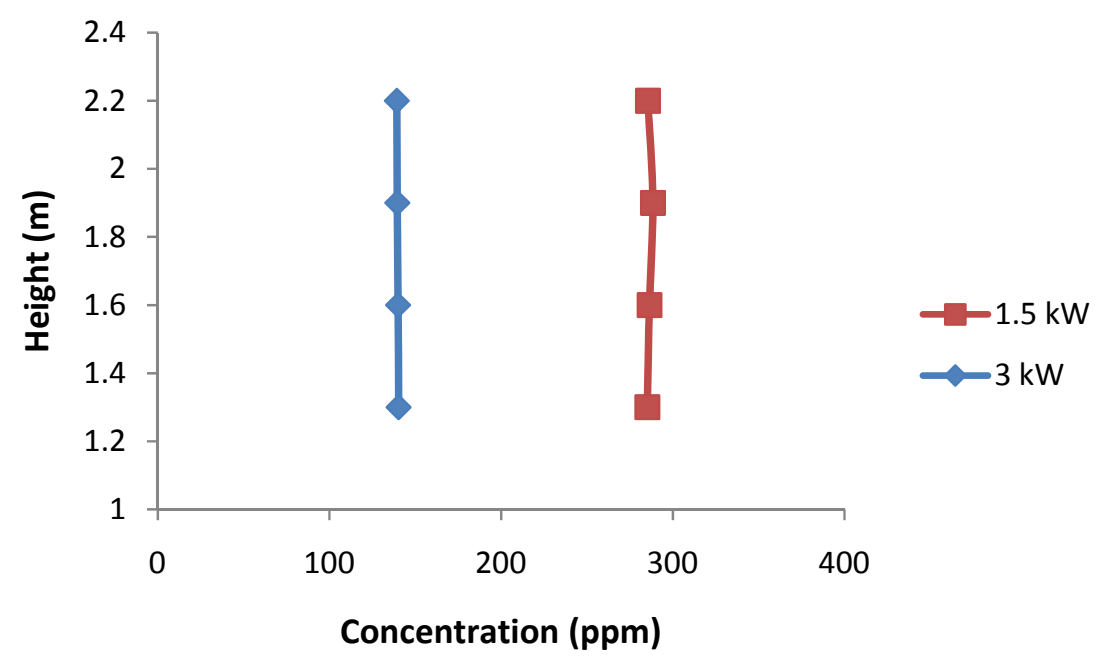

Figure 3.15 Vertical concentration profiles

\subsubsection{Energy balance}

As we know, every building has heat inertial capacity, which delays and decreases the impact of outdoor changed climate on the indoor environment. However, due to the huge indoor equipments heat dissipation rate and almost constant outdoor temperature during measurement, a simplified analysis method mentioned in Section 3.2.6 can be used to analysis the energy performance of technical shelter in our project. This method can clearly express the main influencing factors on energy performance and greatly reduce the simulation time.

Table 3.4 Heat sources and energy balances for technical shelter

\begin{tabular}{|l|r|r|}
\hline Heat sources & $1.5 \mathrm{~kW}$ & $3 \mathrm{~kW}$ \\
\hline $\mathrm{E}_{\mathrm{eq}}(\mathrm{W})$ & 1540.07 & 3155.7 \\
\hline $\mathrm{E}_{\text {vent }}(\mathrm{W})$ & -919.54 & -2687.16 \\
\hline $\mathrm{E}_{\text {trans }}(\mathrm{W})$ & -380.71 & -539.63 \\
\hline$\sum \mathrm{E}(\mathrm{W})$ & 239.83 & -71.09 \\
\hline
\end{tabular}

The outdoor temperature keeps around $19{ }^{\circ} \mathrm{C}$ during the measurements, and average indoor temperature are $26.1{ }^{\circ} \mathrm{C}$ and $29.3{ }^{\circ} \mathrm{C}$ in $1.5 \mathrm{~kW}$ and $3 \mathrm{~kW}$ cases, respectively. As indicated in Table 3.4 , the calculated results by the simplified analysis method accord well with the energy balance rule, where the deviations are in an acceptable level.

The contribution of each heat sources to the total shelter load can be shown clearly in Figure3.16. Due to without any solar radiation, the heat dissipation from electrical equipments (including the heat dissipation from ventilation fan) is the only heat gain source in our cases. Heat transmission through envelop and ventilation cooling are the main ways to remove heat from inside shelter to the outside. Thus, in order to optimize the energy performance of technical shelter when the heat load of equipment is almost constant, it's important to perform energy efficiency envelop design 
and optimize the control of ventilation system. However, the proportion of heat transmission through envelop decreases when indoor equipment heat dissipation increases, which take $24.72 \%$ and $17.1 \%$ in $1.5 \mathrm{~kW}$ and $3 \mathrm{~kW}$ cases, respectively.

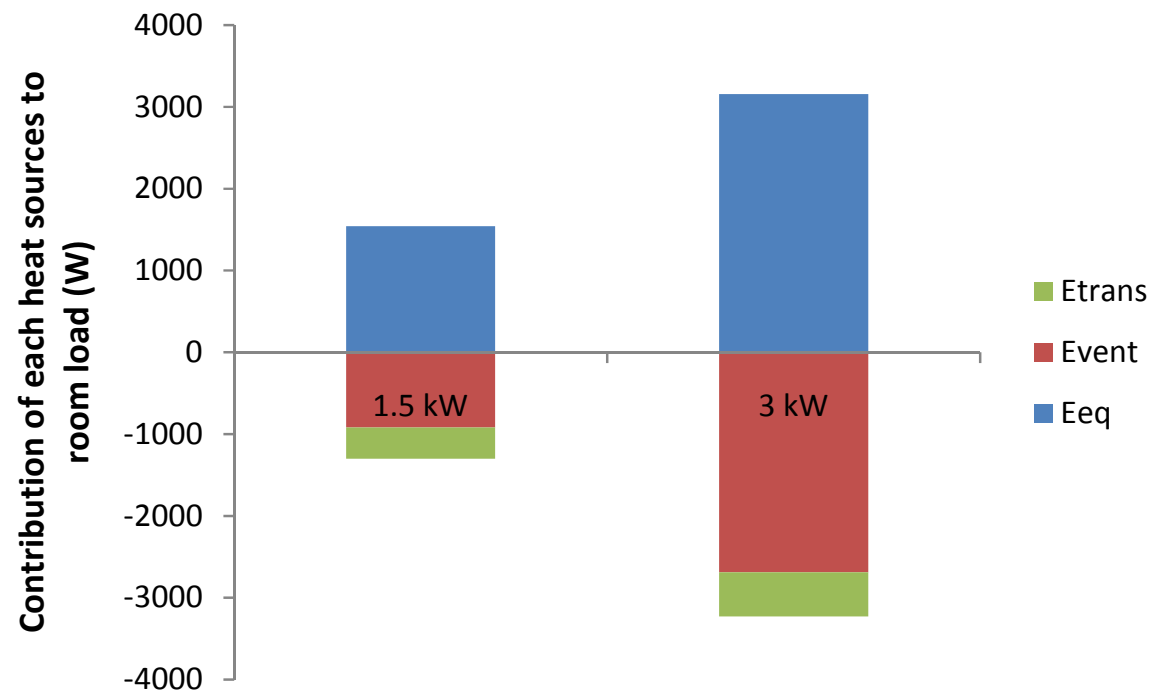

Figure 3.16 Contribution of the main heat sources to the shelter's load in both $1.5 \mathrm{~kW}$ and $3 \mathrm{~kW}$ cases

\section{References}

[1] Materials description list provided by Intego A/S

[2] Installation instructions/ Operation and Maintenance instruction of DeltaMaster 6L 48EC

[3] Heinz R. Trechsel, "Moisture Control in Buildings", Philadelphia, ASTM Manual Series: MNL 18, 1994, pp.225-227

[4] "Development of Chassis Impedance and Fan Curves", Mar. 29, 2011. [Online]. Available: www.engr.sjsu.edu/.../Fan\%20Configuration\%20and\%20Airflow\%20Impedance $\% 20 \mathrm{Lab} \%$. [Accessed: May, 21, 2011]

[5] "Energy efficiency: benefits of variable speed control in pumps, fans and compressors", Schneider Electric Industries SAS, May. 2008 


\section{Chapter 4 BSim Simulation}

\subsection{Introduction}

The aim of this project is to analysis the energy performance of technical shelter and to evaluate the energy saving potential in the shelter by proper design of building envelop and application of an optimal ventilation and mechanical cooling strategy. Evaluation of the energy saving potential can be carried out using building thermal and energy simulation program. In our case, BSim software is adopted to simulate the annual energy performance and indoor climate of a standard technical shelter.

\subsection{BSim}

BSim is an integrated PC tool for analyzing buildings and installations. The software calculates power outputs and energy flows within the building and between the building and its surroundings. For all the spaces or zones being simulated, the software will therefore calculate heat loss through transmission, infiltration and ventilation, heat input in the form of solar heat, heat and moisture given off by people and equipment, electricity consumption for lighting, and power demand and energy consumption for every component of the heating, cooling and ventilation systems. Indoor climate is calculated using hourly values for indoor air temperatures, surface temperatures, relative atmospheric humidity and air exchange for each zone [1].The calculation in BSim performed in a steady state condition for each time step. The software also contains accumulation of heat and moisture calculations. There are two or more time steps per hour [2].

\subsubsection{Rooms and thermal zones}

When using BSim the building is divided into rooms, some in thermal zones. A building consists of an arbitrary number of thermal zones, which are limited by an arbitrary number of surfaces. Thermal zone has not only a description of geometry and constructions attached to it, but also need define systems attached to it, such as equipment, ventilation, heating plant, etc. It needs to notice that only rooms in thermal zones will be simulated dynamically, the rest can be used in other applications.

\subsubsection{Building elements and building materials}

$\operatorname{Sim} D B$ - building materials describe the type, density, thermal capacity, thermal conductivity, and PCM (phase change material) properties. Walls, floors and roof constructions are built in layers according to the description of the materials. All materials and constructions are defined in a database and attached to the model as defaults in one operation or one by one by drag and drop from the database.

\subsubsection{Systems and functions}

Systems consist of all the things that are not the actual building itself, which include internal loads (e.g. persons, lighting, equipment, moisture load), natural single and multi zone ventilation (e.g. 
infiltration, venting), heating (floor/construction and/or radiator) and cooling radiators, and ventilation systems. A system consists of the general physical component, described by a simple mathematical model, and a schedule, which specifies variations, control strategies, etc., described by connected pairs of control and time definition, as indicated by Figure 4.1. All systems in BSim are controlled on the basis of an operative temperature in the thermal zone to which they are attached.

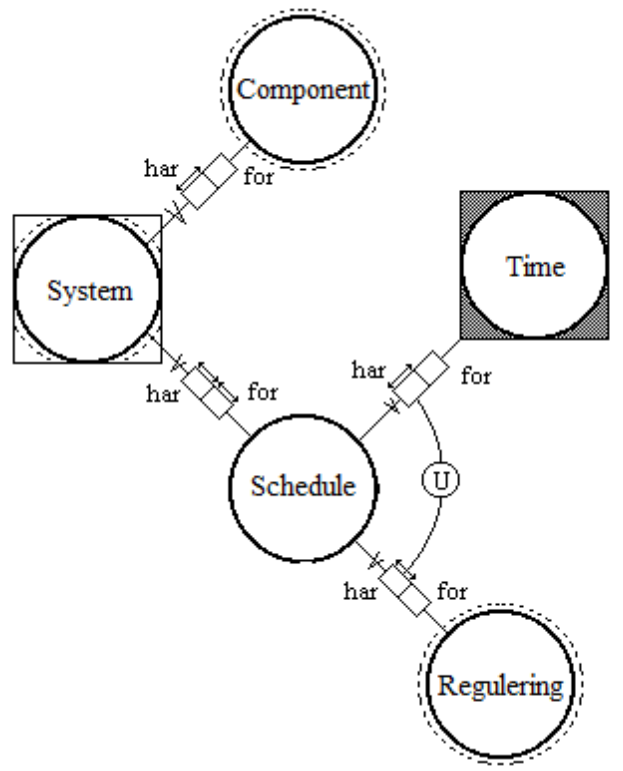

Figure 4.1 General descriptions of systems [1]

\subsubsection{Climate data}

A calculation cannot be carried out with either tsbi5, XSun or SimLight without an attached climate file. Climate data from any geographic location can be used in the simulations. BSim is delivered with complete Danish climate data. BSim also has a built-in function that allows the user automatically to download and convert ASHRAE climate data to the binary BSim format. The conversion function enables the user to establish his own climate data files e.g. from recorded hourly data.

\subsection{Model of technique shelter}

\subsubsection{Location}

Following coordinates define the geographical location of the model, and the climate data is based on Denmark in design reference year. 
Table 4.1 Geographical and site parameters for the model

\begin{tabular}{l|l}
\hline Time Zone & $+1 \mathrm{hr}$ MGT \\
Degrees of longitude & $12^{\circ} 19^{\prime} \mathrm{E}$ \\
Degrees of latitude & $55^{\circ} 46^{\prime} \mathrm{N}$ \\
Altitude & $27 \mathrm{~m}$ \\
\hline
\end{tabular}

\subsubsection{Thermal properties of envelop}

Proper design of building envelop is rather important when outdoor climate changes all year around. Envelop with good heat transfer ability is good for reduction of cooling load, when the outdoor temperature is lower than the indoor temperature, but it also increases the possibility of heating demand. In order to find optimal envelop condition, wall \& ceiling with different insulation thickness are simulated in this project. Four insulation thickness conditions are taken into account: $25 \mathrm{~mm}, 50 \mathrm{~mm}, 85 \mathrm{~mm}$ and $100 \mathrm{~mm}$.

Heat transfer coefficient U-value for the construction is calculated by $\operatorname{Sim} D B$ when user defined the material properties of the construction. The U-value is calculated according to the Danish Norms DS 418. In our model, construction components of the wall \& ceiling, foundation and door are defined according to material descriptions provided by Intego A/S (as described in Section 3.1.2), which resulted in the following properties:

Table 4.2 Thermal properties of envelop components

\begin{tabular}{|l|l|l|}
\hline \multicolumn{2}{|l|}{ Components } & U-value $\left(\mathrm{W} / \mathrm{m}^{2} \mathrm{~K}\right)$ \\
\hline \multirow{3}{*}{$\begin{array}{l}\text { Wall \& Ceiling } \\
\text { (with different insulation } \\
\text { thickness) }\end{array}$} & $25 \mathrm{~mm}$ & 1.45 \\
\cline { 2 - 3 } & $50 \mathrm{~mm}$ & 0.72 \\
\cline { 2 - 3 } & $85 \mathrm{~mm}$ & 0.42 \\
\cline { 2 - 3 } & $100 \mathrm{~mm}$ & 0.36 \\
\hline Foundation & 3.29 \\
\hline Door & 0.66 \\
\hline
\end{tabular}

\subsubsection{Model geometry}

Model geometry is followed the architectural drawing of the standard technical shelter. And we assume that there are no other buildings in the neighborhood, so there is no shadow from the surroundings. The building is in one thermal zone, and all systems are equipped in the thermal zone, in order to simulate the building performance. 


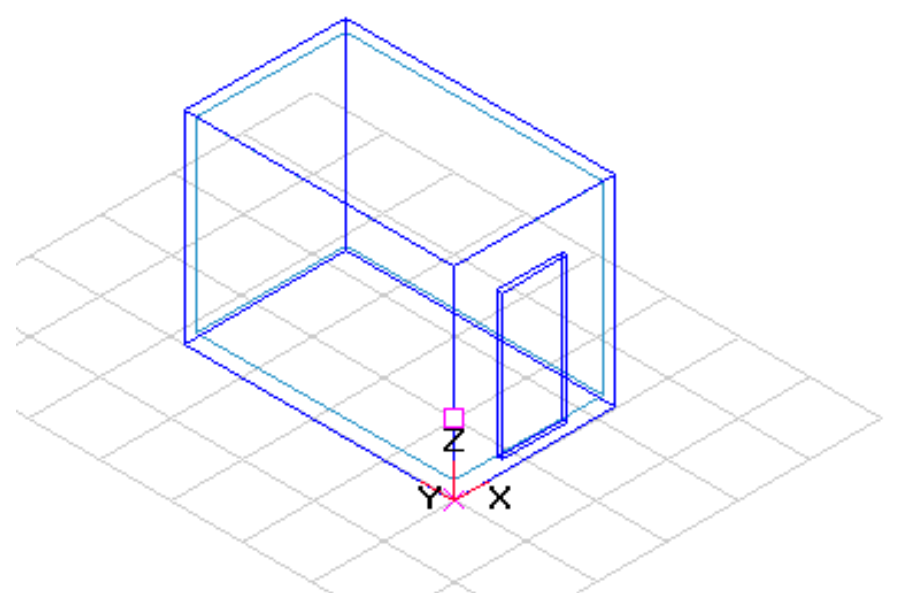

Figure 4.2 Model geometry of standard technical shelter

\subsubsection{Systems}

Systems consist of all the things that are not the actual building itself. That is all the things that influence the thermal and moisture loads: Mixing, People, Equipment, Moisture, Infiltration, Lighting, Ventilation, Heating, Cooling and Venting. In our project, there are four systems which define the building performance. They are: equipments which serve as thermal load, ventilation, mechanical cooling and heating system. Due to the limited period of occupancy, people load and lighting can be ignored in our simulation.

The air temperature in the shelter is primarily controlled by ventilation system. Our ventilation system is quite simple, which only includes a fan and filters and not any heat recovery unit is equipped in this system. In addition, the supply, return airflow rate and pressure rise across the fan are uncertain values. Because of these factors, we can make an assumption that using venting system to replace ventilation system, which will be easier for set up and solves the problem of missing input data. Additional cooling need, necessary to maintain the set point temperature in the shelter is supplied through mechanical cooling system. The heating system is activated only when the indoor temperature lower than the set point. In addition, it's assumed that the technical shelter is well air-tightness, so no infiltration is taken into consideration.

It's important to notice that mechanical cooling system and heating system are only existed in the BSim simulation, where the real shelter used for measurements wasn't equipped with these systems. This assumption aims in calculating the energy saving potential of the shelter.

As described in the instruction manual for BSim, a system consists of the general physical component, described by a simple mathematical model, and a schedule, which specifies variations, control strategies, etc., described by connected pairs of control and time definition. The systems description and their controls in our case are shown in Table 4.3.

Because heat loads in the shelter are greatly determined by the amount and power of equipments stored in the technical shelter, so different heat load conditions are set up in our simulation: $1.5,3$, 
5, 8 and $10 \mathrm{~kW}$. Part to Air specifies the proportion of heat emissions (between 0 and 1) that is supplied straight to the room air by convection. The remaining heat is distributed to the zone's faces [1]. The technical shelters are mainly using for storing electronic and technical equipments, and people go inside only a limited period for equipment maintenance. So heat load of the lighting and people were ignored due to limited period of occupancy. The design indoor temperature in the shelter is set according to temperature sensitive of equipments. Three different cases are used in the simulation, which are 30,40 and $50{ }^{\circ} \mathrm{C}$, respectively.

Table 4.3 Systems and their control

\begin{tabular}{|c|c|c|c|}
\hline \multirow{2}{*}{ System } & \multirow{2}{*}{ Description } & \multicolumn{2}{|l|}{ Schedule } \\
\hline & & Control & Indication of time \\
\hline Equipment & $\begin{array}{l}1.5,3,5,8,10 \mathrm{~kW} \\
\text { Part to air } 0.8\end{array}$ & Full load & Always \\
\hline Heating & $\begin{array}{l}\text { Maxpower: } 50 \mathrm{~kW} \\
\text { Part to Air: } 0.6\end{array}$ & Set Point: $10^{\circ} \mathrm{C}$ & Always \\
\hline Cooling & $\begin{array}{l}\text { Maxpower: }-50 \mathrm{~kW} \\
\text { Part to Air: } 0.6\end{array}$ & Set Point: $30,40,50{ }^{\circ} \mathrm{C}$ & Always \\
\hline Venting & $\begin{array}{l}\text { TmpFactor: } 2 \\
\text { TmpPower: } 0.5 \\
\text { Wind Factor: } 0.2 \\
\text { Max Airchange: } 100\end{array}$ & Set Point: $30,40,50{ }^{\circ} \mathrm{C}$ & Always \\
\hline
\end{tabular}




\subsection{Result of BSim simulation}

\subsubsection{Average air change rate in different conditions}

The simulations are carried out in 60 different conditions, where the heat load of internal equipments is: $1.5,3,5,8,10 \mathrm{~kW}$; insulation thickness is: $25,50,85,100 \mathrm{~mm}$; and indoor temperature is: $30,40,50{ }^{\circ} \mathrm{C}$, respectively. Table 4.4 indicates annual average air change in different conditions where the heat loads are all removed by ventilation cooling.

Table 4.4 Annual average air change rate in different conditions

\begin{tabular}{|c|r|r|r|r|}
\hline \multicolumn{5}{|c|}{ Cooling Setp $30{ }^{\circ} \mathrm{C}$} \\
\hline \multirow{2}{*}{$\begin{array}{c}\text { Heat Load } \\
(\mathrm{kW})\end{array}$} & \multicolumn{4}{|c|}{ Air Change Rate $(/ \mathrm{h})$} \\
\cline { 2 - 5 } & $25 \mathrm{~mm}$ & $50 \mathrm{~mm}$ & $85 \mathrm{~mm}$ & $100 \mathrm{~mm}$ \\
\hline 1.5 & 4.2 & 5.8 & 7.7 & 8.3 \\
\hline 3 & 13.8 & 17.9 & 19.9 & 22.1 \\
\hline 5 & 32.6 & 34.8 & 39.2 & 45 \\
\hline 8 & 65.9 & 66.8 & 81.7 & 84.3 \\
\hline 10 & 85.7 & 94.8 & 114.1 & 117.4 \\
\hline
\end{tabular}

\begin{tabular}{|c|r|r|r|r|}
\hline \multicolumn{5}{|c|}{ Cooling Setp $40{ }^{\circ} \mathrm{C}$} \\
\hline \multirow{2}{*}{$\begin{array}{c}\text { Heat Load } \\
(\mathrm{kW})\end{array}$} & \multicolumn{5}{|c|}{ Air Change Rate $(/ \mathrm{h})$} \\
\cline { 2 - 5 } & $25 \mathrm{~mm}$ & $50 \mathrm{~mm}$ & $85 \mathrm{~mm}$ & $100 \mathrm{~mm}$ \\
\hline 1.5 & 0.6 & 1.2 & 2.2 & 2.6 \\
\hline 3 & 4.1 & 7.7 & 9.9 & 11.1 \\
\hline 5 & 14 & 18.8 & 22.5 & 23.6 \\
\hline 8 & 30.3 & 36.4 & 42.3 & 43 \\
\hline 10 & 41.2 & 47.9 & 53.6 & 57.1 \\
\hline
\end{tabular}

\begin{tabular}{|c|r|r|r|r|}
\hline \multicolumn{5}{|c|}{ Cooling Setp $50{ }^{\circ} \mathrm{C}$} \\
\hline \multirow{2}{*}{$\begin{array}{c}\text { Heat Load } \\
(\mathrm{kW})\end{array}$} & $25 \mathrm{~mm}$ & $50 \mathrm{~mm}$ & $85 \mathrm{~mm}$ & $100 \mathrm{~mm}$ \\
\hline & 0 & 0.2 & 0.5 & 0.7 \\
\hline 1.5 & 1.1 & 3.4 & 5.6 & 6.4 \\
\hline 3 & 7 & 11.4 & 14.6 & 15.5 \\
\hline 5 & 18.9 & 23.3 & 27.7 & 28.6 \\
\hline 8 & 27.3 & 32 & 38.5 & 41 \\
\hline 10 & & & & \\
\hline
\end{tabular}

It's clear to find that the annual average air change rates significantly increase while increase the heat dissipation rate from equipments. This is easy to be understood, because increasing internal heat load, more heat needs to be discharged by ventilation cooling, and higher air change rate is required by ventilation system. 
The result also shows that lower insulation thickness of envelop will cause lower annual average air change rate. This means that envelop with better heat dissipation quality can reduce the cooling demand, but hamper heat preservation in winter which will enhance the heating demand potential. The simulation result shows that heating demand is only needed in $1.5 \mathrm{~kW}$ heat load, $25 \mathrm{~mm}$ insulation thickness condition. However, the annual heating need $(27.244 \mathrm{kWh})$ is quite lower than annual cooling need $(2589.1 \mathrm{kWh})$. So envelop with lower insulation thickness has better performance in most of conditions (especial in higher heat load cases), where not only reduces cooling demand of technical shelter but also reduces the cost on insulation materials.

Finally, the annual average air change rates decrease while increase indoor temperature set point. The indoor temperature set point is determined by the temperature sensitive of electric equipments inside technical shelter. The higher acceptable indoor temperature, the lower inner heating is needed to discharge to outside, which will cause lower air change rate.

\subsubsection{Energy performance of technical shelter}

In order to explore the energy performance of technical shelter, four typical cases are analysis in this section. The energy performance of technical shelter with two kinds of envelop insulation thickness $(25 \mathrm{~mm}$ and $85 \mathrm{~mm})$ and two grades of equipments heat dissipation ( $1.5 \mathrm{~kW}$ and $3 \mathrm{~kW})$ are simulated by BSim, where the indoor temperature set point is $30{ }^{\circ} \mathrm{C}$ and outdoor temperature is from climate data provided BSim. The results are shown in Figure. (It assumes that the cooling need is satisfied by ventilation cooling system, and no mechanical cooling system is taken into account in this section)

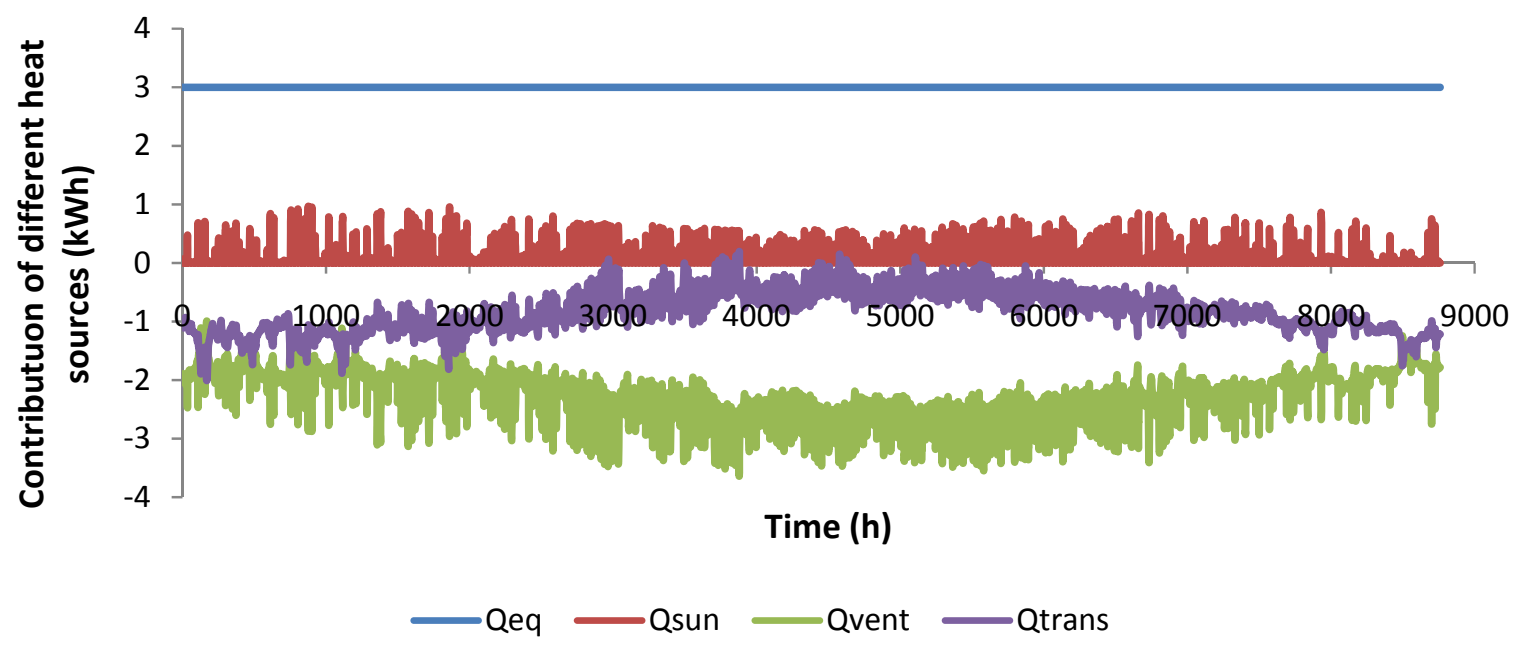

(a) 

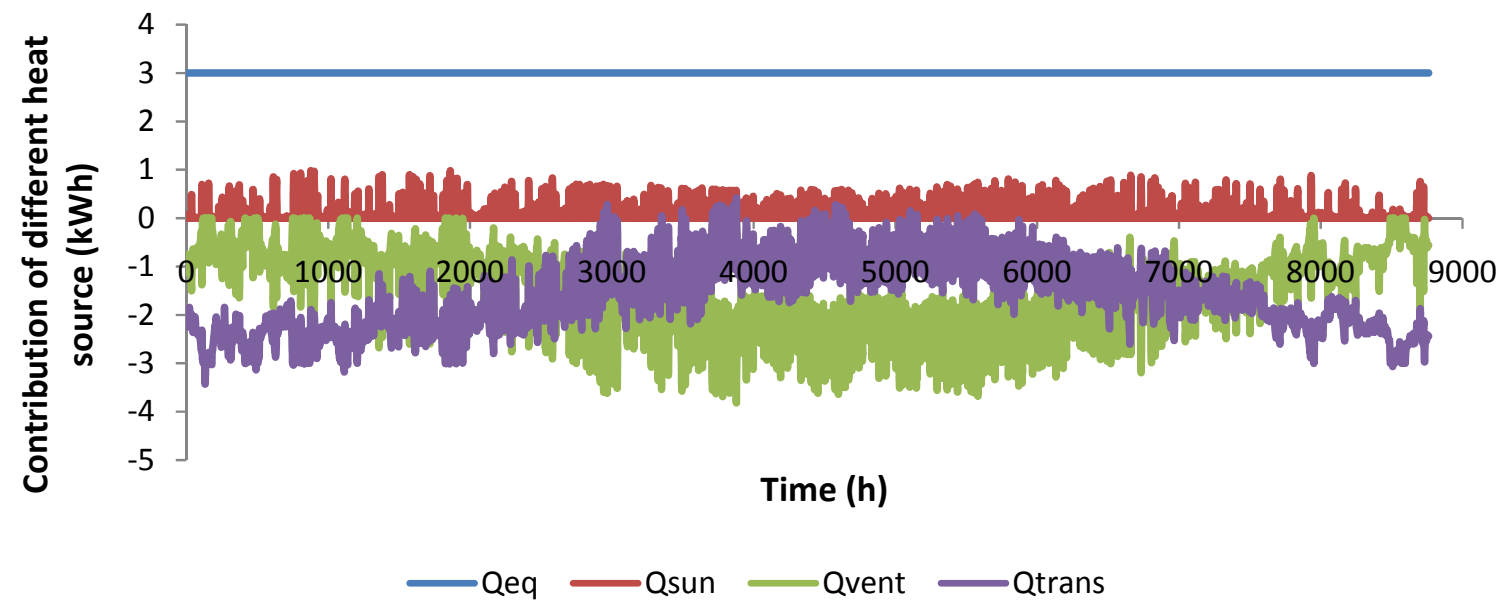

(b)
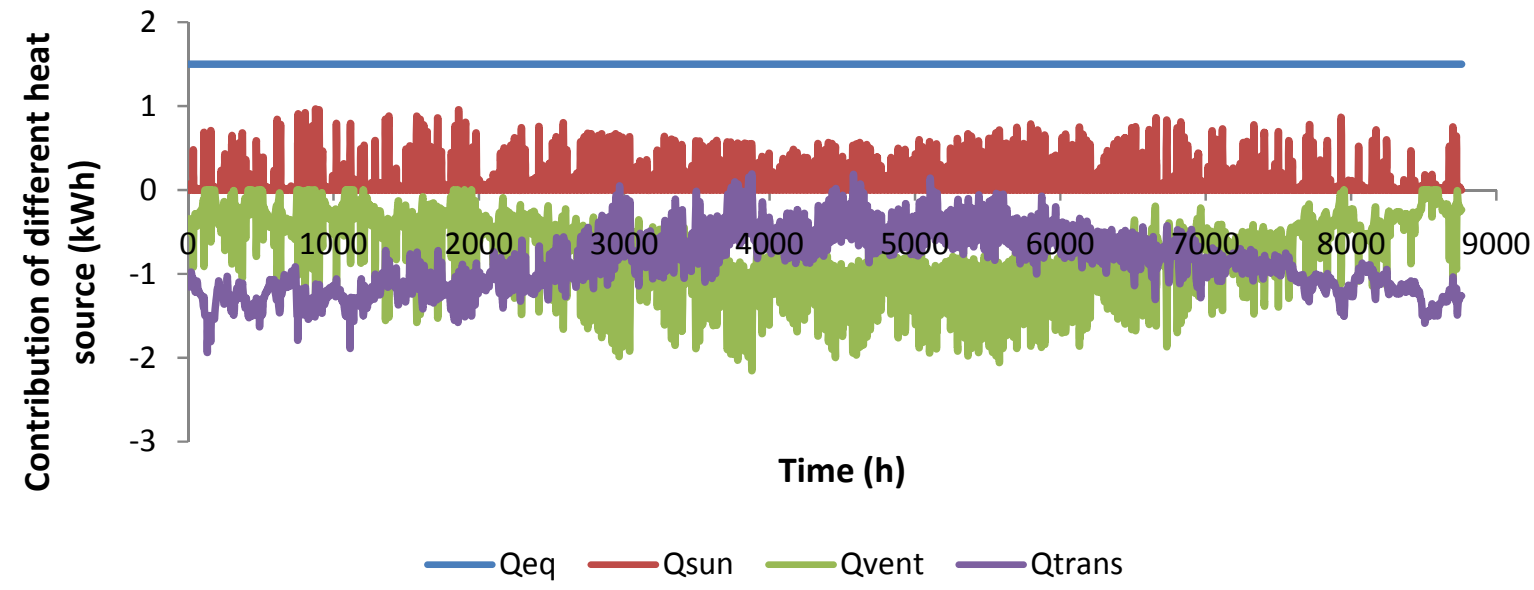

(c)

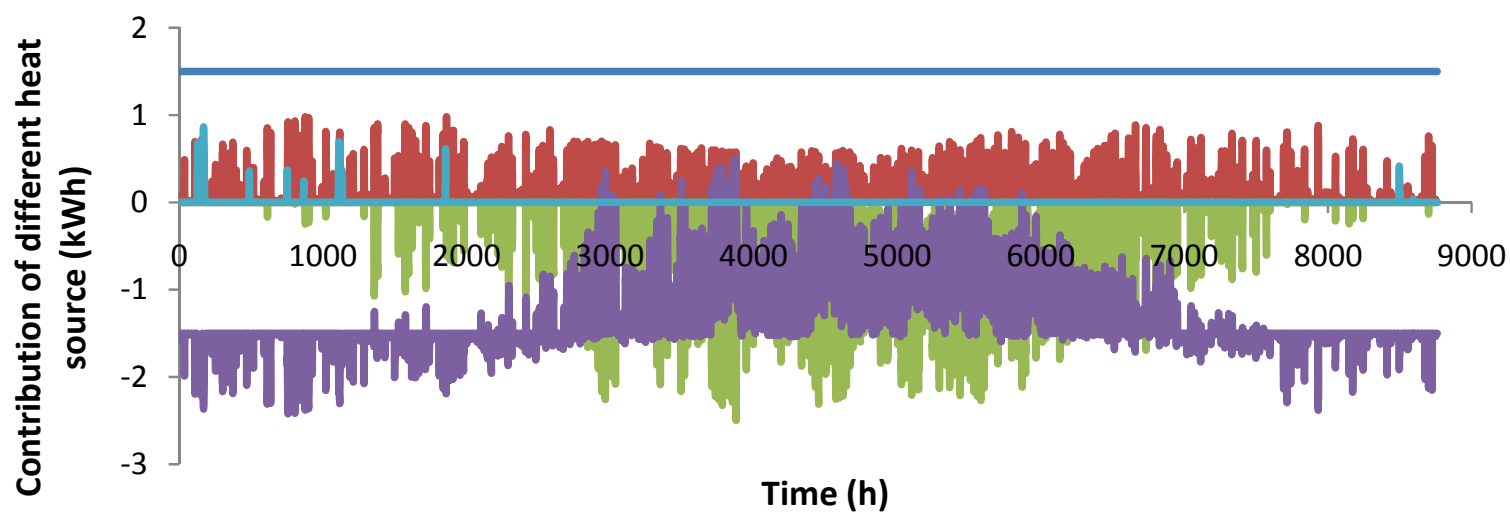

-Qeq —osun - Qvent - Qtrans - Qheating

(d)

Figure 4.3 Energy performance of technical shelter

(a) $85 \mathrm{~mm}, 3 \mathrm{~kW}, 30{ }^{\circ} \mathrm{C}$ (b) $25 \mathrm{~mm}, 3 \mathrm{~kW}, 30{ }^{\circ} \mathrm{C}$ (c) $85 \mathrm{~mm}, 1.5 \mathrm{~kW}, 30{ }^{\circ} \mathrm{C}$ (d) $25 \mathrm{~mm}, 1.5 \mathrm{~kW}, 30{ }^{\circ} \mathrm{C}$ 
Figure 4.3 (a) (b) demonstrates the energy perfromance of technical shelter in the whole year for 3 $\mathrm{kW}$ heat load condition. The electric equipments ran continuously with a total heat loss of $3 \mathrm{~kW}$, so the heat dissipation through electric equipments keeps constant value during the whole year. It's easy to find out that the envelop of technical shelter works in most of time together with the ventilation system to discharge the internal heat generated by the electric equipments and gains heat in only very short time. At the constant equipments heat dissipation condition, the lower outdoor air temperature, the more the heat removed by envelop and the lower cooling load of ventilation cooling system. In the winter, all cooling need can be satisfied by heat transmission through building envelop in some periods. Thus, enhancement of the heat transfer of the building envelopes could save energy by decreasing the cooling load and shortening runtime of the ventilation system.

As indicated in the Figure 4.3 (d), technical shelter with $25 \mathrm{~mm}$ insulation thickness envelops needs heating in winter, when the indoor equipments heat dissipation is $1.5 \mathrm{~kW}$. If the heat dissipation increases to $3 \mathrm{~kW}$, cooling is needed all year around. This means that in the low heat dissipation conditions, although decreasing insulation thickness of envelop will reduce cooling demand in most of time, which in return will increase the heating demand in winter. When equipments heat dissipation is high, heat dissipation is top priority and no heating is needed, where envelop with low insulation thickness will show better performance.

\subsubsection{Cooling strategies analysis}

As mentioned above, cooling demand is the top priority in the technical shelter in most of conditions. In order to obtain optimal control of indoor temperature and achieve the objective of energy saving, we need to explore the optimal solution for the cooling strategies.

Two typical cases are discussed below, where the heat loads are $1.5 \mathrm{~kW}$ and $3 \mathrm{~kW}$ for an indoor temperature set point of $30{ }^{\circ} \mathrm{C}$ and with $85 \mathrm{~mm}$ insulation thickness envelop. Some basic information in the analysis (pressure rise cross the fan and fan efficiency) are achieved by the measurement results. The annual cooling load at different ventilation rate conditions, overheating hours and energy consumption of cooling systems are analyzed in this section. 


\subsubsection{Effect of ventilation rate on annual cooling load}

The air change rate between the outdoor air and the indoor air of technical shelter is changing from $0 / \mathrm{h}$ to $100 / \mathrm{h}$ when applying ventilation cooling and the annual cooling load is simulated.

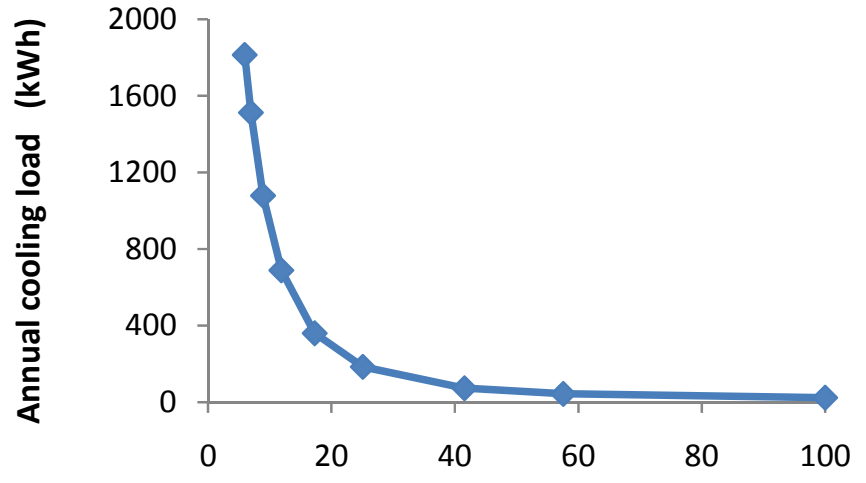

Air change rate $(/ \mathrm{h})$

(a)

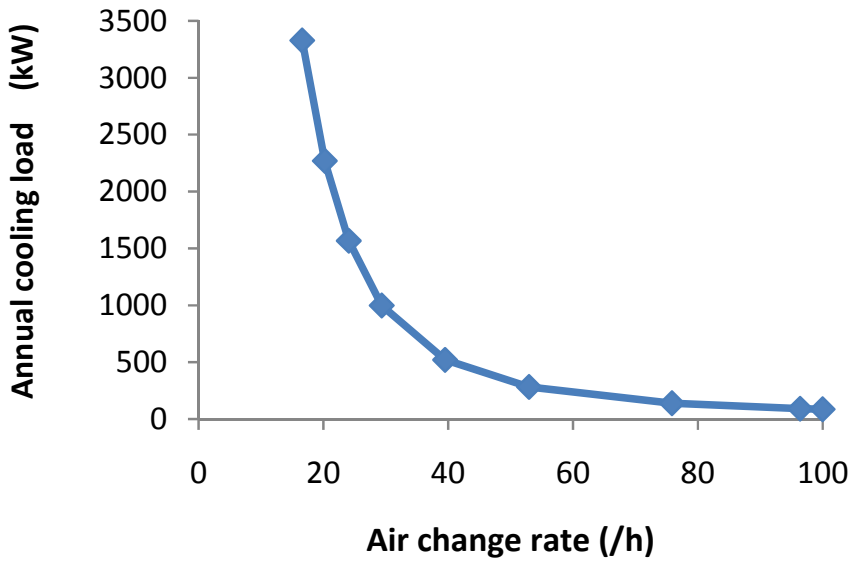

(b)

Figure 4.4 Effect of ventilation rate on annual cooling load

(a) $85 \mathrm{~mm}, 1.5 \mathrm{~kW}, 30{ }^{\circ} \mathrm{C}$ (b) $85 \mathrm{~mm}, 3 \mathrm{~kW}, 30{ }^{\circ} \mathrm{C}$

As indicated in Figure 4.4, the air change rate has a significant effect on annual cooling load. In $1.5 \mathrm{~kW}$ case, when the air change rate increases from $6 / \mathrm{h}$ to $25 / \mathrm{h}$, the annual cooling load by mechanical cooling system decreases from $1813 \mathrm{kWh}$ to $184 \mathrm{kWh}$ and the rate of decline is almost $90 \%$. As the air change rate continues to increase, the annual cooling load does not reduce significantly, which indicated that a reasonable ventilation rate for $1.5 \mathrm{~kW}$ case is around $25 / \mathrm{h}$. For $3 \mathrm{~kW}$, the annual cooling load declines significantly while the ventilation rate increases from $16 / \mathrm{h}$ to $50 / \mathrm{h}$. After that, even the ventilation rate increases twice to $100 / \mathrm{h}$, the annual cooling load only decreases near $10 \%$.

\subsubsection{Overheating hours at different air change rate}

The control of the indoor temperature is very important for obtaining high performance and operation reliability of electric equipments. Thus, we want to explore the indoor temperature performance at different ventilation rate. Overheating hour is chosen as a key parameter to analysis how much time the indoor temperature exceeds the set point temperature. 


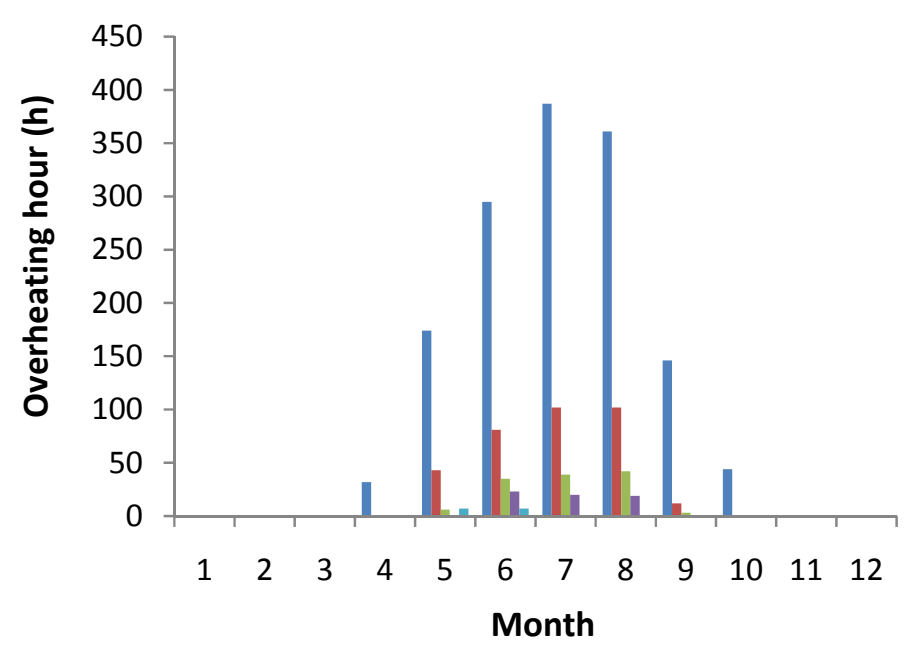

$\square 17.28 / \mathrm{h} \quad 25.07 / \mathrm{h} \quad 41.56 / \mathrm{h} \quad 57.56 / \mathrm{h} \quad 100 / \mathrm{h}$

(a)

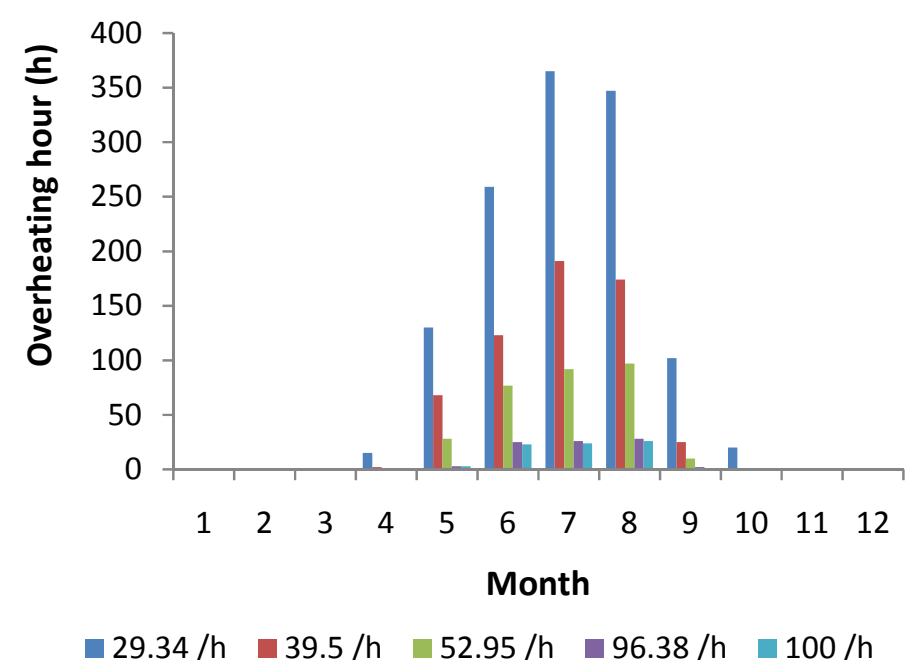

(c)

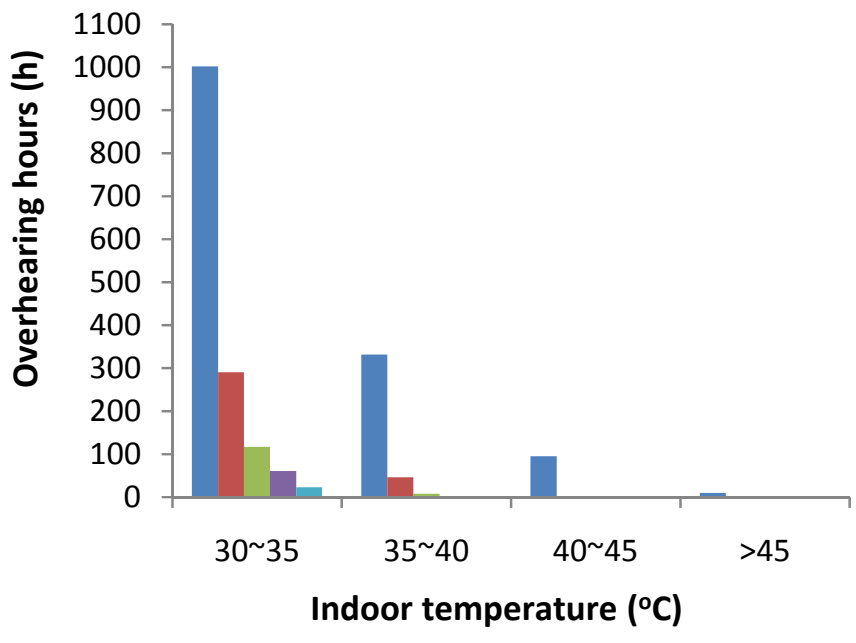

$\square 17.28 / \mathrm{h} \quad 25.07 / \mathrm{h} \quad 41.56 / \mathrm{h} \quad 57.56 / \mathrm{h} \quad 100 / \mathrm{h}$

(b)

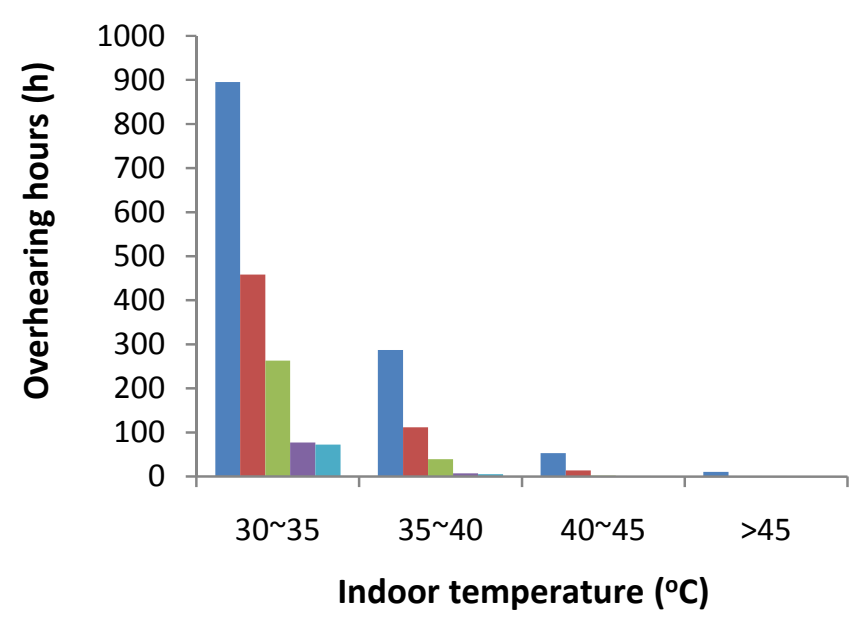

-29.34/h - $39.5 / \mathrm{h} \quad 52.95 / \mathrm{h} \quad 96.38 / \mathrm{h} \quad 100 / \mathrm{h}$

(d)

Figure 4.5 Overheating hours for different ventilation rate (a) Overheating hours per month, $85 \mathrm{~mm}, 1.5 \mathrm{~kW}$, $30{ }^{\circ} \mathrm{C} \quad$ (b) Overheating hours for different indoor temperature, $85 \mathrm{~mm}, 1.5 \mathrm{~kW}, 30{ }^{\circ} \mathrm{C}$ (c) Overheating hours per month, $85 \mathrm{~mm}, 3 \mathrm{~kW}, 30^{\circ} \mathrm{C} \quad$ (d) Overheating hours for different indoor temperature, $85 \mathrm{~mm}, 3$ $\mathrm{kW}, 30{ }^{\circ} \mathrm{C}$

As shown in Figure 4.5 (a) and (c), overheating mainly occurs during summer time from May to September and reaches a peak in July. This is due to ventilation cooling technology make full use of the nature outdoor cooling resources, which greatly depend on the outdoor air temperature and is easily influenced by the climate. Overheating hours exceed $1000 \mathrm{~h}$ when the ventilation rates are $17.28 / \mathrm{h}$ and $29.34 / \mathrm{h}$ in $1.5 \mathrm{~kW}$ and $3 \mathrm{~kW}$ cases, respectively. While increasing ventilation rate, overheating hours decrease significantly. And the overheating in the technical shelter can be 
ignored when the ventilation rates reach $57.56 / \mathrm{h}$ and $96.38 / \mathrm{h}$ in $1.5 \mathrm{~kW}$ case and $3 \mathrm{~kW}$ case, respectively.

Figure 4.5 (b) and (d) indicate the ranges of indoor temperature when it exceeds the set point and how many overheating hours for each temperature range. It's clear to find out that the indoor temperature is mainly in the range of $30 \sim 35{ }^{\circ} \mathrm{C}$, when the overheating occurs. The higher the ventilation rate, the lower indoor temperature will be. The indoor temperature above $45^{\circ} \mathrm{C}$ only last $3 \sim 10$ hours per year when the ventilation rate is $17.28 / \mathrm{h}$ and $29.34 / \mathrm{h}$ in $1.5 \mathrm{~kW}$ and $3 \mathrm{~kW}$ cases, respectively. And in other ventilation rate, indoor temperature is almost below $40{ }^{\circ} \mathrm{C}$. Thus it's very important to find out the temperature sensitive of electric equipments in the technical shelter. The ventilation rate can be greatly reduced if the equipments can still work in the overheating condition for several hours. The fan consume much less power in lower ventilation rate and thus significant energy saving are made. If the indoor temperature exceeds the permitted temperature of electric equipments for a long time, mechanical cooling system needs to work together with ventilation system to discharge the internal heat, especially in the summer time.

\subsubsection{Energy consumption of cooling system}

Energy consumption is an important factor to evaluate the cooling strategies. In our case, energy consumption of cooling system includes two parts: energy consumption of ventilation cooling system (which can be regarded as the energy consumption of fan), and the energy consumption of mechanical cooling system. The energy consumption for each part can be calculated by the equation below.

$$
Q_{\text {total }}=Q_{\text {fan }}+Q_{\text {mech }}
$$

Where:

$Q_{\text {total }} \quad$ is total energy consumption of cooling system, $\mathrm{kWh}$

$Q_{f a n} \quad$ is energy consumption of fan (ventilation cooling), $\mathrm{kWh}$

$Q_{\text {mech }} \quad$ is energy consumption of mechanical cooling, $\mathrm{kWh}$

$$
Q_{\text {fan }}=\frac{q \cdot \Delta P}{\eta} \cdot t
$$

Where:

$\eta \quad$ is fan efficiency,

$\Delta P_{f a n} \quad$ is pressure rise across the fan, $\mathrm{Pa}$

$q \quad$ is airflow rate, $\mathrm{m}^{3} / \mathrm{s}$

$t \quad$ is the running time of fan, $\mathrm{h}$

$$
Q_{m e c h}=\frac{Q}{C O P}
$$

Where: 
$Q \quad$ is annual cooling load, $\mathrm{kWh}$

$C O P$ is coefficient of performance of mechanical cooling system

The fan efficiency and pressure rise across the fan are obtained from measurement results, which can be seen from Section 3.3. COP is the ratio of cooling or heating to energy consumption, which is used generally as a measure of the energy-efficiency of cooling system. Higher the COP, higher the efficiency of the equipment will be. In our case, the COP value is assumed to be 3 .

Table 4.5 Annual energy consumption at different air change rate

(a) $85 \mathrm{~mm}, 1.5 \mathrm{~kW}, 30{ }^{\circ} \mathrm{C}$

\begin{tabular}{|r|r|r|r|}
\hline \multirow{2}{*}{$\begin{array}{c}\text { Air Change } \\
\text { Rate }(/ \mathrm{h})\end{array}$} & \multicolumn{3}{|c|}{ Annual energy consumption $(\mathrm{kWh})$} \\
\cline { 2 - 4 } & \multicolumn{1}{|c|}{ Fan } & Mech cooling & \multicolumn{1}{c|}{ Total } \\
\hline 5.94 & 113.88 & 604.33 & 718.21 \\
\hline 6.93 & 113.88 & 504.03 & 617.91 \\
\hline 8.91 & 113.88 & 359.4 & 473.28 \\
\hline 11.88 & 113.88 & 229.25 & 343.13 \\
\hline 17.28 & 116.71 & 119.82 & 236.53 \\
\hline 25.07 & 121.22 & 61.33 & 182.55 \\
\hline 31.56 & 127.02 & 24.13 & 151.15 \\
\hline 57.56 & 131.22 & 14.27 & 145.49 \\
\hline 100 & 144.51 & 7.71 & 152.22 \\
\hline
\end{tabular}

(b) $85 \mathrm{~mm}, 3 \mathrm{~kW}, 30^{\circ} \mathrm{C}$

\begin{tabular}{|r|r|r|r|}
\hline \multirow{2}{*}{$\begin{array}{c}\text { Air Change } \\
\text { Rate }(/ \mathrm{h})\end{array}$} & \multicolumn{3}{|c|}{ Annual energy consumption $(\mathrm{kWh})$} \\
\cline { 2 - 4 } & \multicolumn{1}{|c|}{ Fan } & Mech cooling & \multicolumn{1}{c|}{ Total } \\
\hline 16.6 & 125.42 & 1109.43 & 1234.84 \\
\hline 20.22 & 138.98 & 756.43 & 895.41 \\
\hline 24.06 & 150.2 & 522.31 & 672.51 \\
\hline 29.34 & 162.1 & 332.79 & 494.89 \\
\hline 39.5 & 178.16 & 173.44 & 351.6 \\
\hline 52.95 & 194.29 & 94.27 & 288.56 \\
\hline 75.85 & 219.34 & 46.53 & 265.87 \\
\hline 96.38 & 246.8 & 30.47 & 277.27 \\
\hline 100 & 253.06 & 28.8 & 281.86 \\
\hline
\end{tabular}




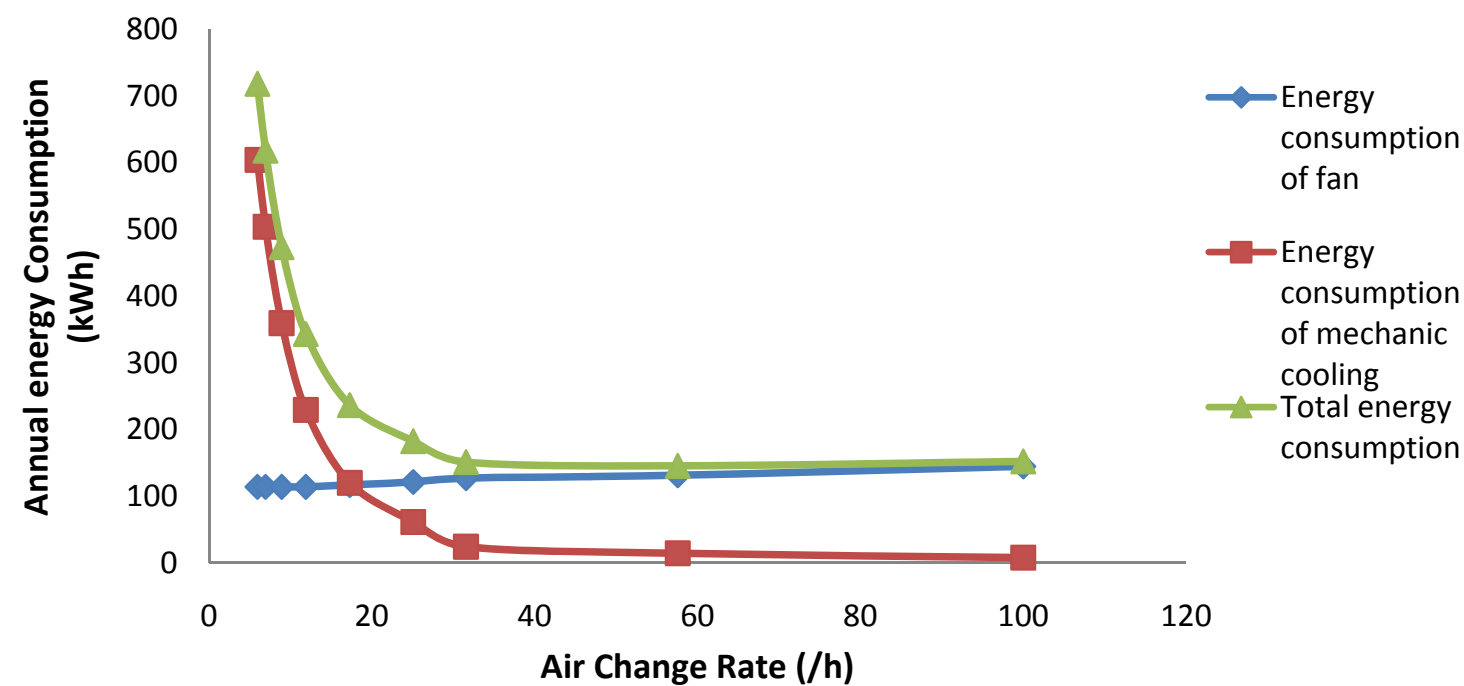

(a)

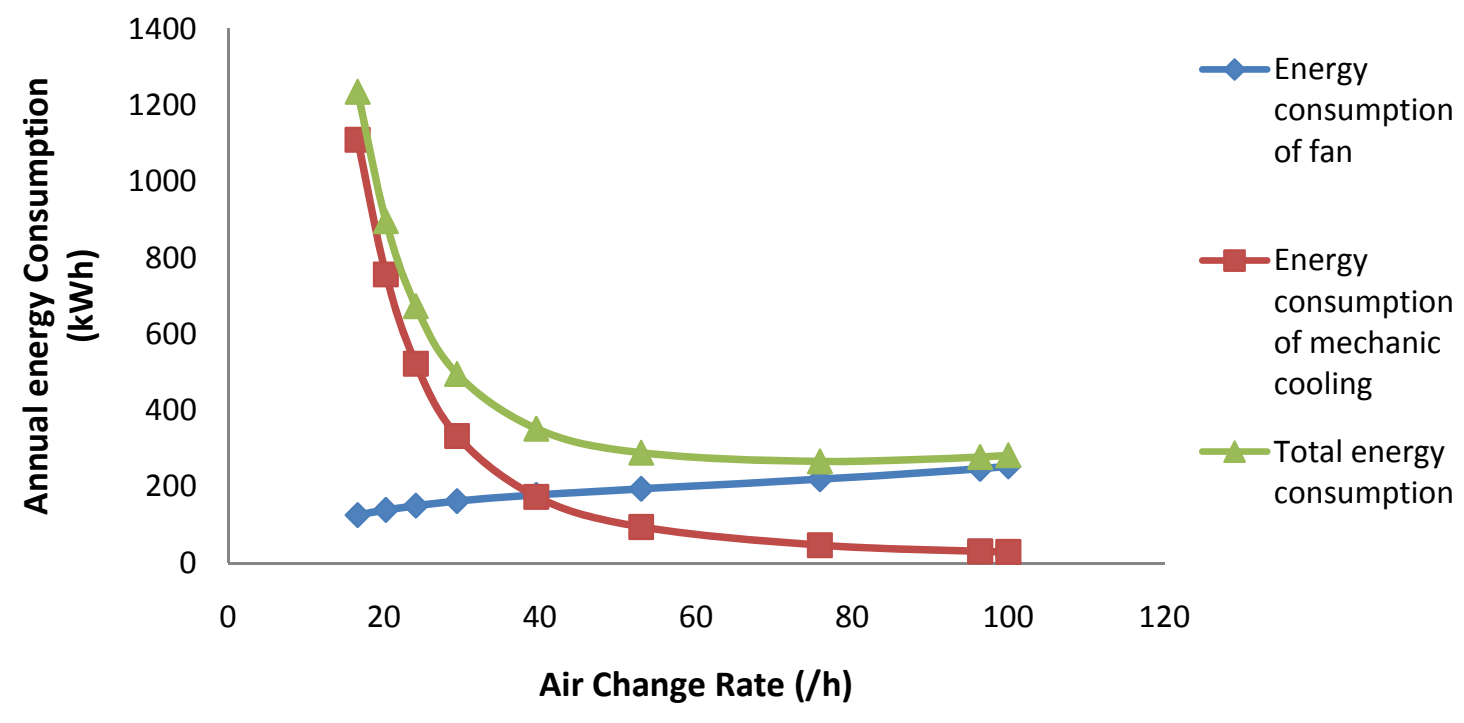

(b)

Figure 4.6 Effect of ventilation rate on annual energy consumption
(a) $85 \mathrm{~mm}, 1.5 \mathrm{~kW}, 30{ }^{\circ} \mathrm{C}$ (b) $85 \mathrm{~mm}, 3 \mathrm{~kW}, 30{ }^{\circ} \mathrm{C}$

As shown in Figure 4.6, each energy consumption curve is a function of air change rate. The energy consumption of fan slightly increases while increasing air change rate. It's easy to find out that the curve of mechanical cooling energy consumption has the similar shape with the curve of annual cooling load (shown in Figure 4.4). This is due to the energy consumption of mechanical cooling is a linear function of annual cooling load. And the total energy consumption curve is a combination of those two curves. The total energy consumptions decrease significantly, when the air change rate increase from $0 / \mathrm{h}$ to $30 / \mathrm{h}$ and $50 / \mathrm{h}$ in $1.5 \mathrm{~kW}$ and $3 \mathrm{~kW}$ cases, respectively. As 
the air change rate continues to increase to $100 / \mathrm{h}$, the total energy consumptions keep almost constant value.

In addition, it's important to notice that when the air change rate reaches $100 / \mathrm{h}$, all cooling demands are satisfied by ventilation cooling system. Although using the same amount of energy, when the air change rate is $30 / \mathrm{h}$ and $50 / \mathrm{h}$ in $1.5 \mathrm{~kW}$ and $3 \mathrm{~kW}$ cases, respectively, the heat in the technical shelter need to dissipate by the combination of ventilation cooling and mechanical cooling systems. So the cooling strategies also depend on the economic factor, additional cost of mechanical cooling system and cost of fan need to be taken into account. However, the costeffectiveness analysis will not discuss in our study.

\section{References}

[1] BSim user's guide

[2] "BSim - Building Simulation", [Online]. Available: http://www.en.sbi.dk/en/publications/ programs_models/bsim/bsim-building-simulation. [Accessed: May 15, 2011] 


\section{Chapter 5 Photovoltaic System Design}

\subsection{Introduction}

Powering technical shelter is particularly challenging in remote areas where the grids are either not available or the expansion of grid will be expensive. Often these technical shelters are powered by diesel generators; continuing a reliance on fossil fuels and adding to greenhouse gas emissions. Thus, more and more attentions have been paid on the renewable energy power solution. Solar energy is a clean, inexhaustible and environment-friendly potential resource among renewable energy options. Recent research and development of solar energy has shown excellent potential as a form of contribution to conventional power generation systems.

Photovoltaic system is planned to build in our project to achieve net-zero energy target. PV modules will design to build on the roof for powering cooling systems which used to maintain a safe operating temperature for electric equipments inside. In order to explore the technical shelter used in different situations, both off-grid and on-grid PV systems are designed based on PVSYST software. Annual energy produced by proposed PV systems are also calculated. In the last, cost estimation will be made on both off-grid and on-grid PV systems to evaluate whether they are economically viable or not.

\subsubsection{PVSYST (Version 5.4)}

PVSYST is a time-step simulation program, developed at the University of Geneva, Switzerland, is able to simulate both grid-coupled and off-grid systems (energy flow, shadowing and economic viability). It provides dimensioning proposals for stand-alone installations (PV generator and battery size), and warns the user if the chosen component combinations are not technically feasible. The dimensioning proposals are calculated on the basis of load inputs, specification of the number of days for autonomous operation and an estimation of the so-called 'loss-of-load probability', i.e. the duration for which the load cannot be served by the PV and battery energy.

As there are no inverter models for off-grid system simulation, it is only possible to model DC systems. The additional generator serves only to charge the batteries. The loads can be specified in various ways: individual inputs, load profile creation, probabilities of particular power values, data import and differentiation of individual periods. Comprehensive component databases are provided, permitting new components to be entered by way of typical technical data. The output options for the calculation results are similarly extensive and offer a wide range of presentation forms (e.g. characteristic curves of specific parameters, scatter plots, histograms, printed reports) [1]. 


\subsection{Model of PV systems}

\subsubsection{Geographical site and solar Meteo}

The geographical site provides the information of latitude, longitude, altitude (which uniquely define the $(\mathrm{x}, \mathrm{y}, \mathrm{z})$ coordinates of a given point of the earth), and the time zone.

Table 5.1 Geographical site information of the model

\begin{tabular}{l|l}
\hline Country & Denmark \\
City & Copenhagen \\
Latitude & $55^{\circ} 23^{\prime} \mathrm{N}$ \\
Longitude & $12^{\circ} 21^{\prime} \mathrm{E}$ \\
Altitude & $5 \mathrm{~m}$ \\
Time zone & $+1 \mathrm{hr}$ MGT \\
\hline
\end{tabular}

The Meteo file includes a complete geographical site object, followed by hourly values of the meteo parameter, that is horizontal global and diffuse irradiations, ambient temperature, and, if available, wind velocity. Table 5.2 shows the meteo file of selected location.

Table 5.2 Meteo parameters for Copenhagen

\begin{tabular}{|l|r|r|r|r|}
\hline \multirow{2}{*}{ Month } & Global Irrad & \multicolumn{1}{c|}{ Diffuse } & \multicolumn{1}{c|}{ Temper } & Wind Vel. \\
\cline { 2 - 5 } & \multicolumn{2}{|c|}{$\mathrm{kWh} / \mathrm{m}^{2} \mathrm{mth}$} & \multicolumn{1}{c|}{${ }^{\circ} \mathrm{C}$} & \multicolumn{1}{c|}{$\mathrm{m} / \mathrm{s}$} \\
\hline Jan & 16.0 & 11.0 & 2.3 & 7.2 \\
\hline Feb & 32.0 & 21.0 & 1.0 & 6.3 \\
\hline Mar & 63.0 & 40.0 & 2.5 & 6.6 \\
\hline Apr & 115.0 & 60.0 & 5.1 & 6.3 \\
\hline May & 156.0 & 79.0 & 10.4 & 5.8 \\
\hline Jun & 154.0 & 83.0 & 13.3 & 5.7 \\
\hline Jul & 165.0 & 82.0 & 15.2 & 5.7 \\
\hline Aug & 132.0 & 68.0 & 15.9 & 5.1 \\
\hline Sep & 80.0 & 47.0 & 13.8 & 5.8 \\
\hline Oct & 44.0 & 28.0 & 10.5 & 5.8 \\
\hline Nov & 20.0 & 14.0 & 6.5 & 6.3 \\
\hline Dec & 11.0 & 8.0 & 4.0 & 6.3 \\
\hline
\end{tabular}

\subsubsection{Orientation of solar panels}

In order to generate the most power from PV system, the PV panel should be arrayed in the optimal direction that captures the most sun. As shown in Figure 5.1, the PV array may either be fixed, sun-tracking with one axis of rotation, or sun-tracking with two axes of rotation. In our project, we assume that the panels are fixed. 


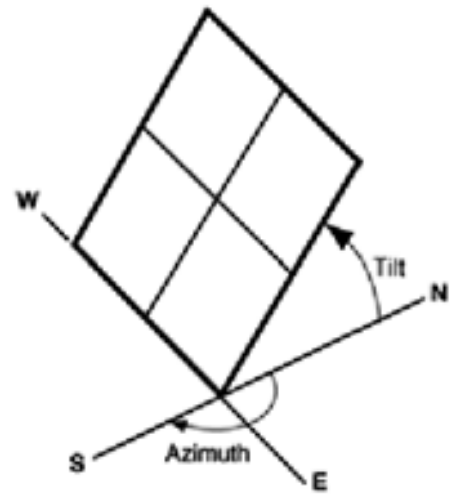

(a)

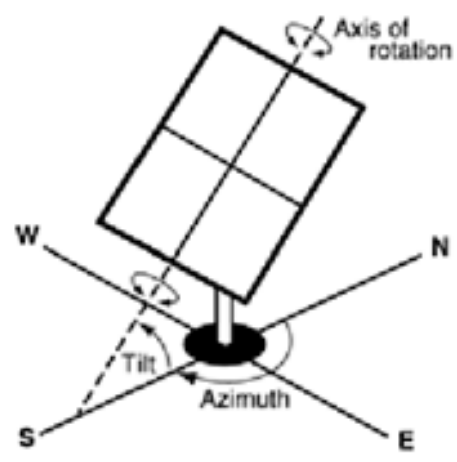

(b)

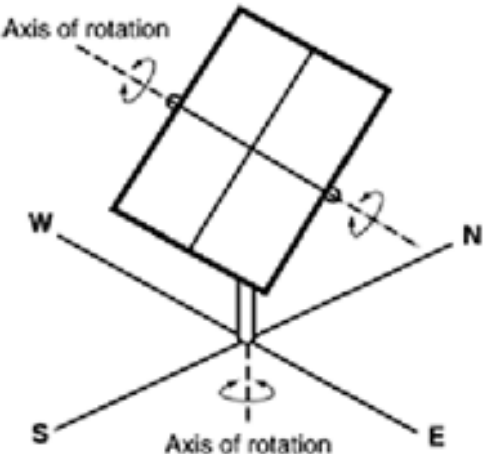

(c)

Figure 5.1 PV array ways (a) Fixed (b) Sun-tracking with one axis of rotation (c) Sun-tracking with two axes of rotation [2]

For a fixed PV array, the tilt angle is the angle from horizontal of the inclination of the PV array $\left(0^{\circ}\right.$ $=$ horizontal, $90^{\circ}=$ vertical). The default value is a tilt angle equal to the station's latitude. This normally maximizes annual energy production. Increasing the tilt angle favors energy production in the winter, while decreasing the tilt angle favors energy production in the summer.

For a fixed PV array, the azimuth angle is the angle clockwise from true north of the direction that the PV array faces. The default value is an azimuth angle of $0^{\circ}$ (south-facing) for locations in the northern hemisphere. This normally maximizes energy production. For the northern hemisphere, increasing the azimuth angle favors afternoon energy production, while decreasing the azimuth angle favors morning energy production. The opposite is true for the southern hemisphere.

Table 5.3 Optimal monthly and annual tilt angle, azimuth angle

\begin{tabular}{|l|r|r|r|r|r|r|r|r|r|r|r|r|r|}
\hline Month & Jan & Feb & Mar & Apr & May & Jun & Jul & Aug & Sep & Oct & Nov & Dec & Year \\
\hline Tilt $\left(^{\circ}\right)$ & 71 & 64 & 50 & 38 & 25 & 17 & 21 & 32 & 47 & 60 & 70 & 73 & 35 \\
\hline Azimuth $\left({ }^{\circ}\right)$ & 0 & 0 & 0 & 0 & 0 & 0 & 0 & 0 & 0 & 0 & 0 & 0 & 0 \\
\hline
\end{tabular}

Table 5.3 shows the optimal tilt angle and azimuth angle for each month. In the design procedure, we take the yearly average value: tilt angle is $35^{\circ}$ and azimuth angle is $0^{\circ}$. As indicated in Figure 5.2, the transposition factor equals to 1.13 at the optimal plane orientation, where the transposition factor is the ratio of incident global irradiation in the plane to the horizontal global irradiation. 

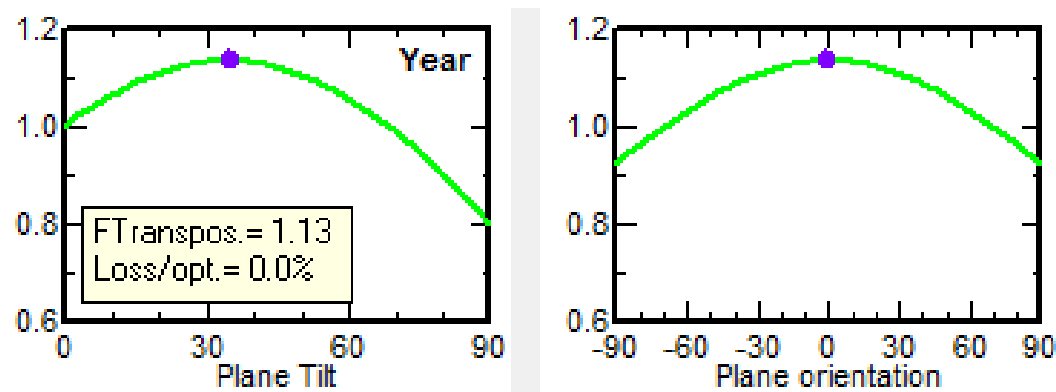

Figure 5.2 Transposition factor at the optimal plane orientation

\subsubsection{Horizon and near shadings}

The horizon is describing far shadings effects. This is the simplest way for defining shadings, but it's use should be limited to obstacles distant of twenty times the PV-array size. Horizon acts on the PV field in a global way: at a given instant, the sun is or is not visible on the field.

Near shadings are partial shadings which affect only a part of the field. The shaded part changes during the day and over the seasons. Near shadings management require a 3-D construction of the field and its environment, and is much more complex to deal with [3].

In our project, we assumed that no shading effect is available. Thus, these two steps can be skipped in our simulation.

\subsubsection{System}

The system definitions are primary aimed to define all the PV system components necessary to fulfill the user's wishes. System definitions are of course different according to system types: offgrid systems, on-grid system. The mainly difference of these two type systems is that in the standalone system the user's power loads definition are absolutely necessary, which closely affect the system design. For grid-connected systems, usually no load is specified and no array size is suggested. However, the user loads can be defined afterwards in order to obtain the user selfconsumed energy part and the energy reinjected into the grid.

\subsubsection{Off-grid system}

As shown in Figure 5.3, the off-grid model represents stand-alone systems with a battery backup, with or without an additional generator backup. The power generated by PV array is either used directly by the user, or goes through the battery and then discharge to the user load. 


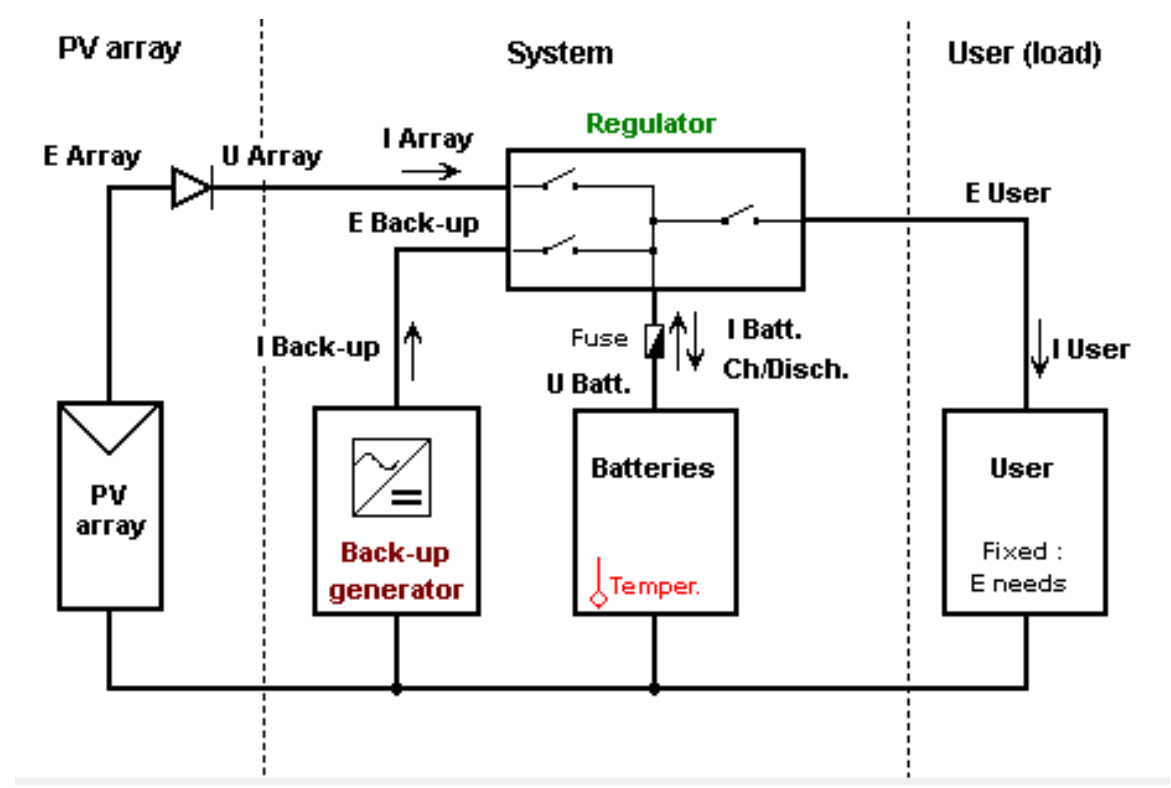

Figure 5.3 Off-grid PV system

\section{User loads}

In our project, we aim to design a PV system to power a technical shelter with $3 \mathrm{~kW}$ heat load, 85 $\mathrm{mm}$ insulation thickness, at $30{ }^{\circ} \mathrm{C}$ indoor temperature set point. Table shows the monthly user loads based on BSim simulation results (as describe in Chapter 5).

Table 5.4 User loads in $3 \mathrm{~kW}, 85 \mathrm{~mm}, 30{ }^{\circ} \mathrm{C}$ case

\begin{tabular}{|l|c|c|c|c|c|c|c|c|c|c|c|c|c|}
\hline Month & Jan & Feb & Mar & Apr & May & Jun & Jul & Aug & Sep & Oct & Nov & Dec & Year \\
\hline Q $_{\text {load }}(\mathrm{kWh})$ & 9.69 & 8.83 & 10.1 & 11.67 & 22.86 & 44.27 & 50.96 & 53.3 & 20.41 & 14.22 & 10.16 & 9.8 & 265.9 \\
\hline
\end{tabular}

\section{Array and battery pre-sizing}

During the sizing process, the Loss-of-Load ( LOL) requirement allows for determining the PV array size needed, for a given battery capacity. The LOL is the probability that the user's loads cannot be supplied. The LOL is calculated using a simplified and fast yearly simulation: the program splits the monthly meteo values into a realistic random sequence of 365 days, each day being divided into 3 periods: morning - day (with solar gains) - and evening. Then it performs a day-by-day balance, and reports the daily system state, in order to accumulate a realistic "LOL" yearly value. This process is repeated with different PV-array sizes, in order to find the exact PV size matching the required "LOL" [3].

In the pre-sizing process, the proposed battery pack capacity is determined according to the required autonomy of the system, given in days. The autonomy is defined as the time during which the load can be met with the battery alone, without any solar inputs, starting from a "full charged" battery state. With non-constant loads (seasonal or monthly definition, weekly use), this is accounted as the worst case over the year. 
In an off-grid PV system with direct coupling to the user, the battery voltage determines the distribution voltage. So battery voltage is also an important parameter which needs user definition. The battery voltage choice should be made according to system and appliance power, as well as the extension of the planned distribution grid to minimize the ohmic wiring losses. The choice should according to the following criteria:

Table 5.5 Criteria for choosing battery voltage

\begin{tabular}{|l|c|c|c|}
\hline Voltage (V) & 12 & 24 & 48 \\
\hline Size & Little & Medium & Special industrial \\
\hline Appliance max power $(\mathrm{W})$ & $<300$ & $<1000$ & $<3000$ \\
\hline Corresponding current $(\mathrm{A})$ & 25 & 42 & 62 \\
\hline Inverter $(\mathrm{kW})$ & $<1$ & $<5$ & $<15$ \\
\hline
\end{tabular}

After user defined the input parameter, the program will then perform a system sizing process to determine the size of the optimal PV array power and battery pack capacity required to match the user's needs. Table 5.6 indicates the input parameters and the suggested size of battery and PV power in our case.

Table 5.6 Input and output parameters in the pre-sizing process

\begin{tabular}{l|l}
\multicolumn{1}{c|}{ Input parameter } & \multicolumn{1}{c}{ Output parameter } \\
\hline $\begin{array}{l}\text { Av. daily user needs }=0.7 \mathrm{kWh} / \text { day } \\
\mathrm{LOL}=5 \%\end{array}$ & Suggested battery capacity $=328 \mathrm{Ah}$ \\
Autonomy $=4$ days & Suggested PV power $=389 \mathrm{Wp}$ (nom.) \\
Battery voltage $=24 \mathrm{~V}$ & \\
\hline
\end{tabular}

\section{Define the system components}

User should choose the battery model and PV module from the database, according to the suggested battery capacity and suggested PV power. The program determines the number of units in series and parallel automatically, according to the battery voltage. It's important to notice that PVSYST cannot support mixing module types in a single system. Table 5.7 and 5.8 demonstrate the PV module and battery module parameters.

Table 5.7 PV module parameters

\begin{tabular}{l|l}
\hline Type & Si-mono \\
Model & SM100-12 \\
Manufacturer & Shell Solar \\
Number of PV modules & $4(2$ in parallel * 2 in series $)$ \\
Unit Nom. Power & $100 \mathrm{Wp}$ \\
Array global power & Normal (STC) $400 \mathrm{Wp}$ \\
Total area & At operating cond. $\left(50^{\circ} \mathrm{C}\right) 354 \mathrm{Wp}$ \\
\hline
\end{tabular}


Table 5.8 Battery module parameters

\begin{tabular}{l|l}
\hline Model & MK 8A4D AGM \\
Manufacturer & MK Battery \\
Voltage & $24 \mathrm{~V}$ \\
Normal Capacity & $332 \mathrm{Ah}$ \\
Number of units & $4(2$ in parrel $* 2$ in series $)$ \\
Temperature & Fixed $\left(20^{\circ} \mathrm{C}\right)$ \\
\hline
\end{tabular}

After that, the program asks for defining the regular. It's recommended to use the "Generic Default regulator", which ensures a standard behavior of the system, regardless of regulator constraints. Table 5.9 shows the parameters of default regulator.

Table 5.9 Regular parameters

\begin{tabular}{l|ll}
\hline Temp coeff. & $5.0 \mathrm{mV} /{ }^{\circ} \mathrm{C} / \mathrm{elem}$. & \\
Battery Management Thresholds & Charging 27.4/26.2 V Discharging 23.5/25.2 V \\
Back-up Genset Command & $23.6 / 25.8 \mathrm{~V}$ & \\
\hline
\end{tabular}

\section{PV-array specific loss parameters}

In PV system, array losses parameters need to be defined in the design process. In PVSYST, array loss includes five types: thermal losses, ohmic wiring losses, module quality losses, mismatch losses and incidence angle (IAM) losses.

\section{- Array thermal losses}

The thermal behavior of the field which strongly influences the electrical performances is determined by an energy balance between ambient temperature and cell's heating up due to incident irradiance:

$$
U \cdot\left(T_{c e l l}-T_{a m b}\right)=\alpha \cdot G_{i n c} \cdot(1-\eta)
$$

Where:

$\alpha \quad$ is the absorption coefficient of solar irradiation, $\alpha=0.9$ in usual

$\eta \quad$ is the PV efficiency

The thermal behavior is characterized by a thermal loss factor designed here by U-value, which can be split into a constant component $U_{c}$ and a factor proportional to the wind velocity $U v$ :

$$
U=U_{C}+U_{V} \cdot v
$$

Where: 
$U c \quad$ is constant component, $U c=20 \mathrm{~W} / \mathrm{m}^{2} \cdot \mathrm{K}$

$U v \quad$ is factor affected by wind, $U v=0 \mathrm{~W} / \mathrm{m}^{2} . \mathrm{K} / \mathrm{m} / \mathrm{s}$

$v \quad$ is wind velocity, $\mathrm{m} / \mathrm{s}$

\section{- Ohmic wiring losses}

The wiring ohmic resistance induces losses $\left(\mathrm{R} \cdot \mathrm{I}^{2}\right)$ between the power available from the modules and that at the terminals of the array. These losses can be characterized by just one parameter $\mathrm{R}$ defined for the global array. The program proposes a default global wiring loss fraction of $3 \%$ by respect to the STC running conditions.

\section{- Module quality losses and mismatch losses}

It is well-known that most of PV modules series don't match the manufacturer nominal specifications. Up to now, this was one of the greater uncertainties in the PV system performance evaluation. PVSYST allows for accounting for this discrepancy by defining a loss factor, which is an energy loss at MPP, constant during the simulation process. For fixed voltage operation (battery, DC grid), the loss factor is supposed to be the same. The module efficiency loss is assumed to be $2.5 \%$ in our simulation.

Losses due to "mismatch" are related to the fact that the real modules in the array do not rigorously present the same I/V characteristics. The simulation asks for a Mismatch Loss Factor (different for MPP or fixed-voltage operation), which is taken as constant during the simulation. The power loss at MPP is $2.0 \%$ and the loss when running at fixed voltage is $4.0 \%$ in our simulation.

\section{- Incidence angle (IAM) losses}

The incidence effect corresponds to the weakening of the irradiation really reaching the PV cells's surface, with respect to irradiation under normal incidence. In principle, this loss obeys Fresnel's Laws concerning transmission and reflections on the protective layer (the glass), and on the cell's surface. In practice, it is often approached using a parameterization called "ASHRAE", depending on one only parameter $b_{o}$ :

$$
F_{I A M}=1-b_{o} \cdot\left(\frac{1}{\cos i}-1\right)
$$

Where:

$i \quad$ is incidence angle on the plane, ${ }^{\circ}$

For single-glazed thermal solar modules, the usually accepted value for $b_{o}$ is of the order of 0.1 . But in a PV module, the lower interface, in contact with the cell, presents a high refraction index and our specific measurements on real crystalline modules actually indicate a value of $b_{o}=0.05$. 


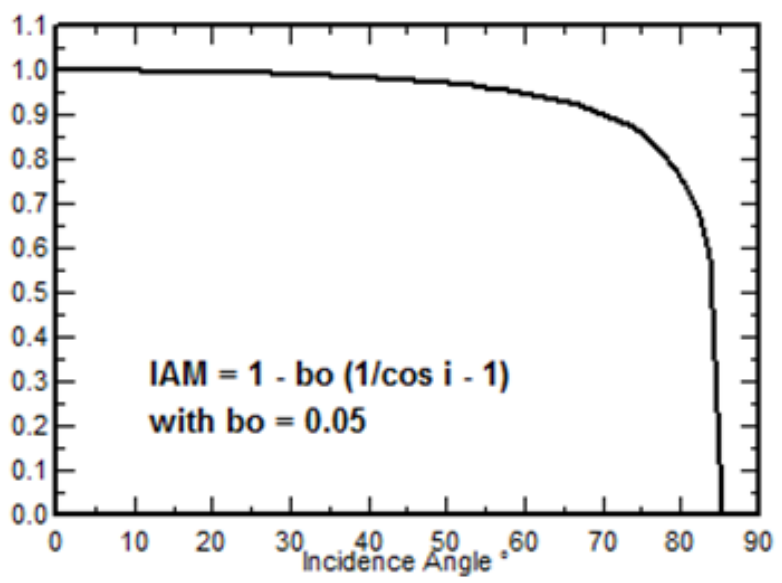

Figure 5.4 Incidence angle modifier

\subsubsection{On-grid system}

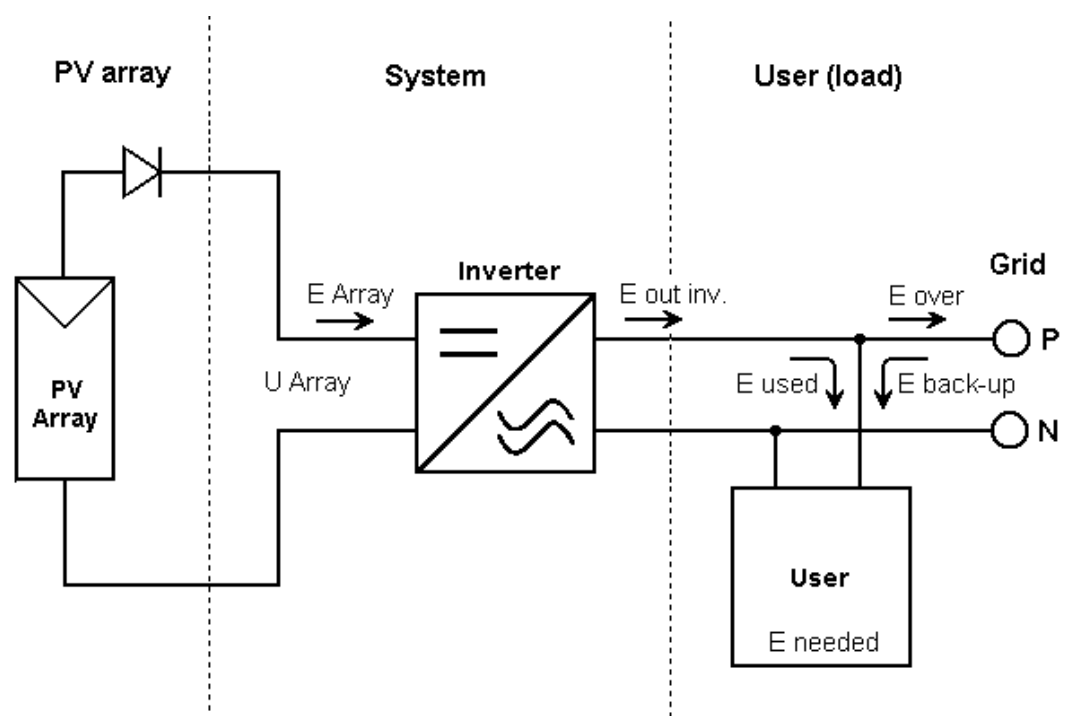

Figure 5.5 On-grid PV system

Different from off-grid PV system, the size of on-grid PV system doesn't depend on the user's load, where user needs to input the desired nominal power, or alternatively the available area for installing PV modules. In our case, we choose the same PV modules as in the off-grid PV system. And no battery module is needed in on-grid system.

In the on-grid PV system, inverter module needs to be chosen from database. All the strings of PV modules connected to the input of an inverter should be homogeneous: identical modules, same number of modules in series, same orientation. Except these differences, the on-grid PV system has the same design process as off-grid PV system. 
Table 5.10 PV module parameters

\begin{tabular}{l|l}
\hline Type & Si-mono \\
Model & SM100-12 \\
Manufacturer & Shell Solar \\
Number of PV modules & $4(4$ in parallel $* 1$ in series $)$ \\
Unit Nom. Power & $100 \mathrm{Wp}$ \\
Array global power & Normal (STC) $400 \mathrm{Wp}$ \\
Total area & At opetating cond. $\left(50^{\circ} \mathrm{C}\right) 354 \mathrm{Wp}$ \\
\hline
\end{tabular}

Table 5.11 Inverter module parameters

\begin{tabular}{l|l}
\hline Module & OK5E-LV \\
Manufacturer & NKF Electronics \\
Operating Voltage & $14-25 \mathrm{~V}$ \\
Unit Nom. Power & $0.2 \mathrm{~kW} \mathrm{AC}$ \\
Number of Inverter & 2 \\
Total Power & $0.4 \mathrm{~kW} \mathrm{AC}$ \\
\hline
\end{tabular}

\subsection{Simulation results}

\subsubsection{Off-grid system}

Table 5.6 shows the annual balances and main results of off-grid PV system. The available energy by PV system is $325 \mathrm{kWh} /$ year and the specific production is $813 \mathrm{kWh} / \mathrm{kWp} /$ year (PV modules nominal power is $400 \mathrm{Wp}$ ). The energy supplied to the user $(249 \mathrm{kWh} /$ year) satisfies the user load (271.5 kWh/year) in most of the times, only except in July and August. The amount of power load cannot by satisfied by PV system is $23 \mathrm{kWh} / y e a r$, which is expressed by "missing energy". This corresponds to the factor of solar fraction (SF), which is the amount of energy provided by the PV system divided by the total energy required. As indicated in Figure 5.6 (b), SF equals to 0.858 and 0.718 in July and August, respectively. In other months, SF are 1.0 for all user loads provided by PV system.

The performance ratio (PR) is the ratio between actual yield (annual system production) and the target yield (Reference Incident Energy in collector plane). The performance ratio, often called "Quality Factor", is independent from the irradiation and therefore useful to evaluate PV system. It takes into account all pre-conversion losses, inverter losses, thermal losses and conduction losses. As shown in Figure 5.6 (b), monthly PR values are more variable during the year, the minimum PR occurs in April and reaches a peak in January. The annual average PR value is 0.541 in our case.

Figure 5.6 (a) demonstrates the monthly normalized production and its balances. The off-grid PV system has higher power production in summer than in winter, which is mainly proportional to the available solar irradiation resource. The unused energy due to full battery reaches a peak in April and May, accounted for almost $25 \%$ of total energy production, while this value can be ignored or 
only occupies a little part in the other months. The PV array losses take a large proportion of the total energy production during the whole year while the system losses and battery charging are more variable for each month. The off-grid PV system loss detail can be seen in Figure 5.7.

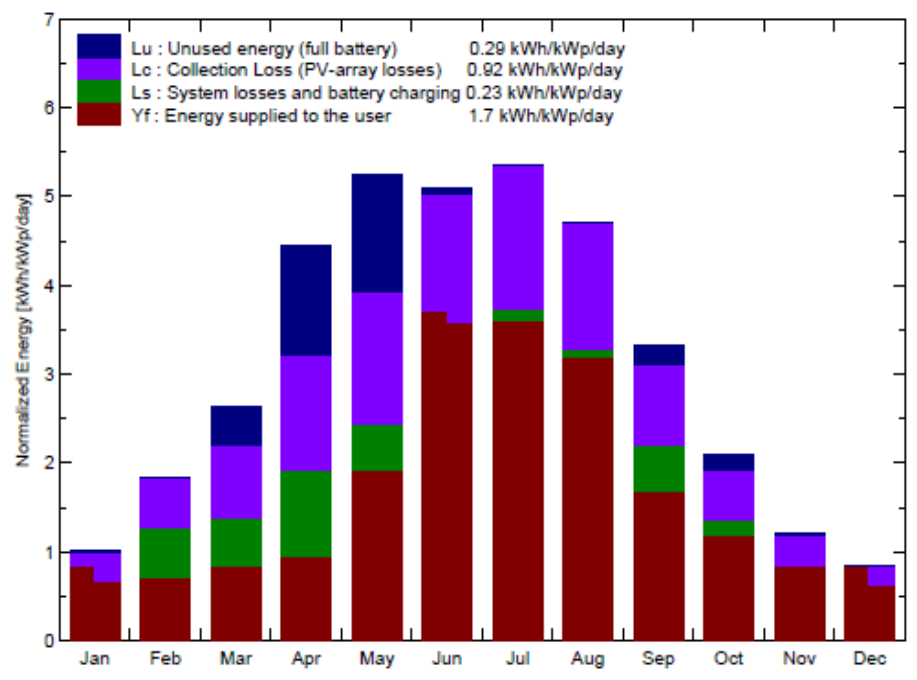

(a)

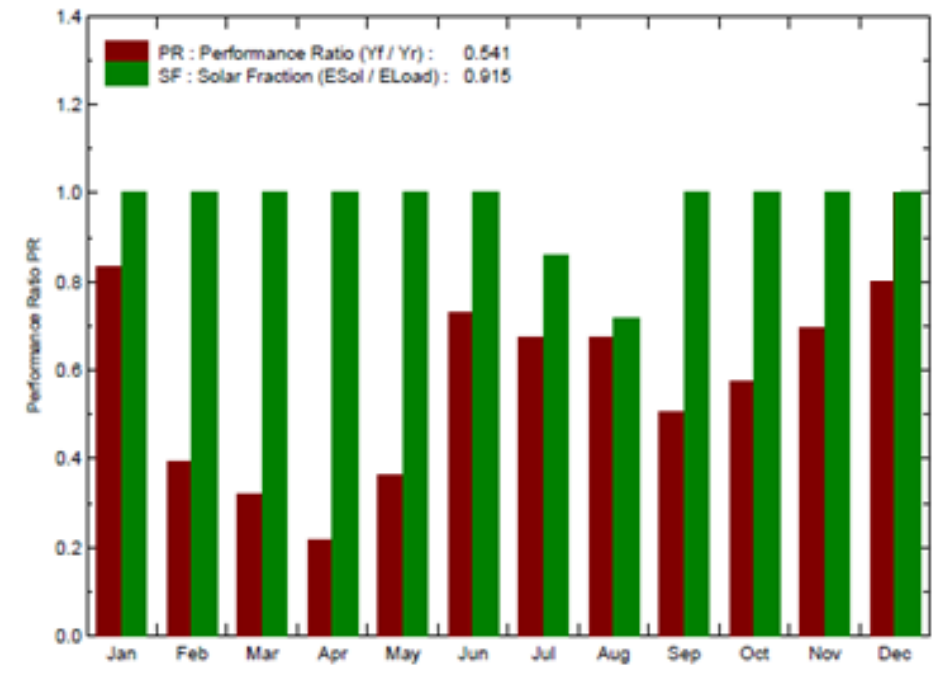

(b)

Figure 5.6 (a) Normalized production (per installed kWp): Nominal power $400 \mathrm{Wp}$ (b) Performance ratio and Solar fraction

Table 5.12 Balance and main resuts of off-grid PV system

\begin{tabular}{|c|c|c|c|c|c|c|c|c|}
\hline & $\begin{array}{c}\mathrm{G}_{\text {Hor }} \\
\mathrm{kWh} / \mathrm{m}^{2}\end{array}$ & $\begin{array}{c}\mathrm{G}_{\text {Eff }} \\
\mathrm{kWh} / \mathrm{m}^{2}\end{array}$ & $\begin{array}{c}\mathrm{E}_{\text {Avail }} \\
\mathrm{kWh}\end{array}$ & $\begin{array}{c}\mathrm{E}_{\text {Unused }} \\
\mathrm{kWh}\end{array}$ & $\begin{array}{c}\mathrm{E}_{\text {Miss }} \\
\mathrm{kWh}\end{array}$ & $\begin{array}{c}\mathrm{E}_{\text {User }} \\
\mathrm{kWh}\end{array}$ & $\begin{array}{c}\mathrm{E}_{\text {Load }} \\
\mathrm{kWh}\end{array}$ & SolFrac \\
\hline Jan & 16.0 & 30.2 & 8.48 & 0.09 & 0.00 & 10.42 & 10.42 & 1.000 \\
Feb & 32.0 & 49.8 & 14.36 & 0.05 & 0.00 & 8.06 & 8.06 & 1.000 \\
Mar & 63.0 & 78.9 & 22.67 & 5.44 & 0.00 & 10.42 & 10.42 & 1.000 \\
Apr & 115.0 & 129.3 & 37.91 & 14.95 & 0.00 & 11.52 & 11.52 & 1.000 \\
May & 156.0 & 157.8 & 46.75 & 16.39 & 0.00 & 23.81 & 23.81 & 1.000 \\
Jun & 154.0 & 148.1 & 43.85 & 0.93 & 0.00 & 44.64 & 44.64 & 1.000 \\
Jul & 165.0 & 160.6 & 46.33 & 0.06 & 7.42 & 44.66 & 52.08 & 0.858 \\
Aug & 132.0 & 141.5 & 40.81 & 0.09 & 15.53 & 39.52 & 55.06 & 0.718 \\
Sep & 80.0 & 96.4 & 28.93 & 2.61 & 0.00 & 20.16 & 20.16 & 1.000 \\
Oct & 44.0 & 62.9 & 19.00 & 1.98 & 0.00 & 14.88 & 14.88 & 1.000 \\
Nov & 20.0 & 35.0 & 10.23 & 0.06 & 0.00 & 10.08 & 10.08 & 1.000 \\
Dec & 11.0 & 21.3 & 6.06 & 0.08 & 0.00 & 10.42 & 10.42 & 1.000 \\
\hline Year & 988.0 & 1111.8 & 325.38 & 42.72 & 22.96 & 248.58 & 271.54 & 0.915 \\
\hline
\end{tabular}

Where:

$\begin{array}{llll}\mathrm{G}_{\text {Hor }} & \text { Horizontal global irradiation } & \mathrm{E}_{\text {Miss }} & \text { Missing energy } \\ \mathrm{G}_{\text {Eff }} & \text { Effective global, corr. For IAM and shading } & \mathrm{E}_{\text {User }} & \text { Energy supplied to the user } \\ \mathrm{E}_{\text {Avail }} & \text { Availble solar energy } & \mathrm{E}_{\text {Load }} & \text { Energy need of the user (Load) }\end{array}$




$$
\mathrm{E}_{\text {Unused }} \quad \text { Unused energy (full battery) loss } \quad \text { SolFrac } \quad \text { Solar fraction (Eused/Eload) }
$$

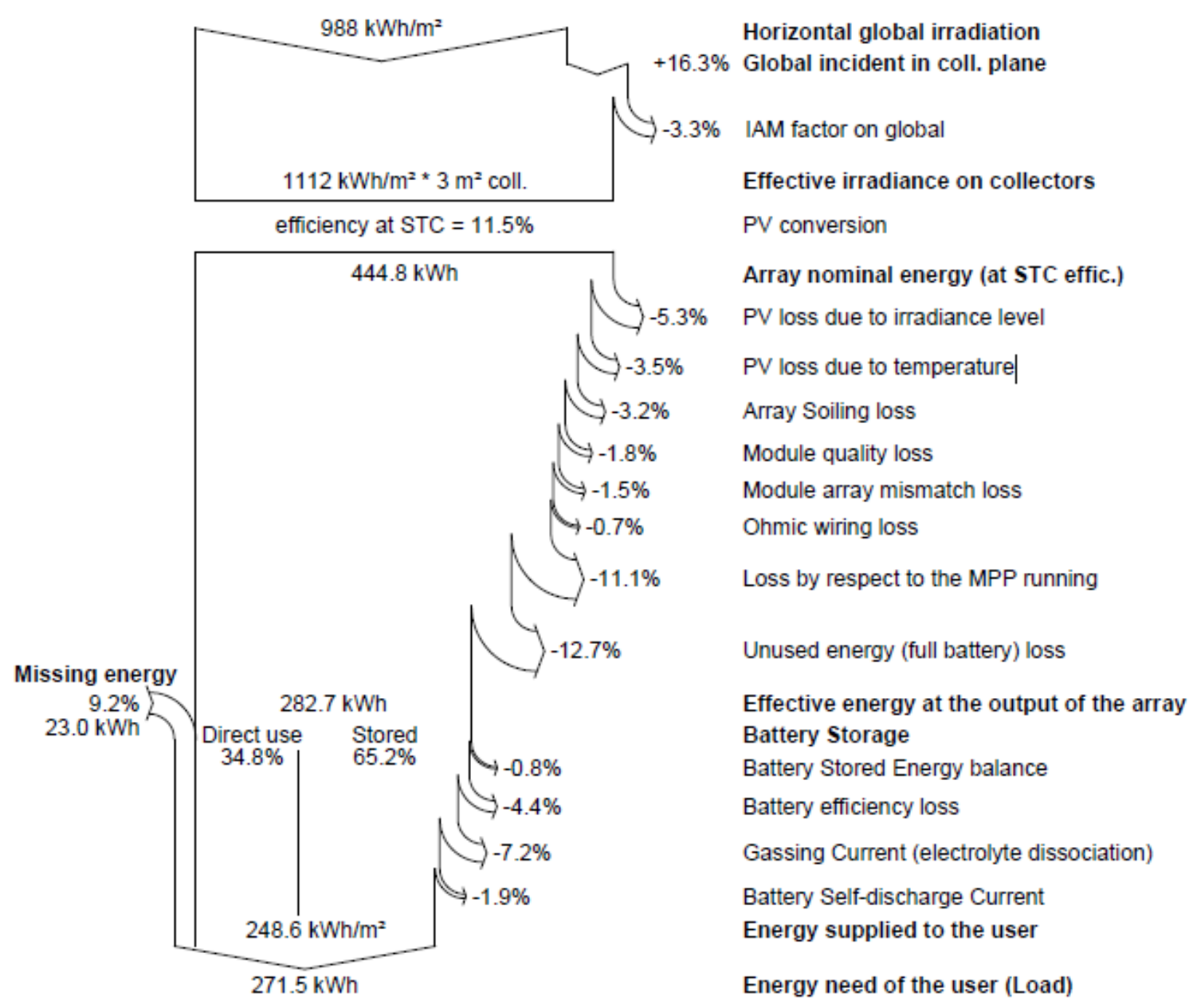

Figure 5.7 Off-grid system loss diagram over the whole year

\subsubsection{On-grid system}

Table 5.13 shows the annual balances and main results of on-grid PV system. The produced energy is $263 \mathrm{kWh} /$ year and specific production is $658 \mathrm{kWh} / \mathrm{kWp} /$ year ( $\mathrm{PV}$ modules' nominal power is $400 \mathrm{Wp}$ ). Different from off-grid system that all the energy supplies to the user load, the energy produced by on-grid system dispatches into two ways: the user self-consumed energy and the energy reinjected into the grid. In our project, the energy supplied to the user is $114.47 \mathrm{kWh} / \mathrm{year}$ and the energy injected into grid is $148.8 \mathrm{kWh} /$ year. In order to satisfy the user load, 157.1 $\mathrm{kWh} /$ year energy need to obtain from grid, which balance with the energy injected into the grid.

As shown in Figure 5.8 (b), the average performance ratio for on-grid system is 0.573 . Because of losses due to PV module temperature, PR values are greater in the winter than in the summer and 
normally fall within the range of 0.5 to 0.7 . Figure 5.9 indicates the on-grid system loss over the whole year.

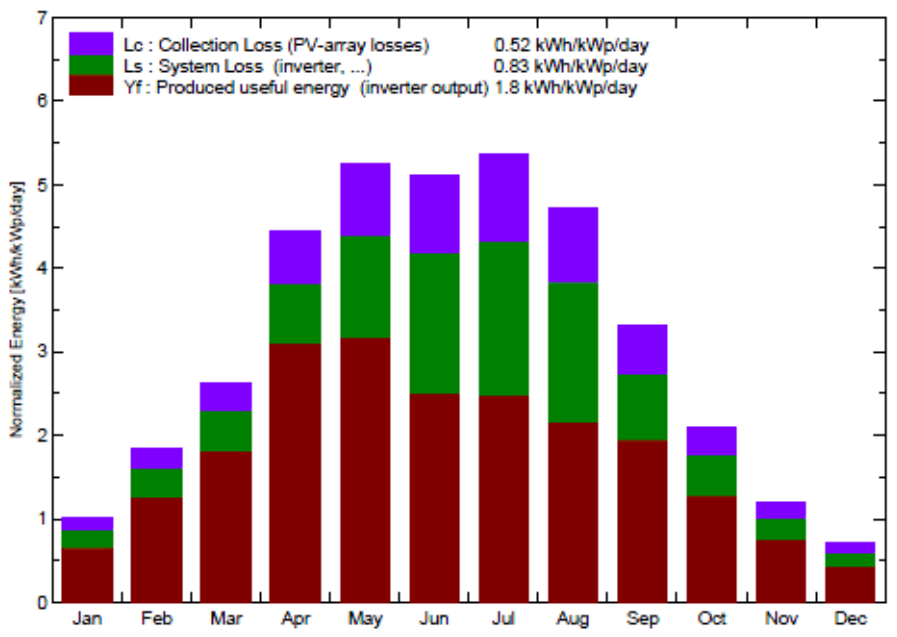

(a)

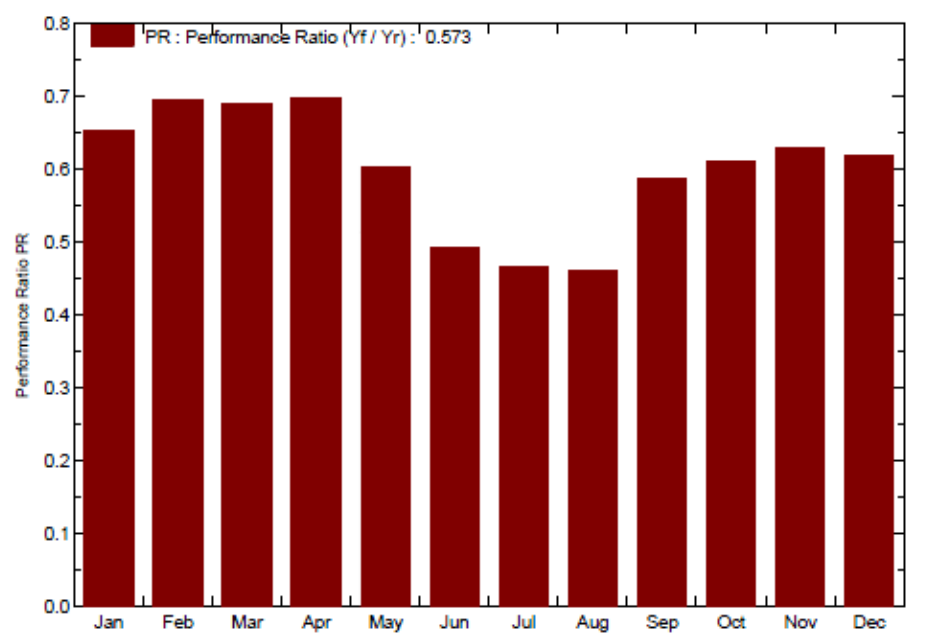

(b)

Figure 5.8 (a) Normalized production (per installed kWp): Nominal power $400 \mathrm{Wp}$ (b) Performance ratio

Table 5.13 Balance and main results of on-grid PV system

\begin{tabular}{|c|c|c|c|c|c|c|c|c|}
\hline & $\begin{array}{c}\mathrm{G}_{\text {Hor }} \\
\mathrm{kWh} / \mathrm{m}^{2}\end{array}$ & $\begin{array}{c}\mathrm{G}_{\text {Inc }} \\
\mathrm{kWh} / \mathrm{m}^{2}\end{array}$ & $\begin{array}{c}\mathrm{G}_{\text {Eff }} \\
\mathrm{kWh} / \mathrm{m}^{2}\end{array}$ & $\begin{array}{c}\mathrm{E}_{\text {Array }} \\
\mathrm{kWh}\end{array}$ & $\begin{array}{c}\mathrm{E}_{\text {Load }} \\
\mathrm{kWh}\end{array}$ & $\begin{array}{c}\mathrm{E}_{\text {Avail }} \\
\mathrm{kWh}\end{array}$ & $\begin{array}{c}\mathrm{E}_{\text {User }} \\
\mathrm{kWh}\end{array}$ & $\begin{array}{c}\mathrm{E}_{\text {Grid }} \\
\mathrm{kWh}\end{array}$ \\
\hline Jan & 16.0 & 31.2 & 30.2 & 10.83 & 10.42 & 8.14 & 2.14 & 6.00 \\
Feb & 32.0 & 51.5 & 49.8 & 18.07 & 8.06 & 14.31 & 2.53 & 11.78 \\
Mar & 63.0 & 81.6 & 78.9 & 28.50 & 10.42 & 22.53 & 4.22 & 18.31 \\
Apr & 115.0 & 133.6 & 129.3 & 45.97 & 11.52 & 37.24 & 5.85 & 31.39 \\
May & 156.0 & 162.9 & 157.8 & 54.50 & 23.81 & 39.28 & 12.70 & 26.58 \\
Jun & 154.0 & 153.1 & 148.1 & 50.26 & 44.64 & 30.06 & 21.37 & 8.69 \\
Jul & 165.0 & 166.3 & 160.6 & 53.80 & 52.08 & 30.96 & 24.93 & 6.03 \\
Aug & 132.0 & 146.1 & 141.5 & 47.57 & 55.06 & 26.97 & 23.36 & 3.61 \\
Sep & 80.0 & 99.7 & 96.4 & 32.93 & 20.16 & 23.37 & 8.27 & 15.10 \\
Oct & 44.0 & 64.9 & 62.9 & 21.90 & 14.88 & 15.87 & 4.93 & 10.94 \\
Nov & 20.0 & 36.2 & 35.0 & 12.29 & 10.08 & 9.11 & 2.54 & 6.57 \\
Dec & 11.0 & 22.0 & 21.3 & 7.49 & 10.42 & 5.45 & 1.63 & 3.82 \\
\hline Year & 988.0 & 1149.2 & 1111.8 & 384.12 & 271.54 & 263.28 & 114.47 & 148.81 \\
\hline
\end{tabular}

Where:

$\begin{array}{llll}\mathrm{G}_{\text {Hor }} & \text { Horizontal global irradiation } & \mathrm{E}_{\text {array }} & \text { Effective energy at the output of the array } \\ \mathrm{G}_{\mathrm{Eff}} & \text { Effective global, corr. For IAM and shading } & \mathrm{E}_{\text {User }} & \text { Energy supplied to the user } \\ \mathrm{G}_{\text {Inc }} & \text { Global incident in coll. Plane } & \mathrm{E}_{\text {Load }} & \text { Energy need of the user (Load) } \\ \mathrm{E}_{\text {Avail }} & \text { Avail solar energy } & \mathrm{E}_{\text {Grid }} & \text { Energy injected into grid }\end{array}$




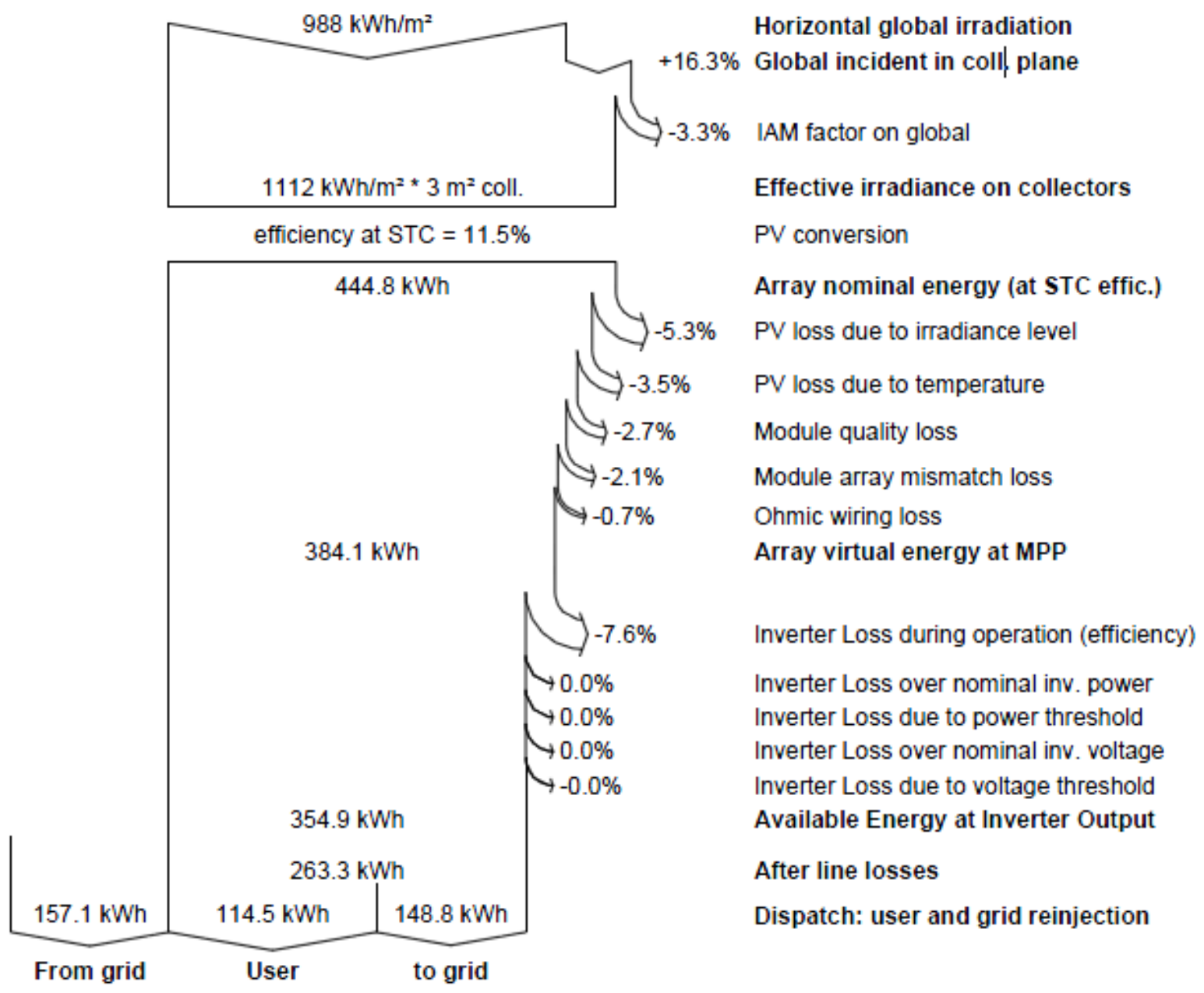

Figure 5.9 On-grid system loss diagram over the whole year 


\subsection{Economic evaluation of PV system}

Economic estimation is an important method to evaluate a PV system. Table 5.14 demonstrates the economic parameters for both off-grid and on-grid PV system.

Table 5.14 Economic parameters for both off-grid and on-grid PV system

\begin{tabular}{|c|c|c|}
\hline & Off-grid & On-grid \\
\hline \multicolumn{3}{|l|}{ Loan } \\
\hline $\begin{array}{l}\text { Lifetime of system } \\
\text { Rate }\end{array}$ & \multicolumn{2}{|c|}{20 years } \\
\hline \multicolumn{3}{|l|}{ Initial Investment } \\
\hline $\begin{array}{l}\text { PV modules } \\
\text { Support / Integration } \\
\text { Batteries } \\
\text { Regulator } \\
\text { Inverters } \\
\text { Transport / Fitting }\end{array}$ & $\begin{array}{c}2,601 € \\
400 € \\
1,262 € \\
331 € \\
\mathrm{n} / \mathrm{a} \\
2,400 €\end{array}$ & $\begin{array}{c}2,601 € \\
400 € \\
\mathrm{n} / \mathrm{a} \\
\mathrm{n} / \mathrm{a} \\
280 € \\
1,000 €\end{array}$ \\
\hline \multicolumn{3}{|l|}{ Net Investment } \\
\hline $\begin{array}{l}\text { Annuities } \\
\text { Annual running Costs, Maintenance }\end{array}$ & $\begin{array}{l}561 € / \text { year } \\
327 € / \text { year }\end{array}$ & $\begin{array}{c}344 € / \text { year } \\
53 € / \text { year }\end{array}$ \\
\hline \multicolumn{3}{|l|}{ Energy Cost } \\
\hline $\begin{array}{l}\text { Produced energy } \\
\text { Yearly cost } \\
\text { Used energy cost }\end{array}$ & $\begin{array}{c}249 \mathrm{kWh} / \text { year } \\
888 € / \text { year } \\
3.57 € / \mathrm{kWh}\end{array}$ & $\begin{array}{c}355 \mathrm{kWh} / \text { year } \\
397 € / \text { year } \\
1.12 € / \mathrm{kWh}\end{array}$ \\
\hline
\end{tabular}

In our study, we assume that two PV systems have the same lifetime (20 years) and loan rate $(5.0 \%)$. The initial investment of the project includes the system components cost, support and integration costs, as well as transport and fitting costs. System technology determines the initial costs. In the case of on-grid PV plants, there is a need to use inverters, in order to invert the produced by the PV plant DC current into AC current. However, in such PV plants, there is no need to use an energy storage system, so the cost of batteries can be ignored.

The running costs also depend on the system type. For an on-grid system, usually very reliable, they are limited to an annual inspection, eventually some cleaning of the collectors and the insurance fees. For an off-grid system, one should add a provision for the maintenance and periodical replacement of the batteries, which significantly increases the annual running costs.

The total annual cost is the sum of the annuities and the running costs. Divided by the effectively produced and used energy, it gives an evaluation of the energy cost. This is depending on the above hypothesis, especially the loan duration and rate, as well as the effective system production. The energy costs by off-grid and on-grid PV system are $3.57 € / \mathrm{kWh}$ and $1.12 € / \mathrm{kWh}$, respectively, which are greatly higher than the electric price $0.2632 € / \mathrm{kWh}$ for households and $0.1009 € / \mathrm{kWh}$ for industrial consumers (exclude VAT) in Denmark [4]. 


\section{References}

[1] "World-wide overview of design and simulation tools for hybrid PV systems", IEA-PVPS T11-01, 2011

[2] "Changing System Parameters", [Online]. Available: http://rredc.nrel.gov/solar/calculators/ PVWATTS/ system.html. [Accessed: Jun.2, 2011]

[3] PVSYST contestual help files

[4] Europe's Energy Portal, "Retail (end-user) energy prices for households and industry", [Online]. Available: http://www.energy.eu/. [Accessed: Jun.5, 2011] 


\section{Chapter 6 Conclusions}

In this project, both experiments and computer simulation are carried out to analyze the indoor climate and energy performance of technical shelter. In addition, solar energy serves as an alternative solution for powering technical shelter, in order to achieve net-zero energy target. According to the findings and the discussions of the study, there are some conclusion can be drawn as follows.

\section{Measurements}

- The vertical temperature gradient is quite high inside technical shelter. The air temperature difference between at floor level and at ceiling level can reach more than $10{ }^{\circ} \mathrm{C}$. This phenomenon is good for reducing the cooling demand if the electric equipments are located at the lower level. In addition, it will be more energy efficiency if the exhaust opening is positioned at the top of the shelter, where the warmest air can be extracted to outside directly.

- Due to the huge indoor electric equipments heat dissipation rate and almost constant outdoor temperature during measurement, the simplified analysis method regardless building heat inertial capacity can be used to analysis the energy performance of technical shelter. The energy performance based on measurement results accords well with the energy balance rule, where the deviation is in an acceptable level.

- Heat transmission through envelop and ventilation cooling are the main ways to remove heat from inside shelter to the outside. The proportion of heat transmission through envelops decreases when indoor equipments heat dissipation rate increases.

\section{BSim simulation}

- Heating demand is only needed in $1.5 \mathrm{~kW}$ heat load, $25 \mathrm{~mm}$ insulation thickness condition, and the annual heating need $(27.244 \mathrm{kWh})$ is much lower than annual cooling need $(2589.1 \mathrm{kWh})$. So reduction of cooling demand is the top priority for technical shelter. Envelop with lower insulation thickness has better performance in most of conditions (especial in higher heat load cases), where not only reduces cooling demand of technical shelter but also reduces the costs on insulation materials.

- The cooling need decreases while increases indoor temperature set point. The indoor temperature set point depends on the temperature sensitive of electric equipments inside technical shelter. The higher acceptable indoor temperature, the lower inner heating is needed to discharge to outside, which will cause lower ventilation rate. 
- Energy consumption is a critical factor to evaluate cooling strategies. In our project the total energy consumption is the summation of ventilation cooling and mechanical cooling energy consumption. When the ventilation rate increases from $0 / \mathrm{h}$ to a certain level, the total energy consumptions decrease significantly. As the ventilation rate continues to increase to the maximum, the total energy consumption almost keeps as a constant value. Thus economic estimation should be made in the optimal design of cooling system, where additional cost of mechanical cooling system and cost of fan need to be taken into account.

\section{PV system design}

- PV system is used in our project to achieve net-zero energy target. Both off-grid and on-grid PV systems are designed based on PVSYST software. The main difference in the design process of these two types of PV system is that the user's loads definition are absolutely necessary in the off-grid system, which closely affect the system size. For grid-connected systems, usually no load is specified and no array size is suggested. However, the user loads can be defined afterwards in order to obtain the user self-consumed energy part and the energy reinjected into the grid.

- The costs of PV system depend on the system technology. The investment on off-grid system is higher than on on-grid system due to the initial cost on batteries and regulator, and expensive annual running and maintenance cost where the most significant replacement cost will likely be the batteries. The energy costs by off-grid and on-grid PV system are $3.57 € / \mathrm{kWh}$ and 1.12 $€ / \mathrm{kWh}$, respectively, which are greatly higher than the electric price in Denmark. As a matter of fact, the PV technology still experiences economic restrictions much more than technical ones. Due to the relatively higher energy cost, PV technology cannot enter into direct competition on the market with conventional technologies. Thus feed-in tariff needs to be introduced to support and incentivize the sustainable development of PV technology. 


\section{Appendix - Equipments}

\subsection{Temperature measurement}

\subsubsection{Equipments}

Thermocouples are the most widely used type of temperature sensor for measurement and control and can also be used to convert heat gradient into electricity. A thermocouple is a junction between two different metals that produces a voltage related to a temperature difference. There are many different types of thermocouples which are best suited for different applications. They are usually selected based on the temperature range and sensitivity needed. The three most common thermocouples alloys for moderate temperatures are Iron-Constantan (Type J), Copper-Constantan (Type T), and Chrome-Alumel (Type K).

In our experiments, $\mathrm{K}$ type thermocouples are used for temperature measurements. $\mathrm{K}$ type thermocouples are widely used because of its inexpensive and wide variety of probes which is available from $-200{ }^{\circ} \mathrm{C}$ to $+1350{ }^{\circ} \mathrm{C}$ range. The sensitivity of $\mathrm{K}$ type thermocouples is approximately $41 \mu \mathrm{V} /{ }^{\circ} \mathrm{C}$.

Radiation can strongly affect the temperature results when measuring the air temperature. In order to avoid the radiation affect and obtain accurate results, silver coated shielding tube is used in air temperature measurement. As shown in Figure 9.2, thermocouple is placed inside the tube which is ventilated by a small fan. It's important to notice that the metal part of thermocouple should avoid touching the surface of silver coated shielding tube.

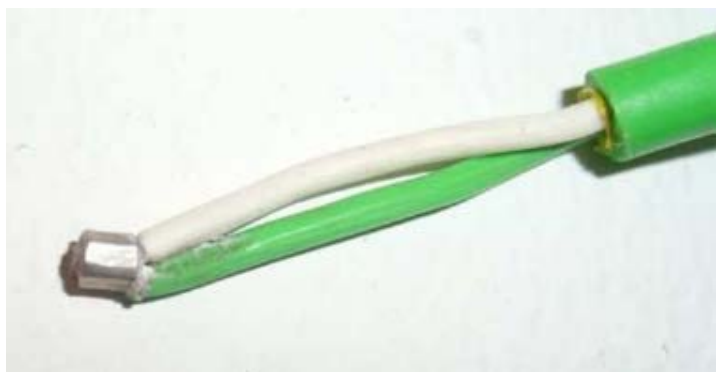

Figure $9.1 \mathrm{~K}$ type thermocouple

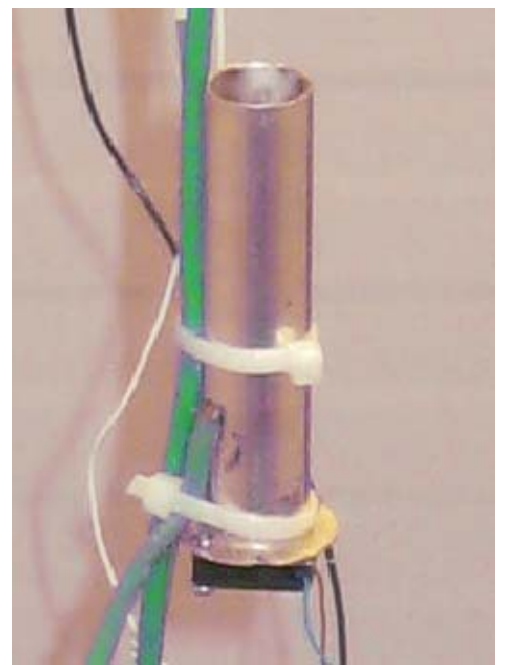

Figure 9.2 Thermocouples in the silver coated shielding tube 
Thermocouples are connected to data acquisition device '2040 series Squirrel Data Logger'. Data logger transfers all the data to PC, where SquirrelView Assistant analyses results and exports them to excel files.

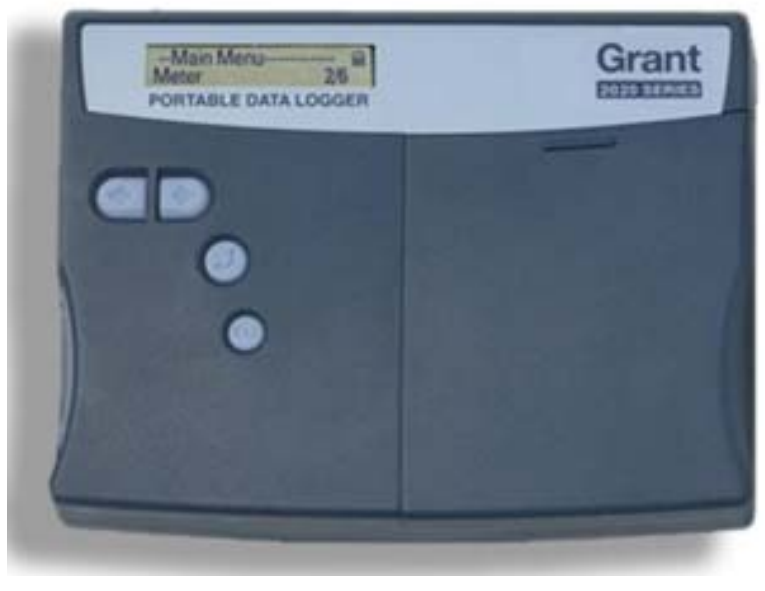

Figure 9.32040 series Squirrel Data Logger

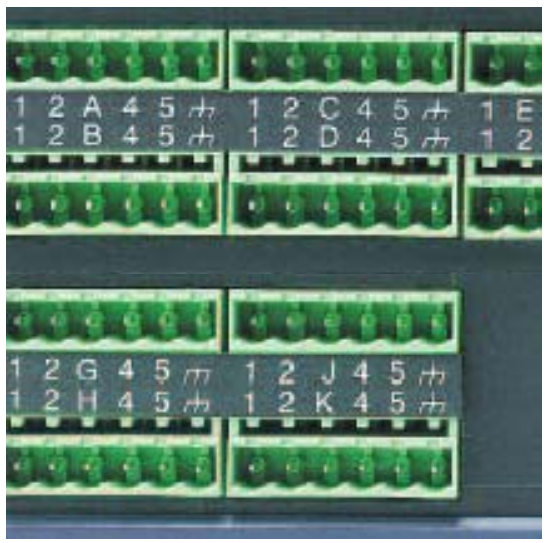

Figure 9.416 to 32 universal analogue inputs

\subsubsection{Calibration of thermocouples}

As shown in Figure 9.5 and 9.6, thermocouples were calibrated by means of ISOCAL 6 VENUS2140B+ and Precision Thermometer F200.

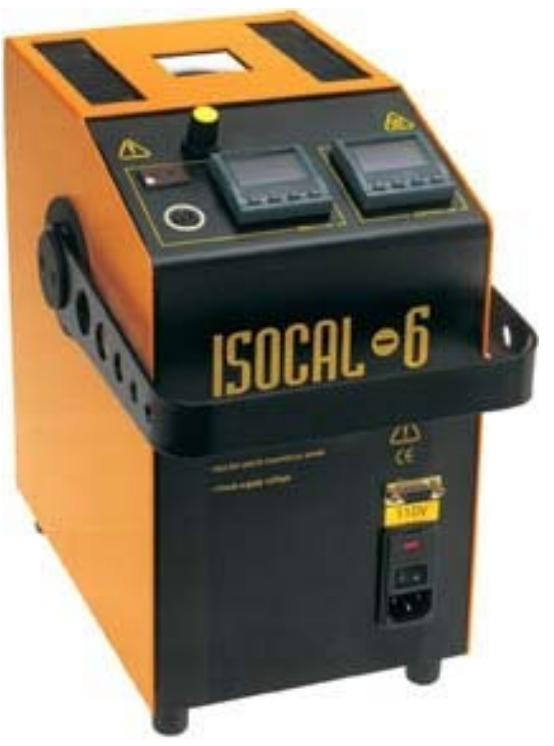

Figure 9.5 ISOCAL 6 VENUS2140B+

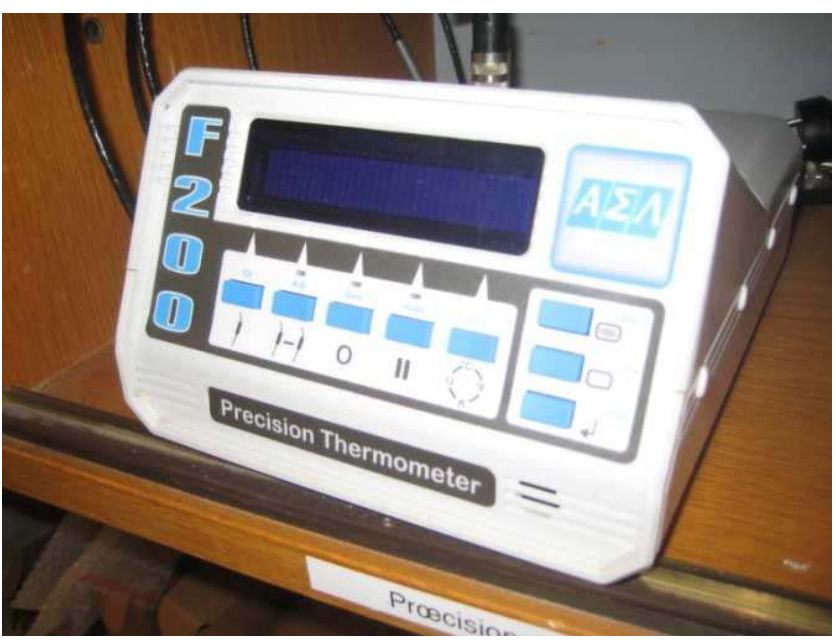

Figure 9.6 Precision Thermometer F200 
The basic principle of thermocouple calibration is to find out the relationship between the precise temperature shown by the precision thermometer and the temperature measured by thermocouple. Calibration is made for three temperatures: $10^{\circ} \mathrm{C}$ and $40^{\circ} \mathrm{C}$. An example of calibration curve of Nr . 29 thermocouple is shown in Figure 9.7.

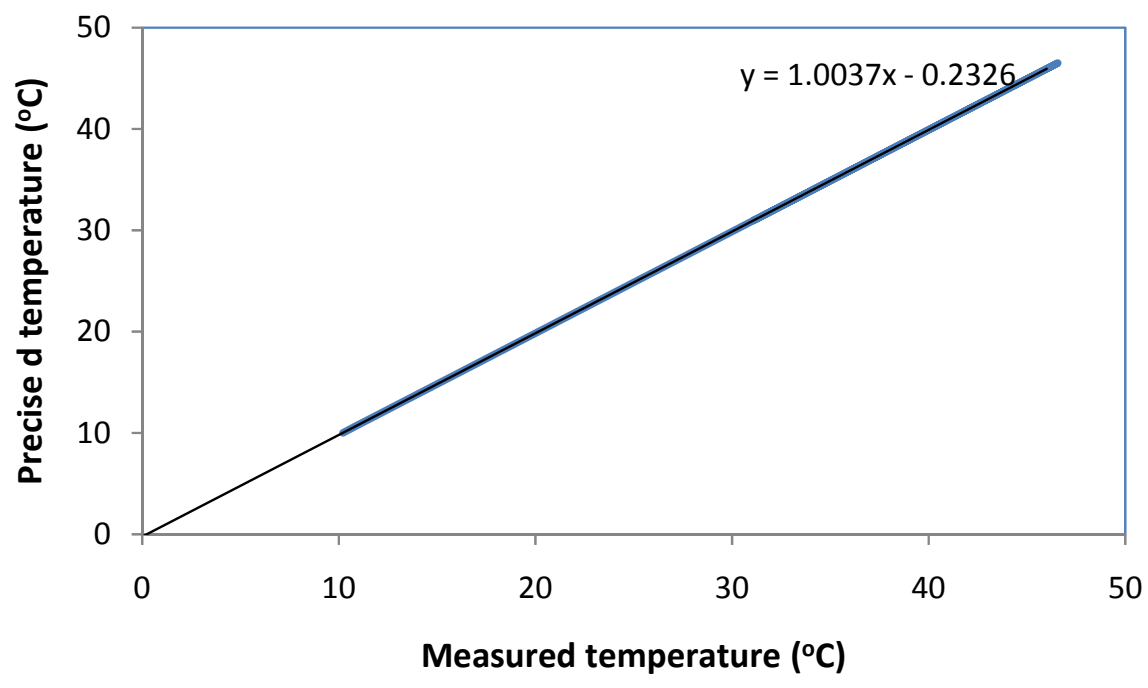

Figure 9.7 Calibration curve of Nr. 29 thermocouple

\subsection{Airflow rate measurement}

\subsubsection{Equipments}

Nitrous oxide $\left(\mathrm{N}_{2} \mathrm{O}\right)$ serves as tracer gas in our measurements. $\mathrm{N}_{2} \mathrm{O}$ is commonly known as laughing gas or sweet air. At room temperature, it is a colorless non-flammable gas, with a slightly sweet odor and taste. Manometer and flow meter are used to adjust certain amount of $\mathrm{N}_{2} \mathrm{O}$ delivered to system. 


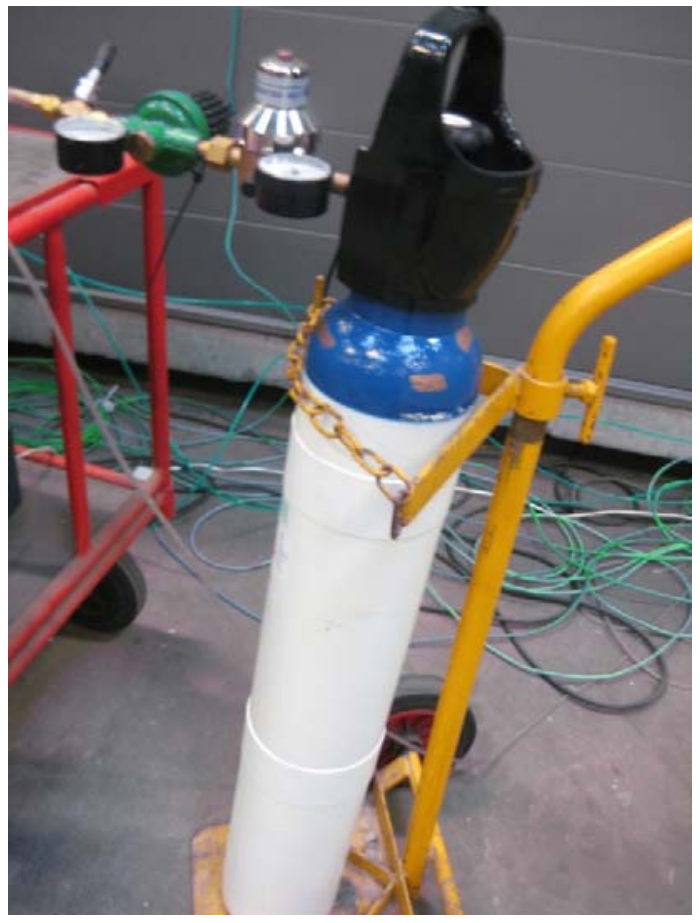

Figure 9.8 Bottle of $\mathrm{N}_{2} \mathrm{O}$ connected with manometer

As shown in Figure 9.9, all tube used to measure tracer gas concentration are connected to the Multipoint Sample and Dozer type 1303 (Bruel \& Kjær, Denmark). The concentration data are analyzed by Tracer Gas Monitoring system and then stored in the PC. There are six channels on the Multipoint Sample and Dozer, and it costs 40 seconds to analysis the concentration of each channel.

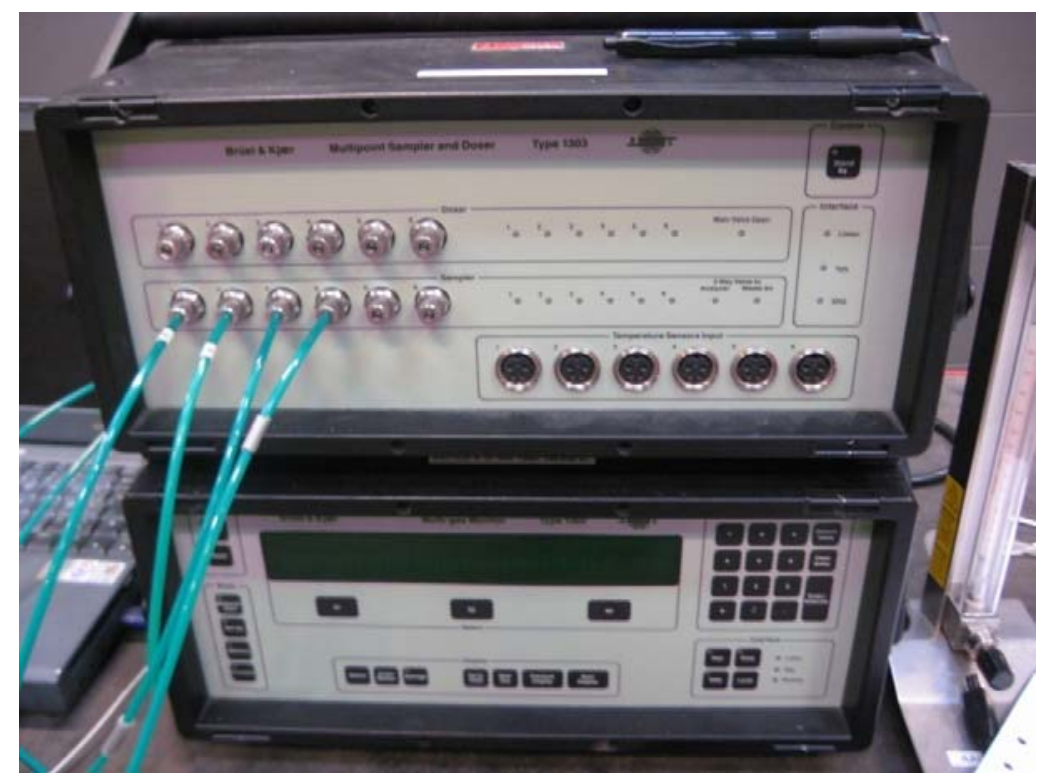

Figure 9.9 The tracer gas measuring devices 


\subsubsection{Calibration of flow meter}

The airflow rate of tracer gas can be read by flowmeter which connected with tracer gas bottle. As shown in Figure 9.10, ABB Ltd. FP- ${ }^{1 / 8}-16-\mathrm{G}-5$ variable area flowmeter is used in our measurement. The relationship between reading on flowmeter and the actual $\mathrm{N}_{2} \mathrm{O}$ flow rate should be calibrated before using. The calibration device is shown in Figure. $\mathrm{N}_{2} \mathrm{O}$ is supplied to this device through the flowmeter, from this device we can get the actual flow and find the relationship between actual flow rate of $\mathrm{N}_{2} \mathrm{O}$ and reading on flowmeter.

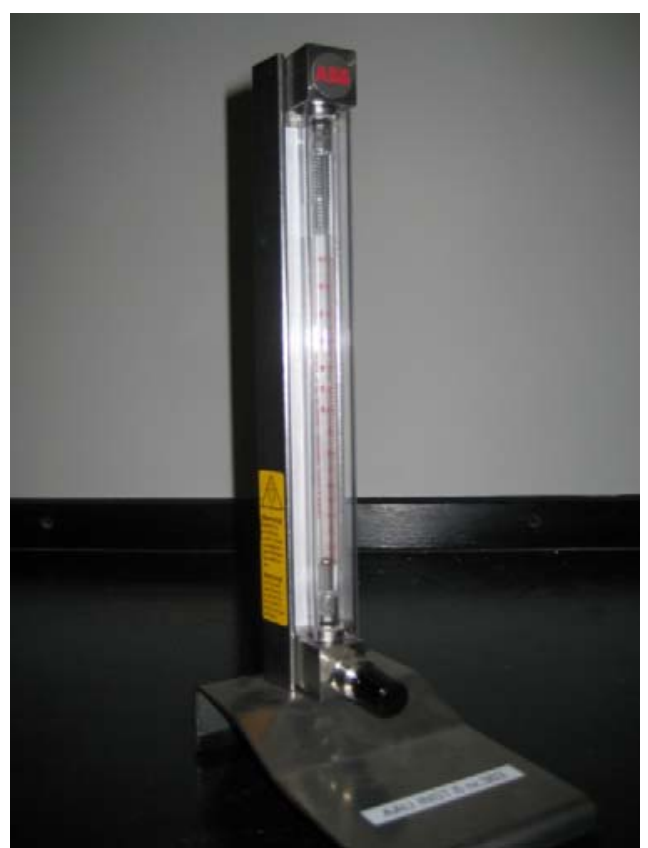

Figure $9.10 \mathrm{FP}^{-1 / 8}-16-\mathrm{G}-5$ flowmeter

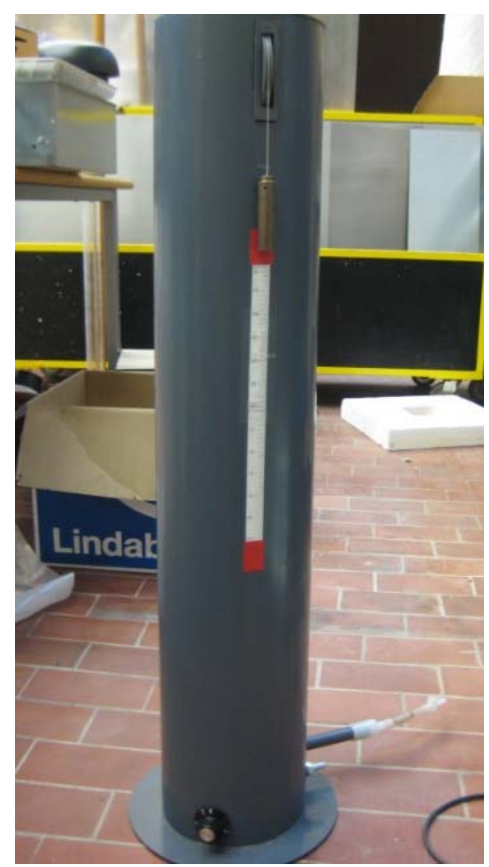

Figure 9.11 Calibration device of flowmeter

\subsection{Power measurements}

To determine accurately the total power of the ventilation system and radiators, a power monitor, with power integrator was used (type NORMA AC-Power Analyser D 5255 S). This allowed to read the total power input and integrated power in $\mathrm{kWh}$ at any time. The overall accuracy of this system is about $0.3 \%$. NORMA AC-Power Analyser D $5255 \mathrm{~S}$ has internal calibration process, so that no additional instruments and process are required. 


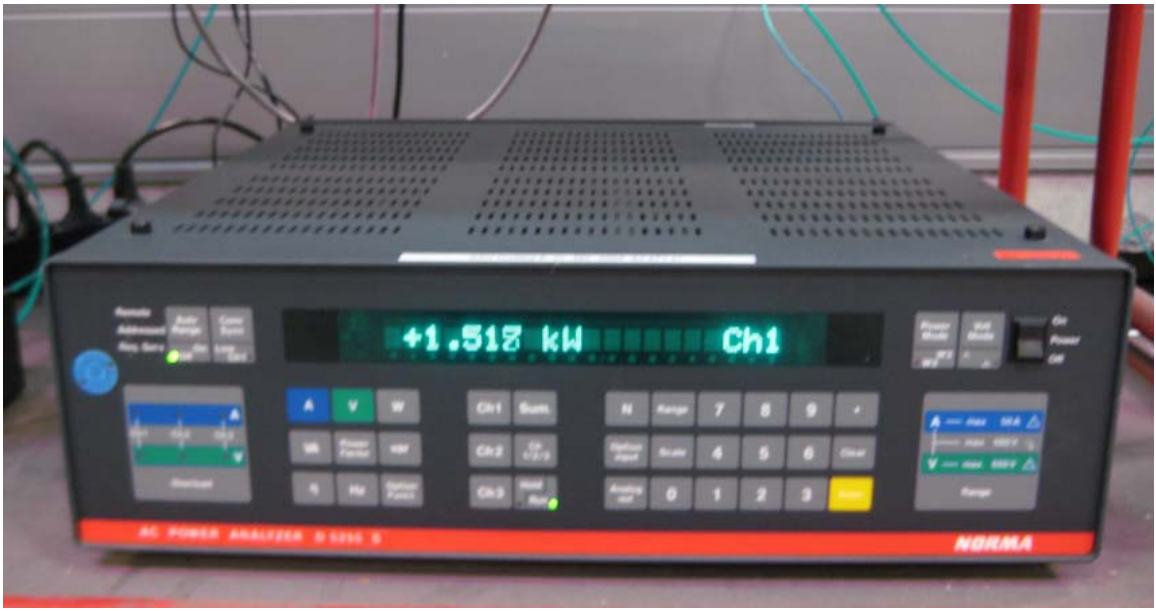

Figure 9.12 NORMA AC-Power Analyser D 5255 S

\subsection{Pressure measurements}

Pressure drop on an orifice plate are checked by using the micromanometer Debro Meerbush Germany (Figure 9.13). Rubber pipes connect device with orifices.

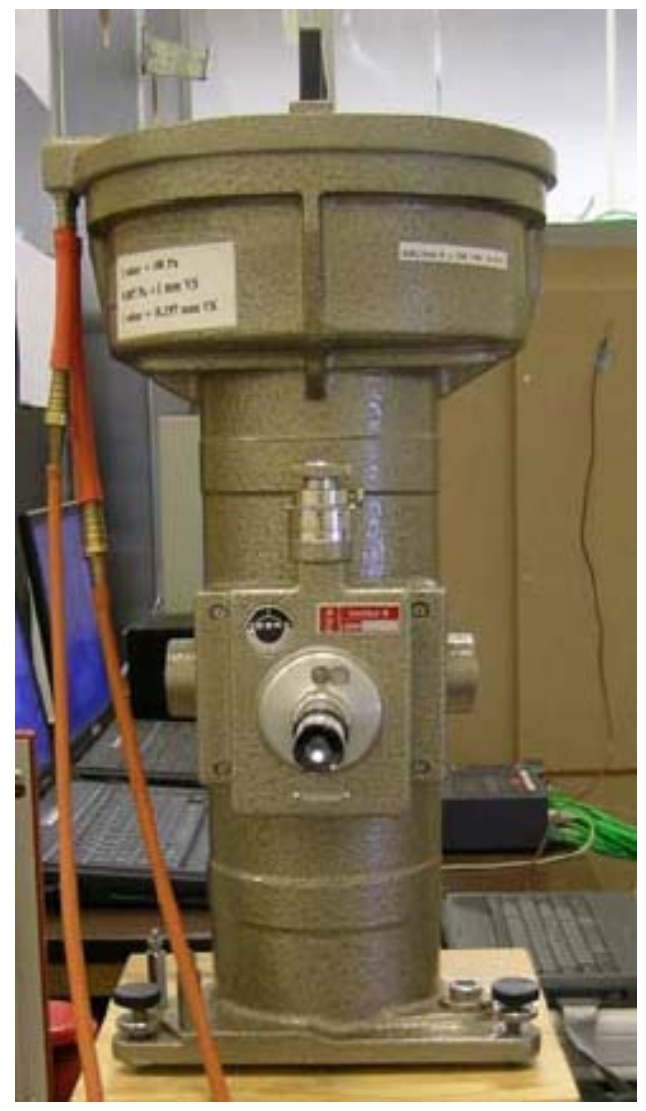

Figure 9.13 Debro Meerbush Micromanometer 
Pressure difference between inside and outside shelter is measured by Digital manometer FC016 Furness Controls Limited. Two pipes are connected with manometer, one is located inside the shelter and the other is located outside.

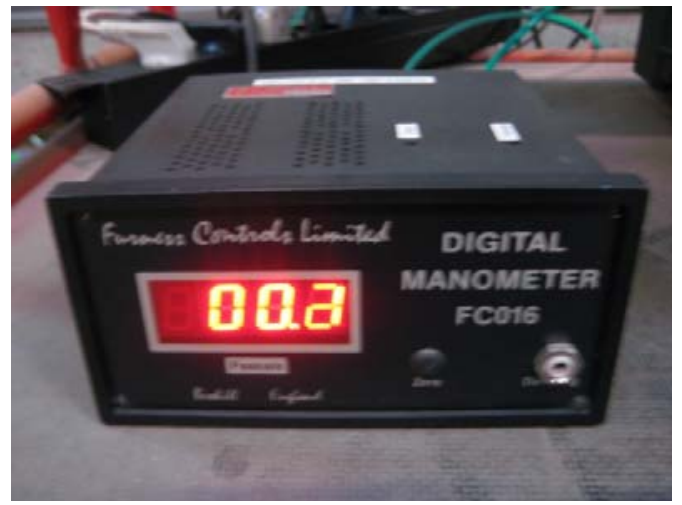

Figure 9.14 FC016 Digital Manometer 